\title{
Experimental ischemia and reperfusion of the small bowel : focus on microvascular events
}

Citation for published version (APA):

Beuk, R. J. (2009). Experimental ischemia and reperfusion of the small bowel : focus on microvascular events. [Doctoral Thesis, Maastricht University]. Maastricht University. https://doi.org/10.26481/dis.20090612rb

Document status and date:

Published: 01/01/2009

DOI:

10.26481/dis.20090612rb

Document Version:

Publisher's PDF, also known as Version of record

\section{Please check the document version of this publication:}

- A submitted manuscript is the version of the article upon submission and before peer-review. There can be important differences between the submitted version and the official published version of record.

People interested in the research are advised to contact the author for the final version of the publication, or visit the DOI to the publisher's website.

- The final author version and the galley proof are versions of the publication after peer review.

- The final published version features the final layout of the paper including the volume, issue and page numbers.

Link to publication

\footnotetext{
General rights rights.

- You may freely distribute the URL identifying the publication in the public portal. please follow below link for the End User Agreement:

www.umlib.nl/taverne-license

Take down policy

If you believe that this document breaches copyright please contact us at:

repository@maastrichtuniversity.nl

providing details and we will investigate your claim.
}

Copyright and moral rights for the publications made accessible in the public portal are retained by the authors and/or other copyright owners and it is a condition of accessing publications that users recognise and abide by the legal requirements associated with these

- Users may download and print one copy of any publication from the public portal for the purpose of private study or research.

- You may not further distribute the material or use it for any profit-making activity or commercial gain

If the publication is distributed under the terms of Article $25 \mathrm{fa}$ of the Dutch Copyright Act, indicated by the "Taverne" license above, 
Experimental ischemia and reperfusion of the small bowel. focus on microvascular events 


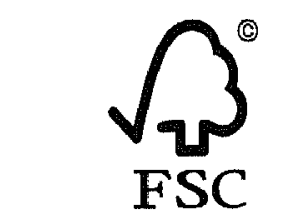

Mixed Sources

Product group from well-managed

forests, controlled sources and

recycled wood or fibre

Cert no. CU-COC-81146

Www. fsc.org
- 1996 Forest Stewardship Council 
Experimental ischemia and reperfusion of the small bowel: focus on microvascular events

\author{
Proefschrift
}

ter verkrijging van de graad van doctor aan de Universiteit Maastricht, op gezag van de Rector Magnificus, Prof. mr. G.P.M.F. Mols

volgens het besluit van het College der Decanen, in het openbaar te verdedigen op vrijdag 12 juni 2009 om 14.00 uur

door

\title{
Roland Johannes Beuk
}

geboren op 12 oktober 1966 te Wassenaar 


\section{Promotores:}

Prof. Dr. E. Heineman

Prof. Dr. G.J. Tangelder (vrije Universiteit, Amsterdam)

\section{Co-promotor:}

Dr. M.G.A. oude Egbrink

\section{Beoordelingscommissie:}

Prof. Dr. J.F.C. Glatz (voorzitter)

Dr. R.H. Geelkerken (Medisch spectrum Twente, Enschede)

Dr. A.J.H.M. Houben

Prof. Dr.P.J.E.H.M. Kitslaar

Prof. Dr. J.L. Waltenberger

Druk: Gildeprint, Enschede

ISBN: 9789490122294 
Aan mijn lieve vader, voor Helena, Ewout, Marike en Florian 


\section{Contents}

Chapter $1 \quad$ Introduction 9

Chapter $2 \quad$ Ischemia and reperfusion injury of the bowel 15

Chapter $3 \quad$ Ischemia/reperfusion injury in rat mesenteric venules: $\quad 41$

red blood cell velocity and leukocyte rolling

Chapter $4 \quad$ Effects of different durations of total warm ischemia

of the gut on rat mesenteric microcirculation

Chapter 5 An evaluation of methods for grading histologic

77

injury following ischemia/reperfusion of the small

bowel

Chapter $6 \quad$ Total warm ischemia and reperfusion impairs flow in

all rat gut layers but increases leukocyte-vessel wall

interactions in the submucosa only

Chapter $7 \quad$ Leukocyte and platelet adhesion in different layers of the small bowel during experimental total warm ischemia and reperfusion

Chapter 8 General discussion

Chapter9 Summary $\quad 151$

Samenvatting $\quad 155$

Curriculum Vitae $\quad 159$

Dankwoord $\quad 161$ 
Chapter 1

\section{Introduction}




\section{introduction}

Inadequate blood supply to a tissue (ischemia) may compromise tissue function. Restoration of blood supply (reperfusion) is necessary to oxygenate the tissue and remove accumulated waste products. However, the combination of ischemia and reperfusion can also initiate an immediate local and systemic response, leading to tissue injury, organ dysfunction, and ultimately even death of a patient.(1-3) The intensity of the reaction depends on the seriousness of the ischemia and reperfusion (I/R) and type of tissue involved. Particularly the small bowel is known to be very sensitive to I/R.(4)

During ischemia endothelial cells are activated and an inflammatory response is induced. The complement system is activated, cytokines and chemokines are produced, and ATP is dephosphorylated leading to accumulation of xanthine oxydase. As the ischemic period continuous both cell necrosis and apoptosis appear. Therefore, reperfusion is essential for survival, but paradoxically causes further harm. Reperfusion leads to reoxygenation of the tissue as well as leukocyte influx and activation, generating free radicals and peroxide. This causes strong chemoattractant gradients and amplifies the inflammatory response, contributing to further endothelial and parenchymal cell death.

Ischemia and reperfusion of the gut is unavoidable in small bowel transplantation, occurs in shock situations, necrotizing enterocolitis (NEC), and as a consequence of cardiac surgery and during clamping of the aorta (supracoeliacal, and even infrarenal). In other clinical situations patients present themselves, mostly in the emergency room, with bowel ischemia as a result of an embolus or thrombus formation following plaque rupture in one of the bowel arteries. In addition, patients arrive with a volvulus, malrotation or strangulated ileus.

In most of the above mentioned clinical cases it is hard to set the diagnosis, because of the great variety of symptoms. When erratic laboratory results are revealed or supplementary examination shows bowel ischemia, significant irreversible tissue damage has already developed. The prolonged ischemic condition together with the inevitable subsequent reperfusion will in many cases lead to deep shock and/or death, despite all efforts made by the clinical team involved. Therefore, it is extremely important to gain more knowledge about the pathophysiological reactions leading to tissue damage following $I / R$ of the small bowel. Such knowledge is needed to develop markers and medicine to reduce tissue injury by earlier diagnosis and control of the inflammatory response. 


\section{Aim of the thesis}

The general aim of the research described in this thesis was to investigate the pathophysiological mechanisms underlying the damaging consequences of $1 / R$ of the small bowel, with special focus on the microcirculation. To this purpose, we developed different rat models in which we were able to visualize the microvascular compartment in the mesentery and within the different layers of the small bowel using intravital videomicroscopy. With this technique tissue perfusion as well as leukocyte and plateletvessel wall interactions can be quantified. In addition, we performed histological examination of different organs and employed a protein specifically present in gut enterocytes, i.e. intestinal fatty acid binding protein (I-FABP), as early diagnostic marker of mucosal damage.

The next chapter of this thesis (chapter 2) provides a brief overview of the literature concerning $I / R$ injury of the bowel, in which relevant clinical conditions are described and present knowledge of pathophysiological mechanisms is presented. Chapter 3 describes the mesenteric $1 / R$ model and discusses its clinical relevance. The importance of the length of the ischemic period was investigated in chapter $4 ;$ even short periods of total warm bowel ischemia resulted in severe microvascular changes. Chapter 5 proposes a new histological grading system to quantify small bowel injury as a result of I/R. In chapter 6 a more advanced rat model was introduced in which we were able to visualize in the different layers of the small bowel local perfusion and leukocyte-vessel wall interactions, in vivo. Already 30 minutes of total warm ischemia and reperfusion impaired perfusion in the whole small bowel, whereas the early inflammatory reaction was limited to the submucosa. At the same time severe mucosal damage was evoked, as diagnosed both histologically and by an increase in circulating I-FABP. In chapter 7 we investigated the involvement of leukocyte and platelet adhesion in both the submucosal perfusion decrease and mucosal damage. To this purpose, the effects of a platelet activating factor (PAF) antagonist as well as an antibody against intercellular adhesion molecule-1 (ICAM1) on the consequences of $I / R$ were studied. The thesis ends with a general discussion and summary (chapter 8 and 9 ).

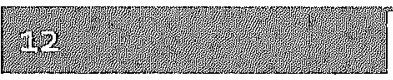




\section{References}

(1) Yasuhara H, Niwa H, Takenove T, Naka S. Factors influencing mortality of acute intestinal infarction associated with SIRS. Hepatogastroenterology 2005 Sep;52(65):1474-8.

(2) Marik PE. Total splanchnic resuscitation, SIRS, and MODS. Crit Care Med 1999 Feb;27(2):257-8.

(3) Yasuhara $\mathrm{H}$. Acute mesenteric ischemia: the challenge of gastroenterology. Surg Today 2005;35(3):185-95.

(4) McCord JM. Oxygen-derived free radicals in postischemic tissue injury. N Engl J Med 1985;312(3):159-63. 
Chapter 2

Ischemia and reperfusion injury of the bowel 


\section{Ischemia and reperfusion injury of the bowel}

\section{twotodution}

Ischemia (reduced blood flow) and subsequent reperfusion of a tissue frequently occur during men's life. Lying down, for instance, impairs perfusion of part of the skin microcirculation. In this case the ischemic condition comes usually to an end by changing posture; microvascular perfusion in the ischemic area is restored and, possibly, a small transient inflammatory response is initiated. This reaction has no apparent adverse consequences, and may even be followed by enhanced resistance to ischemia and reperfusion (I/R) (conditioning). However, a problematic condition occurs when the ischemic period becomes too long, i.e. in case of decubitus $(1 ; 2)$. Following such a prolonged period of ischemia, reperfusion can start an ongoing and destructive inflammatory reaction. This inflammatory reaction can lead to local but also to systemic complications like Systemic Inflammatory Response Syndrome (SIRS), Disseminated Intravascular coagulation (DIC) and even death. (3-5)

The intensity of an $I / R$ reaction depends on the ischemic severity and duration, the presence or absence of pre-conditioning, and the local temperature, but also on the kind of tissue involved. The bowel is much more vulnerable to $I / R$ than most other tissues(6). $I / R$ of the bowel plays an important role in many clinical conditions, like small bowel transplantation, cardiac, aorta and intestinal artery surgery, as well as Necrotizing Enterocolitis (NEC). Other situations which can lead to intestinal ischemia are thrombosis of pre-existent atherosclerotic disease or embolic arterial occlusion of the splanchnic arterial circulation, (septic) shock, (surgical) trauma, malrotation, volvulus, strangulated ileus, mesenteric vasospastic disorders and vasculitides.

\section{The clinical relevance of bowal ischemia and repertusion}

\section{Small bowel transplantation}

Irreversible loss of small bowel function and subsequent failure of parenteral nutrition is the most common indication for transplantation. The main causes of intestinal failure are gastroschisis (21\%), volvulus (27\%) and necrotizing enterocolitis (12\%) in children and ischemia (24\%) in adults. (7) Intestinal transplantation is performed in children (40\%) and adults $(60 \%)$.

The first bowel transplantation was performed in 1964 by Ralph Deterling in Boston.(8) Unfortunately, the intestinal transplants in the 19605 and 70 s were not successful due to technical complications, rejection or infection. However, the introduction of, an immunosuppressive drug, cyclosporine in $1978(9 ; 10)$ made it possible 
to transplant the intestine in the 1980 s with about 30\% graft survival after 1 year. However, only in the 1990 intestinal transplantation became a clinical reality, due to the availability of tacrolimus (FK-506; a new immunosuppressive drug)(11-13). According to the Intestinal Transplant Registry, the 1 year patient survival in the 1990 s was $60 \%$. Registered centres that transplanted 10 or more patients showed significant better results in terms of graft and patient survival. Today, overall about 140 intestinal transplant procedures are performed each year in one of the more than 60 transplantation centres worldwide, of which over 40 are in North-America; 1 and 5 year patient survival increased to $70 \%$ and $50-60 \%$, respectively. However, graft survival nowadays is still poor $(60 \% \mathrm{I} \mathrm{yr}$ and $50 \% 5 \mathrm{yr})$. Intestinal transplants can be isolated bowel, liver-intestine or multivisceral. Graft removal can be necessary because of rejection $(57 \%)$, ischemia or bleeding (21\%) or sepsis (7\%).(14)

\section{Cardiac and aortic surgery}

Tissue oxygenation and blood flow in the gut are impaired during conventional cardiopulmonary bypass surgery.(15-17) Immediately after the cardiopulmonary bypass procedure has ended, and cardiac ouput is restored, a hyperemic response has been detected by laser Doppler flow measurements and tonometry of the gastric mucosa.(16) Surprisingly, an additional progressive decline of gastric mucosal oxygenation occurred during the period 3 to 4 hours following cardiopulmonary bypass.(16) Besides the initial bowel ischemia during cardiac surgery, this additional decline in gastric mucosal oxygenation is believed to play an important role in the development of gastrointestinal complications following cardiac surgery as well. Although the incidence of gastrointestinal complications is relatively low, averaging approximately $1 \%$ in most series, the overall mortality following cardiopulmonary bypass surgery is high, ranging from 11 to $100 \%$. (18-29) The most frequent complications are gastrointestinal bleeding (usually gastroduodenal), intestinal infarction or perforations (including acute mesenteric ischemia), and gastroduodenal alterations. $(18 ; 22-24 ; 26)$ Clinical risk factors include advanced age, emergency operation, valvular surgical treatment, hypotension, intraaortic balloon pump, prolonged pump time, use of pressor substances, and reoperation. $(19 ; 20 ; 2 ; 26)$. In the 1990 s a new technique has been introduced to avoid a cardiopulmonary bypass procedure during coronary artery surgery. By using modern tissue stabilizers (based on suction- or pressure-fixation) accurate construction of a coronary anastomosis can be performed, which was expected to lead to lower morbidity and mortality.(30-32) However, the overall incidence of gastro-intestinal complications has changed little over the last 2 decades.(33)

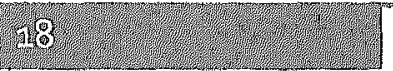


It is quite clear that aortic clamping proximal to the superior mesenteric artery, to allow aortic (aneurism) surgery, leads to ischemia of the gut. Even when left-heart bypass or selective organ perfusion is performed during thoracoabdominal aortic surgery, splanchnic tissue oxygenation is impaired.(34;35) However, discontinuing the blood flow in the lower abdominal aortic tract has been shown to result in bowel ischemia as well. $(36 ; 37)$ Therefore, mesenteric ischemia secondary to low flow states can be divided into occlusive or non-occlusive disease. Massive intestinal vasoconstriction causing nonocclusive gut ischemia is a major threat in aortic surgery, which can result in ischemic colitis and gangrene.(37;38) The etiology behind this mechanism is still unknown and needs to be clarified.

\section{Necrotizing Enterocolitis (NEC)}

NEC is the leading cause of morbidity and mortality in the neonatal intensive care unit, affecting 1-3\% newborn infants.(39-42) The pathogenesis of NEC is still not understood. However, intestinal ischemia is clearly involved, although it is unclear whether ischemia is the primary initiator of the process.(40) Platelet Activating Factor (PAF) is, among others, believed to play an important role in the pathogenesis of NEC. The enzyme PAFacetylhydrolase, degrading PAF into the inert lyso-PAF, is decreased in neonates (43) and is deficient in infants with NEC(44). In addition, in animal models of NEC the administration of PAF-acetylhydrolase reduces the incidence of the disease.(45) Between $27 \%$ and $63 \%$ of the affected infants require surgical intervention ( 46 ), and approximately $25 \%$ develop short bowel syndrome $(47)$, resulting in the need of prolonged parenteral nutrition and intestinal transplantation.

\section{Thrombosis or embolic splanchnic artery occlusion}

Acute intestinal ischemia as a result of artery occlusion due to thrombosis or an embolus may be present in 1 out of every 1000 patients admitted to the emergency room( 48 ), and is associated with poor prognosis. Mortality rates are nowadays between 24 and $60 \%$ (4951). Most emboli arise from a cardiac source; other sources are aneurysms, proximal atherosclerotic disease and iatrogenically produced emboli during intra-arterial endovascular procedures.(52)

Revascularization of the splanchnic circulation can be achieved surgically, by performing embolectomy, thromboendarterectomy, or bypass surgery (antegrade and/or retrograde). In many of these cases cross-clamping of the supra-celiac aorta is performed. To avoid high aortic cross-clamping retrograde iliac-splanchnic artery bypass surgery can be used. However, the performance of retrograde bypasses is worse than antegrade (originating from the supra-celiac aorta) bypasses, because retrograde bypasses need to 
be of much greater length and the risk of kinking leading to occlusion.(53) Surgical crossclamping during these procedures temporarily compromise intestinal circulation even more, followed by a destructive but inevitable intestinal reperfusion phase.

As indicated in the previous paragraphs, ischemia and reperfusion injury of the bowel is a common clinical condition, which in many cases leads to life threatening situations. Therefore, it is important to improve our knowledge of the pathophysiological mechanism leading to IR injury of the gut. Such knowledge will help to perform intervention studies, that may lead to the development of therapeutic strategies to counteract the $1 / R$ response. Therapeutic intervention should be performed as early as possible. Therefore, it is very important to develop diagnostic tools to determine intestinal ischemia in an early stage, and avoid additional and/or irreversible tissue injury. One possible diagnostic tool may be Intestinal Fatty Acid Binding Protein (I-FABP), which is released from injured enterocytes and can be detected from blood and urine samples.

\section{Pathophysiological background/mechanisms of bowel $/ / R$ injury Introduction}

During an ischemic period tissue perfusion is reduced. As an ischemic phase continues, cellular metabolic changes occur leading to local accumulation of toxic substances, finally leading to tissue injury.(54) At some point, that depends on the intensity and cause of ischemia and on the kind of tissue, recovery will not be possible anymore and cell death occurs by necrosis and apoptosis(55). Reperfusion of the tissue is necessary to provide it with oxygen and nutrients to remove waste-products. However, it will also deliver a large amount of reactive agents and cells, like oxygen radicals, interleukins, chemokines, prostaglandins, neutrophils and platelets, resulting in an inflammatory response. Furthermore, reperfusion makes it possible to spread locally accumulated toxic agents to other, non-ischemic sites, initiating a systemic inflammatory response.

\section{Formation of free radicals and other reactive molecules during $\mathrm{I} / \mathrm{R}$}

Free radicals are molecules with an unpaired electron in the outer (valence) shell; in chemical formulas this is indicated by a dot (see tables 1-4). These unpaired electrons are highly reactive and if a free radical reacts with a non-radical molecule the first radical will become more stable, while another free radical is produced. Often, a reactive oxygen species (ROS) or reactive nitrogen species (RNS) is created (see table 1) from the molecule it stole the electron from, like hydrogen peroxide (not a radical but a ROS), superoxide, hydroxyl radical or peroxynitrite. These reactive species will then react to a

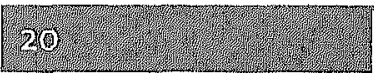


neighbouring molecule, leading to participation of free radicals in long chain reactions, causing macromolecular damage to cellmembranes (lipid peroxidation), DNA and proteins, and eventually causing injury to the cell as a whole.

Table 2: Reaclive oxygen and nitrogen species

\begin{tabular}{|c|c|c|c|}
\hline \multicolumn{2}{|l|}{ Radical } & \multicolumn{2}{|c|}{ Non-radical } \\
\hline $\mathrm{O}_{2}$ & superoxyde radical & $\mathrm{H}_{2} \mathrm{O}_{2}$ & hydrogen peroxide \\
\hline. $\mathrm{OH}$ & hydroxyl radical & NO & nitric oxygen \\
\hline ONOO: & peroxynitrite & & \\
\hline
\end{tabular}

The combination of oxygen radicals and ischemia may seem contradictory, but during ischemia metabolic processes are initiated which will increase oxygen radical formation during subsequent reoxygenation. Adenosine triphosphate (ATP) is normally produced in the mitochondria of the cell to create energy using the electron transport chain. Ischemia induces hypoxia and, as a consequence, dephosphorylation of ATP to adenosine diphosphate (ADP), and adenosine monophosphate (AMP), which is then catabolised to adenosine, inosine and then hypoxanthine. The mucosal villi of the gut contain the highest concentration of xanthine dehydrogenase of any tissue.(56) In physiological circumstances xanthine oxydase exists as an NAD+-dependent dehydrogenase which does not produce reactive oxygen species (type $D$ reaction). According to the amount of oxygen available, xanthine dehydrogenase is converted into xanthine oxydase by proteolysis (irreversible) and thiol oxidation (reversible). During reperfusion, reoxygenation enables xanthine oxydase to catalyze the oxidation of hypoxanthine, which has accumulated to excess levels during ischemia. As a result xanthine is produced, which is subsequently converted to urate and large amounts of superoxide radicals (type $O$ reaction) (see table 2). As part of the body's defence mechanism against the produced superoxide radicals, superoxide dismutase enzymes (CUZnSOD, MnSOD) will catalyze the breakdown of these radicals to the non-radical hydrogen peroxide and oxygen (see table 3). However, in the presence of free ferric iron, hydrogen peroxide can be converted to the very potent hydroxyl radical (see table 4).(57)

Table 2: Type D and type $\mathrm{O}$

(hypo)xanthine $+\mathrm{H}_{2} \mathrm{O}+\mathrm{NAD}^{+}$- type $\mathrm{D} \rightarrow$ urate $+\mathrm{NADH}+\mathrm{H}^{+}$

(hypo) xanthine $+\mathrm{H}_{2} \mathrm{O}+2 \mathrm{O}_{2}$ - type $\mathrm{O} \rightarrow$ urate $+2 \mathrm{O}_{2}{ }^{\circ}+2 \mathrm{H}^{+}$ 
The oxidative burst as adjunct of reperfusion also initiates multiple signalling pathways within the (endothelial) cell, like protein synthesis, cytoskeletal rearrangements and phospholipase $A_{2}$ production. Together, this leads to the expression of adhesion molecules, production of Platelet Activating Factor (PAF), and activation of the complement system, ultimately resulting (among others) in local neutrophil accumulation in the affected tissue.

Table 3 Breakdown superoxide radicals

$\mathrm{O}_{2} \cdot{ }^{\circ}+\mathrm{O}_{2} \cdot+2 \mathrm{H}^{+} \cdot \mathrm{SOD} \rightarrow \mathrm{H}_{2} \mathrm{O}_{2}+\mathrm{O}_{2}$

Table 4 : Reduction of ferri to ferro-ions

$\mathrm{Fe}^{3+}+\mathrm{O}_{2} \cdot \rightarrow \mathrm{Fe}^{2+}+\mathrm{O}_{2}$

$\frac{\mathrm{Fe}^{2+}+\mathrm{H}_{2} \mathrm{O}_{2}}{\mathrm{O}_{2}{ }^{-}+\mathrm{H}_{2} \mathrm{O}_{2}} \rightarrow \mathrm{Fe}^{3+}+\mathrm{OH}_{2}+\mathrm{OH}^{-}$net

\section{Complement system}

The complement system exists of about 35 proteins (enzymes, cofactors, inhibitors), receptors for complement factors and other regulating proteins.(58-60) Three different pathways can activate the complement system: the classical pathway (antibody dependent), the lectin pathway and the alternative pathway (antibody independent). $(58 ; 61-63)$

All three pathways lead to the formation of the biologically active, potent inflammatory anaphylatoxins $C_{3} a$ and $C_{5}$ a, and the cytolytic terminal membrane attack complement complex (MAC) $C_{5} b-9 . C_{5}$ a with its receptor $C_{5} a R$, has been recognized as a potent mediator of local and systemic inflammation. $C_{5 a}$ induces neutrophil accumulation, chemotaxis, cytotoxic activity and the release of reactive oxygen metabolites and proteases.(64) In vitro, $C_{5}$ a stimulation of human umbilical vein endothelial cells (HUVECS) resulted in increased gene expression for intercellular adhesion molecule-1 (ICAM-1), vascular cell adhesion molecule-1 (VCAM-1), E-selectin, cytokines, and chemokines.(65) $C_{3}$ a has a much lower potency and is not a chemoattractant for neutrophils, but mediates the migration of eosinophils and mast cells. (66) MAC is formed as a result of an interaction of $C_{5} b$ with $C 6, C_{7}, C_{8}$ and $C_{9}$ and acts as a transmembrane pore integrated in the phospholipid membrane bilayer causing osmotic lysis. $(67)$

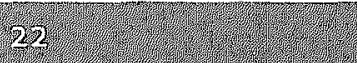




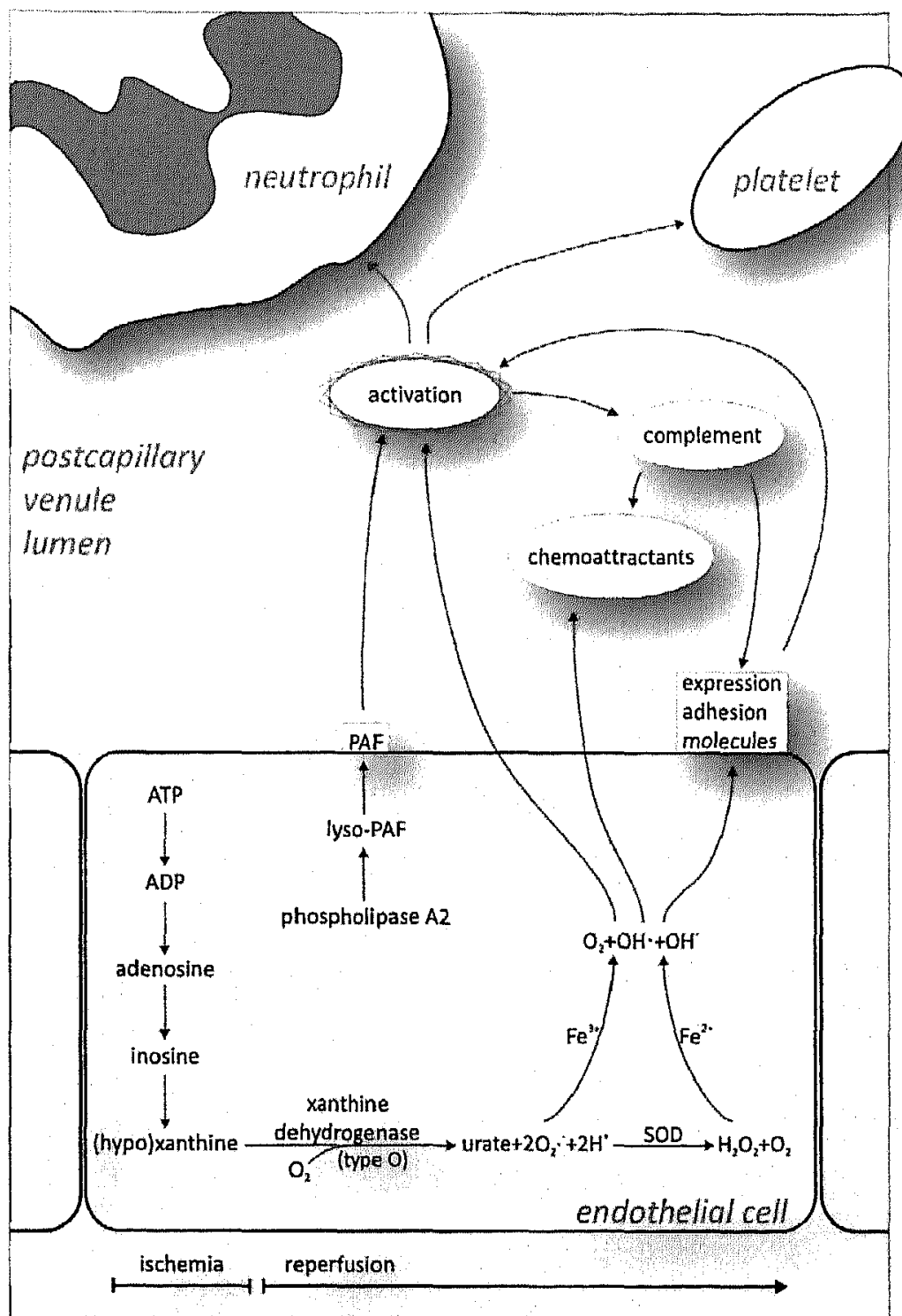

Figure 1. illustrates the degradation of ATP into (hypo)xanthine during ischemia and the formation of oxygen radicals and PAF (platelet activating factor) during reperfusion. As a result adhesion molecules are expressed, chemoattractants are produced, and neutrophils, platelets and the complement system are activated. SOD: superoxide dismutase 
I/R results in activation of the complement system through all three pathways(68-70). In intestinal I/R, the complement system appears to be an important mediator(69-75). Animals treated with complement inhibitors following I/R of the gut had less histological mucosal injury, decreased vascular permeability, and an increased survival rate $(71 ; 73 ; 75 ; 76)$.

\section{Platelet activating factor (PAF)}

PAF is enzymatically synthesized in a variety of cells, among which endothelial cells and leukocytes.(77) First, hydrolysis of long chain fatty acids is catalyzed by cytosolic phospholipase Az producing lyso-PAF, which is thereafter acetylated by an acetyltransferase resulting in bioactive PAF.(78) The continuously present PAF production can be dysregulated in abnormal circumstances like I/R.(79) The pro-inflammatory PAF and other related PAF-like lipids then activate a variety of different cells, including leukocytes and platelets, $(79)$ leading to leukocyte-vessel wall interactions and platelet aggregation.

\section{Leukocyte vessel-wall interactions following I/R}

Extravasation of leukocytes is an important step in host defence and the inflammatory reaction, and is the result of a multistep process: margination, tethering, rolling, activation, adhesion, and migration of leukocytes in postcapillary venules.(80-84) The process leading to leukocyte extravasation can be observed, in vivo, and quantified using intravital microscopy(85) as well as confocal microscopy. In a healthy environment circulating leukocytes do not firmly adhere to venular endothelium. Because of their relative large size, leukocytes are mainly positioned in the centre line of the blood vessel.

Margination of leukocytes from the central blood stream to the vessel wall makes it possible for leukocytes to interact with endothelial cells. Leukocytes are pushed to the vessel wall, as a result of an interaction with erythrocytes and/or the formation of blood cell aggregates(86-89) and also as a result of the interaction between individual leukocytes and red blood cells at bifurcations or postcapillary expansions. $(86 ; 90)$

Tethering is the first contact of leukocytes with endothelial cells. Like rolling, tethering is mainly mediated by adhesion molecules of the selectin family. P-selectin on endothelial cells binds with P-selectin glycoprotein ligand-1 (PSGL-1) on leukocytes(91).

Rolling is initiated by strengthening of the bondage between adhesion molecules on both cell types by dimerization( $(92 ; 93)$ and clustering $(94 ; 95)$, leading to a prolonged lifetime of the selectin-ligand interaction. In addition, redistribution of PSGL-1 and Lselectin (later described) to high-density areas may allow other leukocytes to be

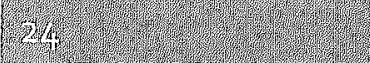


recruited(96). Leukocyte rolling is not necessarily part of an inflammatory reaction, but can also occur spontaneously, especially in the skin microcirculation(97).

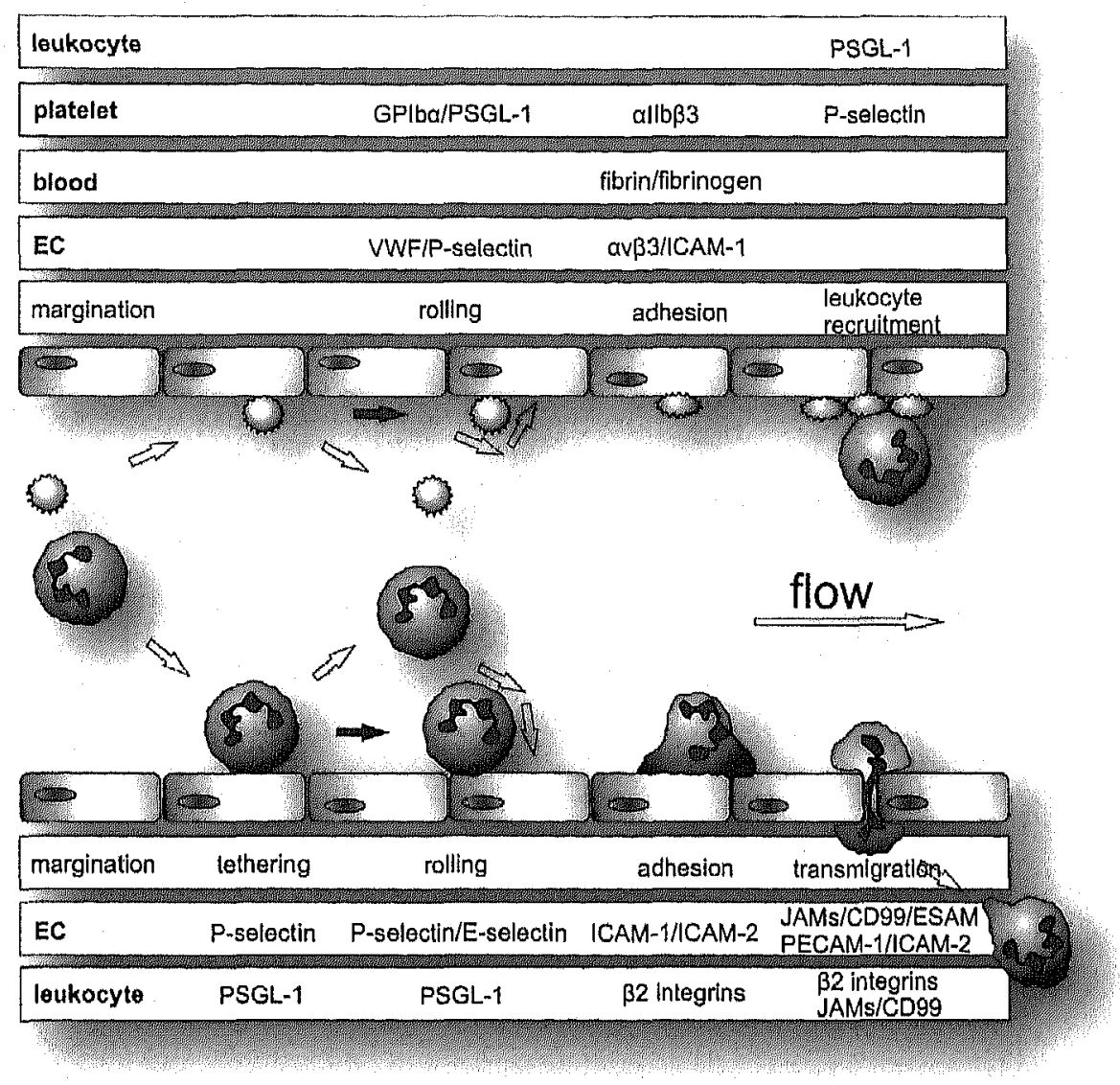

Figure 2: Schematic illustrating leukocyte-vessel wall (bottom), platelet-vessel wall (top), and platelet-leukocyte (top) interactions in a postcapillary venule during reperfusion. Leukocytes and platelets are pushed to the venular wall. The marginated leukocytes and platelets can start to roll along the endothelium and when activated adhere to these cells. Finally, leukocytes can transmigrate between or through endothelial cells into the inflamed tissue. When leukocytes or platelets are not activated they can detach from the vessel wall and re-join the blood stream. Bars at the top show the receptors/ligants involved in platelet-leukocyte and platelet-endothelial cell interactions at the different stages of the cascade, whereas bars at the bottom show their role in leukocyte-endothelial cell interactions. EC: endothelial cell 
P-selectin is the most important selectin involved in leukocyte rolling. Normally, this molecule is stored in Weibel-Palade bodies in endothelial cells(98) and in alpha-granules of platelets(99). Therefore, P-selectin can be rapidly expressed on the cell surface after activation, by fusion of the organelle membrane with the endothelial plasma membrane, with -in vitro- a peak at 3 minutes following activation, after which the expression level returns to baseline at 20 minutes. $(98 ; 100 ; 101)$ The P-selectin molecules will then retreat back into their storage granules.(102) Weibel-Palade bodies and alpha-granules, are believed to play a key role in the rapid initiation of the multistep process(103).

The second selectin that is involved in leukocyte rolling is L-selectin, which is constitutively expressed on most leukocyte cell surfaces and shed within seconds upon activation.(104) As a result of the shedding of L-selectin, the rolling leukocyte can either detach from the vessel wall or will adhere firmly because of Bz-integrin upregulation.(105;106;106) L-selectin is concentrated in leukocyte microvilli, fine cellular protrusions allowing the leukocyte to reach down into the endothelial glycocalyx, a meshed network of sulphated glycosaminoglycans.(103)

E-selectin is expressed on endothelial cells and does not play an important role during the early inflammatory phase, because it requires in most tissues, including the bowel, de novo mRNA and protein synthesis before expression to the cell surface is realized; in vitro, this process takes at least some hours.(107)

Activation of endothelium and leukocytes following I/R leads to firm adhesion. Not only different substances produced by $\mathrm{I} / \mathrm{R}$ (as mentioned before), but also endothelial cell signalling molecules, like PAF and TNF- $\alpha$, can be involved and result in activation. $(108 ; 109)$ In addition, (slow) rolling allows leukocytes to sample chemokines presented by the glycocalyx. Chemokines can selectively activate cells and thereby control cell-vessel wall interactions, and the process of migration into (selected) tissue, serving as chemoattractants. Chemokine synthesis in ischemic or reperfused tissue is stimulated by oxygen radicals, complement system, and Toll-like receptor mediated pathways, by activating the nuclear factor (NF)-KB system.(110;111) important chemokines involved in neutrophil recrutement in the ischemic/reperfused area are CXCL1, CXCL5, and CXCL8 (IL-8).(110)

Adhesion of leukocytes to the endothelium mainly involves integrins on the leukocyte surface that bind to members of the immunoglobulin superfamily on endothelial cells. Every class of leukocytes displays a particular pattern of integrins; integrins are heterodimers consisting of an alpha and beta subunit. Neutrophils mainly express B2integrins, but expressionof $\beta_{1}$ - and $\beta_{3}$-integrins has been reported as well.(112-118) $\beta_{2}$ integrin (CD18) can combine with 4 different $\alpha$ subunits: $\alpha L \beta_{2}$ (also named LFA-1 or $\left.C_{1} 8 / C_{11 a}\right), \alpha M B_{2}$ (Mac-1 or CD18/CD11b), $\alpha X \beta_{2}$ (p150,95 or CD18/CD11C) and $\alpha D_{2}$ 
(CD18/CD11d).(119) Ligands for B2-integrins continue to be identified, but the most important ones are members of the immunoglobulin superfamily, mainly intercellular cell adhesion molecule-1 (ICAM-1) and ICAM-2.(83;119) ICAM-1 is constitutively expressed, in low levels, on the surface of unstimulated endothelial cells of postcapillary venules, as well as on neutrophils, and is significantly upregulated during $I / R$ by cytokines/chemokines.(120) (121) ICAM-2 is present on endothelial cells, most leukocytes and platelets in a much higher concentration than ICAM-1. However, its expression level is not upregulated by inflammatory mediators.(121)

Transmigration of leukocytes out of the vessel lumen into the tissue is the next step. There is growing evidence that integrins, ICAM-1 and ICAM-2, platelet endothelial cell adhesion molecule-1 (PECAM-1), members of the junctional adhesion molecule family (JAM-1, -2, and -3), CD99, VE-cadherin, B-catenin and endothelial cell-selective adhesion molecule (ESAM) are involved in the process of migration.(117;122) Leukocytes can move through junctions between neighboring endothelial cells forming pseudopods, but are also able to migrate through endothelial cells. However, the latter transcellular route seems of less importance.(103) To establish neutrophil migration, a transient increase in intracellular free calcium in endothelial cells is required.(123) This is a very local mechanism in which only surrounding endothelial cells are involved.(124) Triggers, increasing cytosolic free calcium concentration, that have been identified are heparinbinding-protein(125), a soluble product released from leukocytes, and signalling through cross-linking of $\mathrm{P}$ - or E-selectin or vascular cell adhesion molecule-1 (VCAM-1)(126).

\section{Platelet Vessel-wall and platelet-leukocyte interactions}

Beside an inflammatory reaction, $/ / R$ also induces a thrombotic response. The thrombotic reaction initiated by $I / R$ is thought to play an important role in mediating the inflammatory response.(127-131) Platelet-vessel wall interactions following total warm ischemia and reperfusion of the small bowel in vivo, were first described in 1998.(132) These interactions were observed within minutes after start of reperfusion in intestinal venules, but also in arterioles.(Beuk et al, accepted BJS 2008)(132;133) In this model of total ischemia the interaction between platelets and endothelial cells is the result of endothelial P-selectin binding with an unknown receptor on platelets(132), and of endothelial ICAM-1 binding with fibrinogen which, at the other end, binds to glycoprotein Ilb/llla ( $\alpha$ llb/ $\beta 3$ integrin) on platelets.(133) In later studies, another group showed that following partial warm ischemia of the bowel platelet adhesion also occurs, but hours after start of reperfusion and in venules only.(134) In the latter situation, platelet Pselectin appears to be involved in rolling and adhesion of platelets along the endothelium. 
Hence, the thrombotic response as a result of total, as opposed to partial, warm ischemia seems to be more intense and possibly involves another pathophysiological reaction.(134)

In addition to platelets interacting with the vessel wall, there are also platelets interacting with leukocytes that adhere to the endothelium; in addition, leukocytes can bind to platelets that achere to the venular wall. Following partial ischemia of the small bowel the majority of platelet adhesion resulted from interactions with adherent leukocytes (74\%). However, less than $50 \%$ of the adherent leukocytes did bear platelets, indicating that only part of the adherent leukocytes supported platelet adhesion. (135) This binding between platelets and leukocytes is believed to be accomplished by platelet P-selectin binding to an unknown ligand on leukocytes, possibly PSGL-1.(135-137)

\section{Markers (diagnostic cools) of I/R injury of the bowel Introduction}

Just like cardiac markers for ischemia, i.e. troponin I and T, it is important to develop diagnostic tools to diagnose intestinal ischemia in an early stage. With the use of these markers proper actions can be taken to treat the disease with the best expected results. One promising marker is intestinal fatty acid binding protein (I-FABP). More (rapid) tests need to be developed to deal with the high mortality of bowel ischemia and reperfusion in the future.

\section{Fatty acid binding proteins}

The fatty acid binding protein (FABP) superfamily consists of $14^{-15} \mathrm{kDa}$ cytoplasmic proteins of which various tissue specific types occur.(138-140) FABPs mainly facilitates intracellular long-chain fatty acid transport.(141) Within the cytosol of enterocytes several FABP subtypes have been reported. Each FABP subtype shows a characteristic pattern of tissue distribution.(142) During $1 / R$ the integrity of enterocytes is harmed and the FABPs leak from the cells into the circulation and urine, where these biomarkers can be measured. Liver fatty acid-binding protein (L-FABP) is present in the liver, kidneys and mainly proximal gut (duodenum and jejunum).(142-146) Intestinal fatty acid-binding protein (I-FABP) constitutes $2 \%$ of enterocyte protein, and can be found in the whole small bowel, with the highest concentration in the proximal ileum villi tips.(139) lleal fatty acid-binding protein (IL-FABP) is only present in the ileum, with concentrations increasing from the proximal to the distal part.(139)

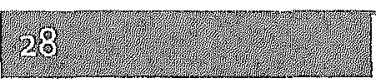




\section{References}

(1) Peerless JR, Davies A, Klein D, YU D. Skin complications in the intensive care unit. Clin Chest Med 1999 Jun;20(2):453-67.

(2) van Rijswijk $L$, Braden BJ. Pressure ulcer patient and wound assessment: an AHCPR clinical practice guideline update. Ostomy Wound Manage 1999 Jan;45(1A Suppl):565-675.

(3) Yasuhara $H$, Niwa $H_{1}$ Takenoue $T$, Naka $S$. Factors influencing mortality of acute intestinal infarction associated with SIRS. Hepatogastroenterology 2005 Sep; $52(65): 1474-8$.

(4) Marik PE. Total splanchnic resuscitation, SIRS, and MODS. Crit Care Med 1999 Feb;27(2):257-8.

(5) Yasuhara $\mathrm{H}$. Acute mesenteric ischemia: the challenge of gastroenterology. Surg Today 2005;35(3):185-95.

(6) McCord JM. Oxygen-derived free radicals in postischemic tissue injury. N Engl J Med 1985;312(3):159-63.

(7) Dijkstra G, Rings EH, Bijleveld CM, Van Dullemen HM, Hofker HS, Porte RJ, et al. Intestinal transplantation in The Netherlands: first experience and future perspectives. Scand J Gastroenterol Suppl $2006 \mathrm{May}_{i}(243): 39-45$.

(8) Fryer JP. Intestinal transplantation: an update. Curr Opin Gastroenterol 2005 Mar; $21(2): 162-8$.

(9) Calne RY, White DJ, Thiru S, Evans DB, McMaster P, Dunn DC, et al. Cyclosporin A in patients receiving renal allografts from cadaver donors. Lancet $1978 \mathrm{Dec}$ 23;2(8104-5):1323-7.

(10) Calne RY, Rolles K, White DJ, Thiru S, Evans DB, McMaster P, et al. Cyclosporin A initially as the only immunosuppressant in 34 recipients of cadaveric organs: 32 kidneys, 2 pancreases, and 2 livers. Lancet 1979 Nov 17;2(8151):1033-6.

(11) Asfar S, Atkison P, Ghent C, Duff J, Wall W, Williams $S$, et al. Small bowel transplantation. A life-saving option for selected patients with intestinal failure. Dig Dis Sci 1996;41(5):875-83.

(12) Kino T, Hatanaka $H_{1}$ Miyata S, Inamura N, Nishiyama M, Yajima T, et al. FK-506, a novel immunosuppressant isolated from a Streptomyces. II. Immunosuppressive effect of FK-506 in vitro. J Antibiot (Tokyo) 1987 Sep; $40(9): 1256-65$.

(13) Kino T, Hatanaka $H$, Hashimoto $M$, Nishiyama $M$, Goto $T$, Okuhara $M$, et al. FK506, a novel immunosuppressant isolated from a Streptomyces. I. Fermentation, isolation, and physico-chemical and biological characteristics. J Antibiot (Tokyo) $1987 \operatorname{Sep} ; 40(9): 1249-55$. 
(14) Grant D. Intestinal transplantation: 1997 report of the international registry. Intestinal Transplant Registry. Transplantation 1999 Apr 15;67(7):1061-4.

(15) Ohri SK. Systemic inflammatory response and the splanchnic bed in cardiopulmonary bypass. Perfusion 1996 May;11(3):200-12.

(16) Ohri SK, Bowles CW, Mathie RT, Lawrence DR, Keogh BE, Taylor KM. Effect of cardiopulmonary bypass perfusion protocols on gut tissue oxygenation and blood flow. Ann Thorac Surg 1997 Jul;64(1):163-70.

(17) Ohri SK, Bowles CT, Siddiqui A, Khaghani A, Keogh BE, Wright $G$, et al. The effect of cardiopulmonary bypass on gastric and colonic mucosal perfusion: a tonometric assessment. Perfusion 1994 Mar;9(2):101-8.

(18) Lazar $H L$, Hudson $H$, McCann J, Fonger JD, Birkett D, Aldea GS, et al. Gastrointestinal complications following cardiac surgery. Cardiovasc Surg $1995 ; 3(3): 341-4$.

(19) Zimmerman BJ, Granger DN. Reperfusion-induced leukocyte infiltration: role of elastase. Am J Physiol 1990;259:H390-4.

(20) Allen $K B$, Salam $A A$, Lumsden $A B$. Acute mesenteric ischemia after cardiopulmonary bypass. J Vasc Surg 1992;16(3):391-5.

(21) Aranha GV, Pickleman J, Pifarre R, Scanlon PJ, Gunnar RM. The reasons for gastrointestinal consultation after cardiac surgery. Am Surg 1984 Jun;50(6):301-4.

(22) Gennaro $M$, Ascer $E$, Matano R, Jacobowitz IJ, Cunningham JN, Jr., Uceda P. Acute mesenteric ischemia after cardiopulmonary bypass. Am J Surg 1993;166(2):231-6.

(23) Hanks JB, Curtis SE, Hanks BB, Andersen DK, Cox JL, Jones RS. Gastrointestinal complications after cardiopulmonary bypass. Surgery 1982;92(2):394-400.

(24) Huddy SP, Joyce WP, Pepper JR. Gastrointestinal complications in 4473 patients who underwent cardiopulmonary bypass surgery. Br J Surg 1991;78(3):293-6.

(25) Lawhorne TWJ, Davis JL, Smith GW. General surgical complications after cardiac

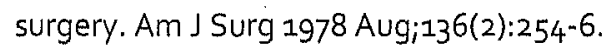

(26) Leitman IM, Paull DE, Barie PS, Isom OW, Shires GT. Intra-abdominal complications of cardiopulmonary bypass operations. Surg Gynecol Obstet $1987 ; 165(3): 251-4$.

(27) Reath DB, Maull KI, Wolfgang TC. General surgical complications following cardiac surgery. Am Surg 1983 Jan;49(1):11-4.

(28) Spotnitz WD, Sanders RP, Hanks JB, Nolan SP, Tribble CG, Bergin JD, et al. General surgical complications can be predicted after cardiopulmonary bypass. Ann Surg 1995 May; 221(5):489-96.

(29) Schutz A, Eichinger W; Breuer $M_{1}$ Gansera B, Kemkes BM. Acute mesenteric ischemia after open heart surgery. Angiology 1998 Apr;49(4):267-73.

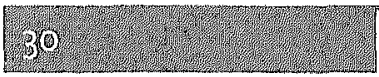


(30) Bredée $\mathrm{JJ}$, Jansen EW. Coronary artery bypass grafting without cardiopulmonary

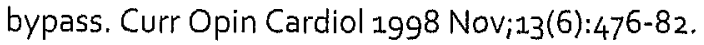

(31) Scott NA, Knight JL, Bidstrup BP, Wolfenden $H$, Linacre RN, Maddern GJ. Systematic review of beating heart surgery with the Octopus Tissue Stabilizer. Eur J Cardiothorac Surg 2002 May; 21(5):804-17.

(32) Hart JC, Spooner TH, Pym J, Flavin TF, Edgerton JR, Mack MJ, et al. A review of 1,582 consecutive Octopus off-pump coronary bypass patients. Ann Thorac Surg $2000 \operatorname{Sep}_{7} 70(3): 1017-20$.

(33) Ohri 5K, Velissaris T. Gastrointestinal dysfunction following cardiac surgery. Perfusion $2006 \mathrm{Jul} ; 21(4): 215-23$.

(34) Idu MM, Heintjes RJ, Scholten EW, Balm R, de Mol BA, Legemate DA. Visceral and renal tissue oxygenation during supraceliac aortic crossclamping and left heart bypass with selective organ perfusion. Eur 」 Vasc Endovasc Surg 2004 Feb;27(2):138-44.

(35) Hanssen SJ, Derikx JP, Vermeulen W, I, Heijmans JH, Koeppel TA, Schurink GW, et al. Visceral injury and systemic inflammation in patients undergoing extracorporeal circulation during aortic surgery. Ann Surg $2008 \mathrm{Jul} ; 248(1): 117-25$.

(36) Eldrup JJ, Hawkins RE, Bredenberg CE. Abdominal vascular catastrophes. Surg Clin North Am 1997 Dec;77(6):1305-20

(37) Haglund U, Bergqvist D. Intestinal ischemia -- the basics. Langenbecks Arch Surg 1999 Jun;384(3):233-8.

(38) Gandhi SK, Hanson MM, Vernava AM, Kaminski DL, Longo WE. Ischemic colitis. Dis Colon Rectum 1996 Jan;39(1):88-100.

(39) Henry MC, Moss RL. Current issues in the management of necrotizing enterocolitis. Semin Perinatol 2004 Jun;28(3):221-33.

$(40)$ Lee JS, Polin RA. Treatment and prevention of necrotizing enterocolitis. Semin Neonatol 2003 Dec;8(6):449-59.

(41) Hsueh W, Caplan MS, Qu XW, Tan XD, De P, I, Gonzalez-Crussi F. Neonatal necrotizing enterocolitis: clinical considerations and pathogenetic concepts. Pediatr Dev Pathol 2003 Jan;6(1):6-23.

(42) Kosloske AM. Epidemiology of necrotizing enterocolitis. Acta Paediatr Suppl 1994;396:2-7.

(43) Caplan $M$, Hsueh W, Kelly A, Donovan M. Serum PAF acetylhydrolase increases during neonatal maturation. Prostaglandins 1990;39(6):705-14.

(44) Caplan MS, Sun XM, Hseuh W, Hageman JR. Role of platelet activating factor and tumor necrosis factor-alpha in neonatal necrotizing enterocolitis. J Pediatr 1990 Jun;116(6):960-4. 
(45) Caplan MS, Lickerman M, Adler $L$, Dietsch GN, Yu A. The role of recombinant platelet-activating factor acetylhydrolase in a neonatal rat model of necrotizing enterocolitis. Pediatr Res 1997 Dec;42(6):779-83.

(46) Ricketts RR. Surgical treatment of necrotizing enterocolitis and the short bowel syndrome. Clin Perinatol 1994 Jun;21(2):365-87.

(47) Patel JC, Tepas JJ, Huffman SD, Evans JS. Neonatal necrotizing enterocolitis: the long-term perspective. Am Surg 1998 Jun;64(6):575-9.

(48) Ottinger LW. The surgical management of acute occlusion of the superior mesenteric artery. Ann Surg 1978 Dec;188(6):721-31.

(49) Foley MI, Moneta GL, bou-Zamzam AM, Jr., Edwards JM, Taylor LM, Jr., Yeager $R A$, et al. Revascularization of the superior mesenteric artery alone for treatment of intestinal ischemia. J Vasc Surg $2000 \mathrm{Jul} ; 32(1): 37-47$.

(50) Park WM, Gloviczki P, Cherry KJ, Jr., Hallett JW, Jr., Bower TC, Panneton JM, et al. Contemporary management of acute mesenteric ischemia: Factors associated with survival. IVasc Surg 2002 Mar;35(3):445-52.

(51) Endean ED, Barnes SL, Kwolek CJ, Minion DJ, Schwarcz TH, Mentzer RM, Jr. Surgical management of thrombotic acute intestinal ischemia. Ann Surg 2001 Jun;233(6):801-8.

(52) Sternbach $Y_{1}$ Perler BA. Acute mesenteric ischemia. In: Yeo CJ, editor. Shackleford's surgery of the alimentary tract. 5 ed. WB Saunders; 2001. p. 17-31.

(53) Cho JS, Carr JA, Jacobsen G, Shepard AD, Nypaver TJ, Reddy DJ. Long-term outcome after mesenteric artery reconstruction: a 37-year experience. $J$ Vasc Surg $2002 \operatorname{Mar}_{335(3): 453-60 .}$

(54) Li C, Jackson RM. Reactive species mechanisms of cellular hypoxia-reoxygenation injury. Am J Physiol Cell Physiol 2002 Feb;282(2):C227-C241.

(55) Saikumar $P$, Dong $Z$, Weinberg $J M$, Venkatachalam MA. Mechanisms of cell death in hypoxia/reoxygenation injury. Oncogene 1998 Dec 24;17(25):3341-9.

(56) Sackler ML. Xanthine oxidase from liver and duodenum of the rat: histochemical localization and electrophoretic heterogeneity. J Histochem Cytochem 1966 Apr;14(4):326-33.

(57) Zimmerman BJ, Granger DN. Mechanisms of reperfusion injury. Am 」 Med Sci 1994;307:284-92.

(58) Arumugam TV, Magnus $T$, Woodruff TM, Proctor LM, Shiels IA, Taylor SM. Complement mediators in ischemia-reperfusion injury. Clin Chim Acta 2006 $\operatorname{Dec}_{3374(1-2): 33-45 .}$

(59) Sim RB, Tsiftsoglou SA. Proteases of the complement system. Biochem Soc Trans 2004 Feb;32(Pt 1):21-7.

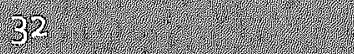


(60) Morgan BP. Complement regulatory molecules: application to therapy and transplantation. Immunol Today 1995 Jun;16(6):257-9.

(61) Hurst MM, Volanakis JE, Stroud RM, Bennett JC. $C_{1}$ fixation and classical complement pathway activation by a fragment of the $\mathrm{Cmu}_{4}$ domain of IgM. J Exp Med 1975 Nov 1;142(5):1322-6.

(62) Fearon DT, Austen KF. Properdin: initiation of alternative complement pathway. Proc Natl Acad Sci U S A 1975 Augi72(8):3220-4.

(63) Thiel S, Vorup-Jensen T, Stover CM, Schwaeble W, Laursen SB, Poulsen K, et al. A second serine protease associated with mannan-binding lectin that activates complement. Nature 1997 Apr 3;386(6624):506-10.

(64) Ember JA, Sanderson SD, Taylor SM, Kawahara M, Hugli TE. Biologic activity of synthetic analogues of $C_{5}$ a anaphylatoxin. J Immunol 1992 May 15;148(10):3165-

73.

(65) Albrecht EA, Chinnaiyan AM, Varambally S, Kumar-Sinha C, Barrette TR, Sarma $J V$, et al. $C_{5}$ a-induced gene expression in human umbilical vein endothelial cells. Am J Pathol 2004 Mar;164(3):849-59.

(66) DiScipio RG, Daffern PJ, Jagels MA, Broide DH, Sriramarao P. A comparison of C3a and $C_{5}$ a-mediated stable adhesion of rolling eosinophils in postcapillary venules and transendothelial migration in vitro and in vivo. J Immunol 1999 Jan $15 ; 162(2): 1127-36$.

(67) Morgan BP. Regulation of the complement membrane attack pathway. Crit Rev Immunol 1999;19(3):173-98.

(68) Link C, Hawlisch H, Meyer z, V, Gyleruz S, Nagel E, Kohl J. Selection of phagedisplayed anti-guinea pig $C_{5}$ or $C_{5}$ a antibodies and their application in xenotransplantation. Mol Immunol 1999 Dec;36(18):1235-47.

(69) Arumugam TV, Shiels IA, Woodruff TM, Granger DN, Taylor SM. The role of the complement system in ischemia-reperfusion injury. Shock 2004 May;21(5):401-9.

(70) Stahl GL, Xu Y, Hao L, Miller M, Buras JA, Fung $M$, et al. Role for the alternative complement pathway in ischemia/reperfusion injury. Am J Pathol 2003 Feb;162(2):449-55.

(71) Atkinson C, Song $H$, LU B, Qiao F, Burns TA, Holers VM, et al. Targeted complement inhibition by $C_{3} d$ recognition ameliorates tissue injury without apparent increase in susceptibility to infection. J Clin Invest 2005 Sep;115(9):244453.

(72) Hart ML, Ceonzo KA, Shaffer LA, Takahashi K, Rother RP, Reenstra WR, et al. Gastrointestinal ischemia-reperfusion injury is lectin complement pathway dependent without involving C1q. J Immunol 2005 May 15;174(10):6373-80. 
(73) Proctor LM, Arumugam TV, Shiels I, Reid RC, Fairlie DP, Taylor SM. Comparative anti-inflammatory activities of antagonists to $C_{3}$ and $C_{5}$ a receptors in a rat model of intestinal ischaemia/reperfusion injury. $\mathrm{Br} J \mathrm{Pharmacol} 2004 \mathrm{Jun} ; 142$ 2(4):756-64.

(74) Zhang M, Austen WG, Jr., Chiu I, Alicot EM, Hung R, Ma M, et al. Identification of a specific self-reactive $\lg M$ antibody that initiates intestinal ischemia/reperfusion injury. Proc Natl Acad Sci U S A 2004 Mar 16;101(11):3886-91.

(75) Fleming SD, Mastellos D, Karpel-Massler G, Shea-Donohue T, Lambris JD, Tsokos GC. C5a causes limited, polymorphonuclear cell-independent, mesenteric ischemia/reperfusion-induced injury. Clin Immunol 2003 Sep;108(3):263-73.

(76) Arumugam TV, Shiels IA, Woodruff TM, Reid RC, Fairlie DP, Taylor SM. Protective effect of a new $C_{5}$ a receptor antagonist against ischemia-reperfusion injury in the rat small intestine. J Surg Res $2002 \mathrm{Apr}_{1} 103(2): 260-7$.

(77) Prescott SM, Zimmerman GA, 5tafforini DM, McIntyre TM. Platelet-activating factor and related lipid mediators. Annu Rev Biochem 2000;69:419-45.

(78) Snyder F, Lee TC, Blank M, Malone B, Woodard D, Robinson M. Platelet-activating factor: alternate pathways of biosynthesis, mechanism of inactivation, and reacylation of lyso-PAF with arachidonate. Adv Prostaglandin Thromboxane Leukot Res 1985;15:693-6.

(79) Castro Faria Neto HC, Stafforini DM, Prescott SM, Zimmerman GA. Regulating inflammation through the anti-inflammatory enzyme platelet-activating factoracetylhydrolase. Mem Inst Oswaldo Cruz 2005 Mar;100 Suppl 1:83-91.

(80) Butcher EC. Leukocyte-endothelial cell recognition: three (or more) steps to specificity and diversity. Cell 1991;67:1033-6.

(81) von Andrian UH, Arfors KE. Neutrophil-endothelial cell interactions in vivo: a chain of events characterized by distinct molecular mechanisms. Agents Actions Suppl 1993;41:153-64.

(82) Springer TA. Traffic signals for lymphocyte recirculation and leukocyte emigration: the multistep paradigm. Cell 1994;76(2):301-14.

(83) Mclntyre TM, Prescott SM, Weyrich AS, Zimmerman GA. Cell-cell interactions: leukocyte-endothelial interactions. Curr Opin Hematol 2003 Mar;10(2):150-8.

(84) Muller WA. Leukocyte-endothelial-cell interactions in leukocyte transmigration and the inflammatory response. Trends Immunol 2003 Jun;24(6):327-34.

(85) Beuk RJ, Heineman E, Tangelder GJ, Quaedackers JS, Marks WH, Lieberman JM, et al. Total warm ischemia and reperfusion impairs flow in all rat gut layers but increases leukocyte-vessel wall interactions in the submucosa only. Ann Surg 2000 Jan;231(1):96-104.

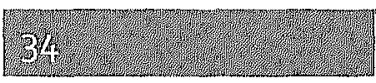


(86) Munn LL, Dupin MM. Blood cell interactions and segregation in flow. Ann Biomed Eng 2008 Apr;36(4):534-44.

(87) Mayrovitz HN, Kang SJ, Herscovici B, Sampsell RN. Leukocyte adherence initiation in skeletal muscle capillaries and venules. Microvasc Res 1987;33(1):22-34.

(88) Pearson MJ, Lipowsky HH. Influence of erythrocyte aggregation on leukocyte margination in postcapillary venules of rat mesentery. Am J Physiol Heart Circ Physiol 2000 Oct; $279(4): \mathrm{H}_{14} 60-\mathrm{H}_{1} 147$.

(89) Goldsmith HL, Spain S. Margination of leukocytes in blood flow through small tubes. Microvasc Res $1984 \operatorname{Mar}_{i 2}$ (2):204-22.

(90) Schmid-Schonbein GW, Usami S, Skalak R, Chien S. The interaction of leukocytes and erythrocytes in capillary and postcapillary vessels. Microvasc Res 1980 $\operatorname{Jan} ; 19(1): 45-70$.

(91) McEver RP. Selectins: lectins that initiate cell adhesion under flow. Curr Opin Cell Biol 2002 Oct; $14(5): 581-6$.

(92) McEver RP. Adhesive interactions of leukocytes, platelets, and the vessel wall during hemostasis and inflammation. Thromb Haemost 2001 Sep;86(3):746-56.

(93) Ramachandran V, Yago T, Epperson TK, Kobzdej MM, Nollert MU, Cummings RD, et al. Dimerization of a selectin and its ligand stabilizes cell rolling and enhances tether strength in shear flow. Proc Natl Acad Sci U S A 2001 Aug 28;98(18):1016671.

(94) Dwir O, Kansas GS, Alon R. Cytoplasmic anchorage of L-selectin controls leukocyte capture and rolling by increasing the mechanical stability of the selectin tether. J Cell Biol 2001 Oct 1;155(1):145-56.

(95) Dwir O, Steeber DA, Schwarz US, Camphausen RT, Kansas GS, Tedder TF, et al. Lselectin dimerization enhances tether formation to properly spaced ligand. J Biol Chem 2002 Jun 14;277(24):21130-9.

(96) Sperandio M, Smith ML, Forlow SB, Olson TS, Xia L, McEver RP, et al. P-selectin glycoprotein ligand-1 mediates $L$-selectin-dependent leukocyte rolling in venules. J Exp Med 2003 May 29;197(10):1355-63.

(97) Janssen GHGW, Tangelder GJ, oude Egbrink MGA, Reneman RS. Spontaneous leukocyte rolling in venules in untraumatized skin of conscious and anesthetized animals. Am J Physiol 1994; 267:H1199-204.

(98) Hattori R, Hamilton KK, Fugate RD, McEver RP, Sims PJ. Stimulated secretion of endothelial von Willebrand factor is accompanied by rapid redistribution to the cell surface of the intracellular granule membrane protein GMP-140. J Biol Chem 1989 May $15 ; 264(14): 7768-71$. 
(99) Stenberg PE, McEver RP, Shuman MA, Jacques $Y$, Bainton DF. A platelet alphagranule membrane protein (GMP-140) is expressed on the plasma membrane after activation. J Cell Biol 1985 Sep;101(3):880-6.

(100) McEver RP, Beckstead JH, Moore KL, Marshall-Carlson L, Bainton DF. GMP-140, a platelet alpha-granule membrane protein, is also synthesized by vascular endothelial cells and is localized in Weibel-Palade bodies. I Clin Invest 1989 Jul;84 8 (1):92-9.

(101) Bonfanti R, Furie BC, Furie B, Wagner DD. PADGEM (GMP140) is a component of Weibel-Palade bodies of human endothelial cells. Bंlood 1989 Apr;73(5):1109-12.

(102) Subramaniam $M$, Koedam JA, Wagner DD. Divergent fates of $P$ - and E-selectins after their expression on the plasma membrane. Mol Biol Cell 1993;4:791-801.

(103) Wagner DD, Frenette PS. The vessel wall and its interactions. Blood 2008 Jun 1;111(11):5271-81.

(104) Walcheck B, Moore KL, McEver RP, Kishimoto TK. Neutrophil-neutrophil interactions under hydrodynamic shear stress involve L-selectin and PSGL-1. A mechanism that amplifies initial leukocyte accumulation of P-selectin in vitro. J Clin Invest 1996 Sep 1;98(5):1081-7.

(105) Kishimoto TK, Jutila MA, Berg EL, Butcher EC. Neutrophil Mac-1 and MEL-14 adhesion proteins inversely regulated by chemotactic factors. Science 1989 Sep $15 ; 245(4923): 1238-41$.

(106) McEver RP. Leukocyte interactions mediated by selectins. Thromb Haemost 1991 Jul $12 ; 66(1): 80-7$.

(107) Bevilacqua MP, Pober JS, Mendrick DL, Cotran RS, Gimbrone MA, Jr. Identification of an inducible endothelial-leukocyte adhesion molecule. Proc Natl Acad Sci U S A $1987 \mathrm{Dec} ; 84(24): 9238-42$.

(108) Johnston $B$, Butcher EC. Chemokines in rapid leukocyte adhesion triggering and migration. Semin Immunol 2002 Apr;14(2):83-92.

(109) Zimmerman GA, McIntyre TM, Prescott SM. Adhesion and signaling in vascular cell--cell interactions. J Clin Invest 1996 Oct 15;98(8):1699-702.

(110) Frangogiannis NG. Chemokines in ischemia and reperfusion. Thromb Haemost 2007 May;97(5):738-47.

(111) Girn HR, Ahilathirunayagam S, Mavor Al, Homer-Vanniasinkam S. Reperfusion syndrome: cellular mechanisms of microvascular dysfunction and potential

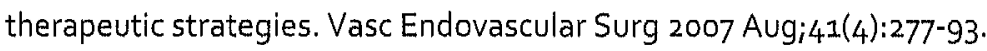

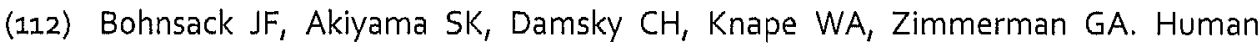
neutrophil adherence to laminin in vitro. Evidence for a distinct neutrophil integrin receptor for laminin. J Exp Med 1990 Apr 1;171(4):1221-37. 
(113) Kubes P, Niu XF, Smith CW, Kehrli ME, Jr., Reinhardt PH, Woodman RC. A novel beta 1-dependent adhesion pathway on neutrophils: a mechanism invoked by dihydrocytochalasin B or endothelial transmigration. FASEB J 1995 Aug;9(11):1103-11.

(114) Hendey B, Lawson M, Marcantonio EE, Maxfield FR. Intracellular calcium and calcineurin regulate neutrophil motility on vitronectin through a receptor identified by antibodies to integrins alphav and betaz. Blood 1996 Mar $1 ; 87(5): 2038-48$.

(115) Yauch RL, Berditchevski F, Harler MB, Reichner J, Hemler ME. Highly stoichiometric, stable, and specific association of integrin alphazbeta1 with CD151 provides a major link to phosphatidylinositol 4-kinase, and may regulate cell migration. Mol Biol Cell 1998 Oct; $9(10): 2751-65$.

(116) Taooka $Y$, Chen J, Yednock $T$, Sheppard D. The integrin alphagbeta1 mediates adhesion to activated endothelial cells and transendothelial neutrophil migration through interaction with vascular cell adhesion molecule-1. J Cell Biol $1999 \mathrm{Apr}$ $19 ; 145(2): 413-20$.

(117) Weber C. Novel mechanistic concepts for the control of leukocyte transmigration: specialization of integrins, chemokines, and junctional molecules. $J$ Mol Med 2003 $\operatorname{Jan} ; 81(1): 4-19$.

(118) Worthylake RA, Burridge K. Leukocyte transendothelial migration: orchestrating the underlying molecular machinery. Curr Opin Cell Biol 2001 Oct;13(5):569-77.

(119) Harris ES, McIntyre TM, Prescott SM, Zimmerman GA. The leukocyte integrins. J Biol Chem 2000 Aug 4;275(31):23409-12.

(120) Lefer AM, Lefer DJ. The role of nitric oxide and cell adhesion molecules on the microcirculation in ischaemia-reperfusion. Cardiovasc Res 1996 Oct;32(4):743-51.

(121) Imhof BA, Dunon D. Basic mechanism of leukocyte migration. Horm Metab Res 1997 Dec;29(12):614-21.

(1.22) Huang MT, Larbi KY, Scheiermann C, Woodfin A, Gerwin N, Haskard DO, et al. ICAM-2 mediates neutrophil transmigration in vivo; evidence for stimulus specificity and a role in PECAM-1-independent transmigration. Blood 2006 Jun $15 ; 107(12): 4721-7$.

(123) Huang AJ, Manning JE, Bandak TM, Ratau MC, Hanser KR, Silverstein SC. Endothelial cell cytosolic free calcium regulates neutrophil migration across monolayers of endothelial cells. J Cell Biol $1993 \operatorname{Mar}_{12}$ 20(6):1371-80.

(124) Su WH, Chen $H I$, Huang JP, Jen CJ. Endothelial $[\mathrm{Ca}(2+)](i)$ signaling during transmigration of polymorphonuclear leukocytes. Blood 2000 Dec 1;96(12):381622. 
(125) Gautam $N$, Olofsson AM, Herwald $H$, Iversen LF, Lundgren-Akerlund $E$, Hedqvist $P$, et al. Heparin-binding protein (HBP/CAP37): a missing link in neutrophil-evoked alteration of vascular permeability. Nat Med 2001 Oct;7(10):1123-7.

(126) Lorenzon $P$, Vecile $E_{1}$ Nardon $E_{1}$ Ferrero $E_{1}$ Harlan JM, Tedesco F, et al. Endothelial cell $E$ - and P-selectin and vascular cell adhesion molecule-1 function as signaling receptors. J Cell Biol 1998 Sep 7;142(5):1381-91.

(127) Campbell B, Chuhran CM, Lefer DJ, Lefer AM. Cardioprotective effects of abciximab (ReoPro) in an isolated perfused rat heart model of ischemia and reperfusion. Methods Find Exp Clin Pharmacol 1999 Oct;21(8):529-34.

(128) Cywes R, Packham MA, Tietze L, Sanabria JR, Harvey PR, Phillips MJ, et al. Role of platelets in hepatic allograft preservation injury in the rat. Hepatology 1993 Sep;18(3):635-47.

(129) Golino P, Maroko PR, Carew TE. Efficacy of platelet depletion in counteracting the detrimental effect of acute hypercholesterolemia on infarct size and the no-reflow phenomenon in rabbits undergoing coronary artery occlusion-reperfusion. Circulation $1987 \mathrm{Ju} \mid ; 76(1): 173^{-80}$.

(130) Koo DD, Welsh KI, Roake JA, Morris PJ, Fuggle SV. Ischemia/reperfusion injury in human kidney transplantation: an immunohistochemical analysis of changes after reperfusion. Am J Pathol 1998 Aug;153(2):557-66.

(131) Petnehazy T, Cooper D, Stokes KY, Russell J, Wood KC, Granger DN. Angiotensin II type 1 receptors and the intestinal microvascular dysfunction induced by ischemia and reperfusion. Am J Physiol Gastrointest Liver Physiol 2006 Jun;290(6):G1203G1210.

(132) Massberg S, Enders G, Leiderer R, Eisenmenger S, Vestweber D, Krombach F, et al. Platelet-endothelial cell interactions during ischemia/reperfusion: the role of $P$ selectin. Blood $1998 \mathrm{Jul}$ 15;92(2):507-15.

(133) Massberg S, Enders G, Matos FC, Tomic LI, Leiderer R, Eisenmenger $S$, et al. Fibrinogen deposition at the postischemic vessel wall promotes platelet adhesion during ischemia-reperfusion in vivo. Blood 1999 Dec 1;94(11):3829-38.

(134) Cooper D, Chitman KD, Williams MC, Granger DN. Time-dependent platelet-vessel wall interactions induced by intestinal ischemia-reperfusion. Am J Physiol Gastrointest Liver Physiol 2003 Jun;284(6):G1027-G1033.

(135) Cooper D, Russell J, Chitman KD, Williams MC, Wolf RE, Granger DN. Leukocyte dependence of platelet adhesion in postcapillary venules. Am J Physiol Heart Circ Physiol 2004 May; 286(5):H1895-H1900. 
(136) Larsen E, Celi A, Gilbert GE, Furie BC, Erban JK, Bonfanti R, et al. PADGEM protein: a receptor that mediates the interaction of activated platelets with neutrophils and monocytes. Cell 1989 Oct 20;59(2):305-12.

(137) Moore KL, Stults NL, Diaz S, Smith DF, Cummings RD, Varki A, et al. Identification of a specific glycoprotein ligand for P-selectin (CD62) on myeloid cells. J Cell Biol 1992 Jul; $118(2): 445 * 56$.

(138) Peisers MM, Hermens WT, Glatz JF. Fatty acid-binding proteins as plasma markers of tissue injury. Clin Chim Acta 2005 Feb;352(1-2):15-35.

(139) Besnard P, Niot I, Poirier H, Clement L, Bernard A. New insights into the fatty acidbinding protein (FABP) family in the smail intestine. Mol Cell Biochem 2002 Oct;239(1-2):139-47.

(140) Gollin G, Marks C, Marks WH. Intestinal fatty acid binding protein in serum and urine reflects early ischemic injury to the small bowel. Surgery 1993;113(5):545-51.

(141) Schaap FG, Binas B, Danneberg $H$, van d, V, Glatz JF. Impaired long-chain fatty acid utilization by cardiac myocytes isolated from mice lacking the heart-type fatty acid binding protein gene. Circ Res 1999 Aug 20;85(4):329-37.

(142) Glatz JF, van $d, V$. Cellular fatty acid-binding proteins: their function and physiological significance. Prog Lipid Res 1996 Sep;35(3):243-82.

(143) Bass NM, Barker ME, Manning JA, Jones AL, Ockner RK. Acinar heterogeneity of fatty acid binding protein expression in the livers of male, female and clofibratetreated rats. Hepatology 1989 Jan; $9(1): 12-21$.

(144) Ockner RK, Manning JA, Kane JP. Fatty acid binding protein. Isolation from rat liver, characterization, and immunochemical quantification. J Biol Chem $1982 \mathrm{Jul}$ 10;257(13):7872-8.

(145) Gordon JI, Alpers DH, Ockner RK, Strauss AW. The nucleotide sequence of rat liver fatty acid binding protein mRNA. J Biol Chem 1983 Mar 10;258(5):3356-63.

(146) Derikx JP, Poeze $M$, van Bijnen AA, Buurman WA, Heineman E. Evidence for intestinal and liver epithelial cell injury in the early phase of sepsis. Shock 2007 Nov; $28(5): 544-8$. 


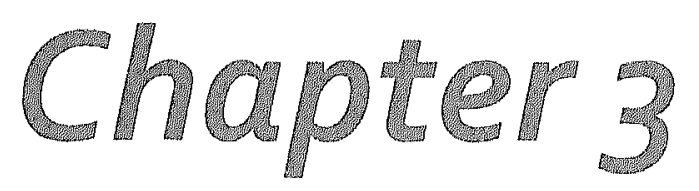

\section{Ischemia/reperfusion injury in rat mesenteric venules: red blood cell velocity and leukocyte rolling}

Roland J. Beuk, Mirjam G.A. oude Egbrink, Harrie A.J.M. Kurvers, Harm-Jan Bonke, Geert-Jan Tangelder and Erik Heineman 


\section{Abstract}

The authors determined the effects of $15(n=9)$ and $30(n=12)$ minutes of warm ischemia on the rat mesentery and compared the results with those of a sham-operated group ( $n=$ 10). Red blood cell velocity and number of rolling leukocytes were assessed before ischemia as well as $10,20,30,60,90$, and 120 minutes after the start of reperfusion. Leukocyte rolling is considered to be an early step of the inflammatory process. Leukocytes roll along the vessel wall at a velocity that is clearly lower than that of the other blood cells. The preischemic values of red blood cell velocity and number of rolling leukocytes in the 15-and 30-minute ischemia groups did not differ from those of the sham group. In the sham group, no significant changes in red blood cell velocity and number of rolling leukocytes were observed over time. Compared with the sham group, the red blood cell velocity of the 15 -minute ischemia group was significantly lower at 30,60,90, and 120 minutes after the start of reperfusion the number of rolling leukocytes did not differ significantly. For the 30-minute ischemia group, red blood cell velocity also was significantly lower at 20,30,60,90, and 120 minutes after the start of reperfusion, and the number of rolling leukocytes was higher at 10, 20, and 30 minutes after the start of reperfusion. The results of this study indicate that short periods of total warm ischemia of the rat small bowel and subsequent reperfusion result in a significantly impaired microcirculatory blood flow in the mesentery. However, a prolonged period of ischemia is required to increase leukocyte-vessel wall interactions. In the future, this model will enable us to study the effect of pharmacological interventions during an early stage of the inflammatory response to ischemia/reperfusion in the gut. 


\section{Ischemialreperfusion injury in rat mesenteric venules: red blood cell velocity and leukocyte rolling}

\section{Introduction}

Ischemia/reperfusion (I/R) injury of the gut plays a significant role in small bowel transplan- tation and ischemic enterocolitis, and may play a role in the development of necrotizing enterocolitis (NEC). $(1 ; 2)$ Recently we developed a rat model that enables us to study, in vivo, the effects of total warm ischemia and subsequent reperfusion on gut microcirculation.(3) In the present study we used intravital video microscopy to investigate the effects of varying periods of warm ischemia on red blood cell velocity (RBCV) and leukocyte rolling in mesenteric venules. The rolling of leukocytes along the venular endothelium is a prerequisite step for adhesion and diapedesis in the inflammatory response following I/R. $(4-6)$

We demonstrate that a prolonged period of warm ischemia induces in these venules a decrease in RBCV and an increase in leukocyte rolling.

\section{Materials and methods}

Animals and surgical procedure

All experiments were approved by the local ethical committee on the use of laboratory animals. Thirty-one male Lewis rats, (mean weight, $270 \mathrm{~g}$; range, 210 to $320 \mathrm{~g}$ ) were fasted for 24 hours. Anesthesia was induced by intraperitoneal injection of sodium pentobarbital ( $6.6 \mathrm{mg} / 100 \mathrm{~g}$ body weight). A steady-state anesthetic depth was achieved by continuous infusion of sodium pentobarbital $(2.6 \mathrm{mg} / 100 \mathrm{~g}$ body weight $/ \mathrm{h})$ through a catheter ( $P E$ 10) in the right femoral vein, starting 1 hour after the bolus injection. Throughout the experiments, body temperature was maintained at $37^{\circ} \mathrm{C}$ using an infrared heating lamp controlled by a thermoanalyzer system connected to a rectal probe.

A midline laparotomy was performed, and the superior mesenteric artery (SMA) was identified, dissected free, and marked by a vessel loop. Imodium ( $0.5 \mathrm{~mL}$ ) was administered directly into the duodenum. The inferior mesenteric artery was ligated (Ethicon 3-o sutures). Subsequently, a right flank incision was made.

The anesthetized rats were transported to the intravital microscope. A segment of the distal ileum was exteriorized through the right flank incision. The mesentery was carefully spread over a siliconized glass plate mounted in the electrically heated microscope table $\left(37^{\circ} \mathrm{C}\right)$. An additional dose of imodium was injected locally $(0.5 \mathrm{~mL})$ into the ileum. The mesentery was superfused continuously with buffered Tyrode's solution $\left(37^{\circ} \mathrm{C} ; \mathrm{pH}, 7.35\right.$ to 7.40 ) that was bubbled with a mixture of $95 \% \mathrm{~N}_{2}$ and $5 \% \mathrm{CO}_{2}$. The ileum was kept moist 
with overlying wet gauze. During the entire procedure, utmost precaution was taken not to manipulate the abdominal contents any more than absolutely necessary. Preparations were allowed to stabilize for 30 minutes.

\section{Intravital video microscopy}

Observations were made using a Leitz intravital microscope adapted to telescopic imaging, (7) equipped with a Leitz Ploemopak 2.2 (tube factor $\times 1.6$ ) and a Leitz $\times 25$ saltwater immersion objective (numerical aperture, 0.6 ). Under transillumination with a $60-\mathrm{W}$ tungsten lamp, images were projected on a TV camera (Ultricon 4532; Bosch, Darmstadt, Germany), displayed on a monitor screen, and recorded for off-line analysis on videotape (Betamax SL-C9; Sony, Tokyo, Japan). The final optical magnification at the front plane of the TV camera was $\times 51.6$.

Mean RBCV was measured on-line at the time points indicated below, using a threestage prism grating system with the slit covering the entire vessel width.(8)

\section{Experimental protocol}

One venule (of 21 to $53 \mu \mathrm{m}$ in diameter) was selected per mesentery. In all experiments the midplane of this venule (ie, its largest diameter) was kept in focus. Contiguous to the stabilization period, the venule was recorded on video, and RBCV was measured during at least 5 minutes for control purposes.

In one group of rats (group $I, n=9$ ), 15 minutes of total, warm ischemia was induced by occlusion of the SMA with a nontraumatic vessel clamp; in the second group (group II, $n=12$ ), this ischemic period was 30 minutes. Recordings were made and RBCV was measured at $10,20,30,60,90$, and 120 minutes after the start of reperfusion.

A sham-operated control group (sham group, $\mathrm{n}=10$ ) was included in the study. After a period of 15 minutes (sham ischemia), data collection was identical to that of the ischemia groups.

\section{Data and statistical analysis}

Vessel diameters were measured off-line with a home-built image-shearing device.(9)

The number of rolling leukocytes ( $\mathrm{nRL}$ ) per minute was determined from video during two separate periods of 120 seconds (one immediately before and the other after the RBCV had been determined). Leukocytes roll along the vessel wall at a velocity that is clearly lower than that of the other blood cells. Analysis was performed with the use of a computer program, which allowed quick counting and data acquisition. The data obtained from both counting periods were averaged.

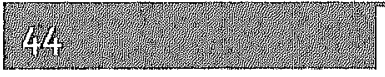


Because of their asymmetrical distribution, data are presented as medians with their interquartile ranges (ie, the spread from the $25^{\text {th }}$ to $75^{\text {th }}$ percentiles).

For the sham group, statistical analysis was performed using the Wilcoxon signed rank test. The Mann-Whitney $U$ test was used to compare data from the ischemia groups with those of the sham group at each time point. $P$ values of less than 0.05 were considered statistically significant.

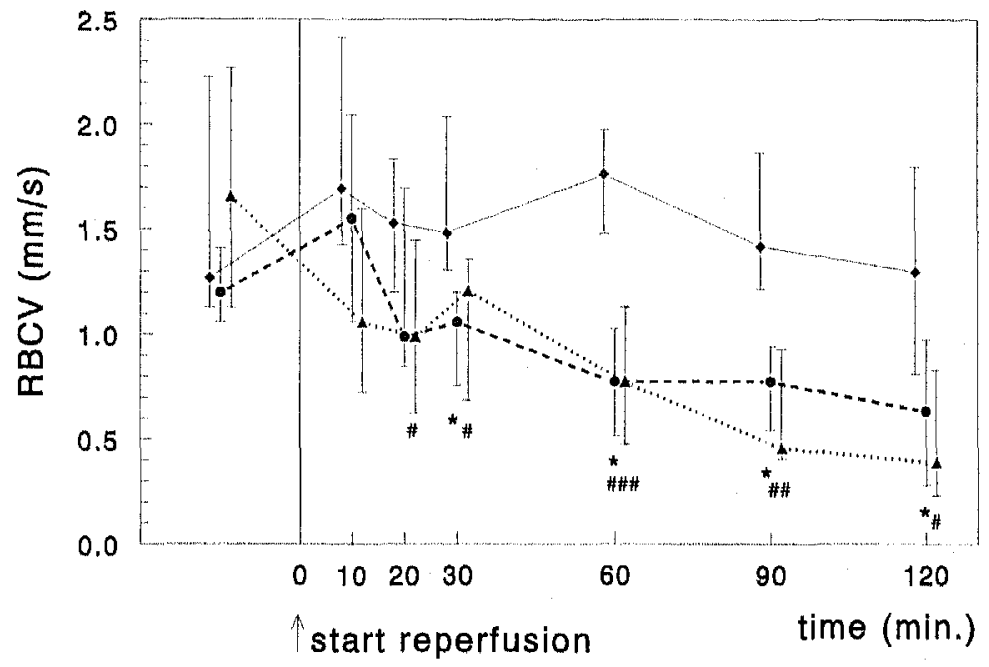

Figure j.: Median venular red blood cell velocity (RBCV) in the three groups: sham (solid line), 15 -minute ischemia (broken line), and 30-minute ischemia (dotted line). Bars denote interquartile ranges ( $25^{\text {th }}$ to $75^{\text {th }}$ percentiles). Times shown along the $X$ axis indicate the number of minutes after the start of reperfusion (vertical line). The data on the left side of the vertical line represent the values before total warm ischemia (or sham ischemia).

* $P<0.05$ for 15-minute ischemia group versus sham group. \# $P<0.05$, \# $P<0.01$, \#\#\# $P<0.001$ for 30 -minute ischemia group versus sham group. In the sham group no significant changes were observed over time.

\section{Results}

In our model, we obtained complete ischemia of the mesentery, as verified through the microscope by the observation of cessation of flow in all vessels. The median venular diameters were $33 \mu \mathrm{m}$ (range, 21 to 50 ) in the sham group, $30 \mu \mathrm{m}$ (range, 22 to 53 ) in the 15-minute ischemia group, and $35 \mu \mathrm{m}$ (range, 23 to 51) in the 30-minute ischemia group. 
In the sham group, the venular diameter remained unchanged throughout the experiment. In both the 15- and 30-minute ischemia groups, the venular diameter was not significantly affected at any time point (compared with the sham group).

\section{Mean red blood cell velocity ( $R B C V$ )}

The RBCV measurements obtained are shown in Fig 1. The preischemic values for the 15and 30 -minute groups $(1.2 \mathrm{~mm} \cdot \mathrm{s}-1$ and $1.7 \mathrm{~mm} \cdot \mathrm{s}-1$, respectively) did not differ significantly from those of the sham group (1.3 mm - s-1). Within the sham group, no significant change in RBCV was observed during the reperfusion phase (compared with the preischemic value) median values ranged from 1.3 to $1.8 \mathrm{~mm} \bullet 5-1$. Compared with the sham group, the RBCV of the 15-minute ischemia group was significantly lower from 30 minutes onward after the start of reperfusion $(P<0.05)$. In the 30-minute ischemia group, RBCV was lower at $20,30,60,90$, and 120 minutes after the start of reperfusion $(P<0.05)$.

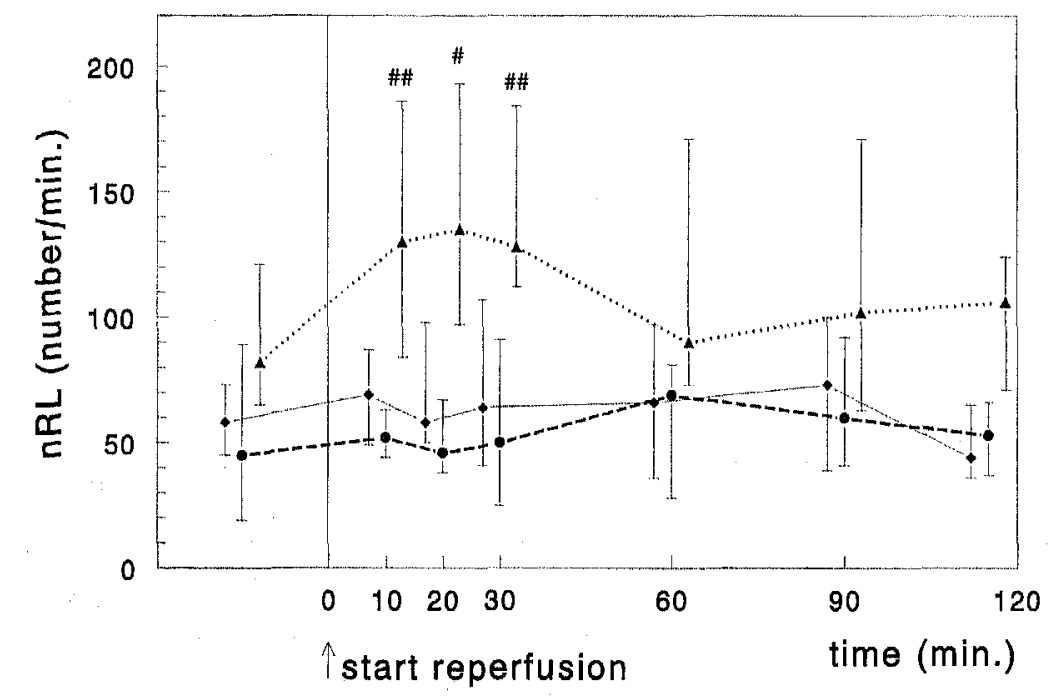

Figure 2: Median number of rolling leukocytes (nRL) in the three groups: sham (solid line), 15-minute ischemia (broken line), and 30-minute ischemia (dotted line). Bars denote interquartile ranges ( 25 th to 75 th percentiles). Times shown along the $X$ axis indicate the number of minutes after the start of reperfusion (vertical line). The data on the left side of the vertical line represent the values before total warm ischemia (or sham ischemia).

\# $P<0.05$, \# $P<0.01$, for 30-minute ischemia group versus sham group. There were no significant differences between the sham and 15 -minute ischemia groups. In the sham group, no significant changes were observed over time.

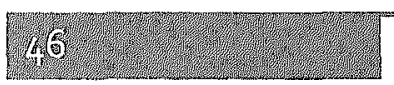




\section{Leukocyte rolling}

The data on leukocyte rolling are shown in Fig 2. The control level of $n R L$ did not differ significantly between the sham group ( 58 minutes-1) and the 15- or 30-minute ischemia group ( 45 and 82 minutes-1, respectively). In the sham group, no significant changes were observed over time. The median values of $\mathrm{nRL}$ for the sham group did not differ from those of the 15 -minute ischemia group. However, the $n R L$ of the 30-minute group, was significantly higher than that of the sham group at 10,20 , and 30 minutes $(P<0.05)$ after the start of reperfusion ( 130,135 , and 128 minutes-1, respectively).

\section{Discussion}

The results of the present study indicate that $I / R$ injury of the rat small bowel results in a significantly decreased microcirculatory red blood cell velocity in the mesentery. I/R injury induces an increase in the $\mathrm{NRL}$ of the 30 -minute but not the 15 -minute ischemia group. Our finding that in the 15-minute ischemia group the microcirculatory blood flow was impaired (compared with controls) but the $\mathrm{nRL}$ did not differ argues against a causal relation between these two phenomena. A decrease in microcirculatory blood flow after ischemia, although not a significant one, has been reported previously, but this occurred after a longer period (60 minutes) of partial (80\%) warm ischemia.(10) Therefore, a short period of total warm ischemia of the small bowel may realize more injury than an equally short period of partial warm ischemia.

In neonates, children, and adults, phenomena caused by $I / R$ of the intestine play an important role in a number of diseases such as necrotizing enterocolitis and ischemic enterocolitis after aortic surgery, as well as in solid organ transplantation (ie, the small bowel).

How are the data of this study relevant to preservation of the small bowel? Extensive damage to the intestine usually occurs during the reperfusion phase of the $I / R$ cycle. Tissue-bound xanthine oxidase generates oxygen free radicals during enzymatic breakdown of hypoxanthine, which had accumulated during the antecedent ischemia.(11) In addition, free radicals are derived from activated leukocytes,(12) catecholamine oxidation,(13) endothelial cells,(14) and prostaglandins.(15) A host of responses is initiated, including the formation of inflammatory mediators such as platelet activating factor $(\mathrm{PAF})_{1}(16)$ leukotriene $\left.\mathrm{B}_{4}(\mathrm{LTB})_{4}\right)_{1}(17)$ and endothelin-1 (ET-1),(18) and also including the inactivation of nitric oxide,(19) which may result in vasoconstriction, platelet aggregation, and leukocyte-vessel wall interactions.(20) The subsequent migration of leukocytes into the tissue and the release of more free radicals result in further tissue injury. This I/R cycle may be interrupted by the addition of enzyme inhibitors or receptor 
antagonists to the preservation fluid. The effect of such substances on leukocyte-vessel wall interactions and microcirculatory blood flow after I/R can be studied using our model.

How are the present data relevant to the pathogenesis of NEC? In this disorder, I/R is believed to play a primary and/or secondary role.(1) As a primary factor, ischemia of the small bowel can result from severe hypoxia, asphyxia, and cardiac arrest, initiating the above-described I/R cycle. I/R could play a secondary role, for example in the case of mucosal inflammation, leading to local leukocyte activation and/or production and release of PAF, followed by the formation of free radicals and probably vasoconstriction, again initiating the l/R cycle described above.(1)

The data presented herein have been obtained from adult rats, and, therefore, might not be directly applicable to the situation in neonates or children. However, the newborn gut appears to be even more susceptible to $I / R$, probably because of the unique resting circulatory conditions characteristic of newborn intestine.(2I) Although the tissue activity of xanthine oxidase has been reported to be low in the intestine of the newborn, and the resident leukocyte population is relatively deficient,(22) PAF plays a more important role in the newborn intestine.(23) Normally, PAF has a very short half-life in vivo because of the rapid degradation catalyzed by acetylhydrolase.(23) However, this PAF-specific enzyme is suppressed at birth,(24) probably resulting in much higher plasma PAF levels after I/R. It is our aim to develop, in the near future, an in vivo model to assess I/R injury of the small bowel in premature animals.

In summary, the present study indicates that reperfusion of the rat small bowel after a short period of total warm ischemia results in significantly impaired mesenteric microcirculatory blood flow. On the other hand, the level of leukocyte rolling requires a pro- longed period of ischemia to increase significantly during reperfusion. Our model provides adequate parameters to assess $1 / R$ injury of the small bowel and may prove valuable in the investigation of pharmacological interventions that reduce $I / R$ injury.

\section{Acknowledgement}

The authors thank Sabrina van Velzen for her technical assistance. 


\section{References}

(1) Nowicki PT, Nankervis CA. The role of the circulation in the pathogenesis of necrotizing enterocolitis. Clin Perinatol 1994;21(2):219"34.

(2) Kliegman RM, Walker WA, Yolken RH. Necrotizing enterocolitis: research agenda for a disease of unknown etiology and pathogenesis. Pediatr Res 1993;34(6):701-8.

(3) Bonke $H$, Kurvers $H A$, Oude Egbrink MG, Weijmer van Velzen $S$, Tangelder GJ,

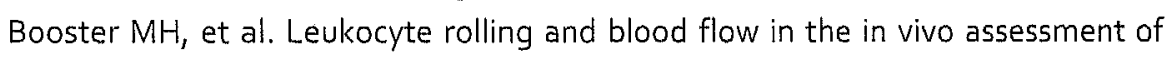
ischemia-reperfusion damage in rat mesenteric venules. Transplant Proc 1994;26:1478-80.

(4) von Andrian UH, Arfors KE. Neutrophil-endothelial cell interactions in vivo: a chain of events characterized by distinct molecular mechanisms. Agents Actions Suppl 1993;41:153-64.

(5) Adams DH, Shaw S. Leucocyte-endothelial interactions and regulation of leucocyte migration [see comments]. Lancet 1994;343(8901):831-6.

(6) Springer TA. Traffic signals for lymphocyte recirculation and leukocyte emigration: the multistep paradigm. Cell 1994;76(2):301-14.

(7) Slaaf DW, Alewijnse $R$, Wayland $H$. Use of telescopic imaging in intravital microscopy: a simple solution for conventional microscopes. Int J Microcirc Clin $\operatorname{Exp} 1982 ; 1(2): 121-34$.

(8) Slaaf DW, Rood JP, Tangelder GJ, Jeurens TJ, Alewijnse R, Reneman RS, et al. A bidirectional optical ( $B D O$ ) three-stage prism grating system for on-line measurement of red blood cells velocity in microvessels. Microvasc Res 1981;22(1):110-22.

(9) Intaglietta $M$, Tompkins WR. Microvascular measurements by video image shearing and splitting. Microvasc Res 1973;5(3):309-12.

(10) Granger DN, Benoit JN, Suzuki M, Grisham MB. Leukocyte adherence to venular endothelium during ischemia- reperfusion. Am J Physiol 1989;257(5 Pt 1):G683-8.

(11) McCord JM. Oxygen-derived free radicals in postischemic tissue injury. $N$ Engl J Med 1985;312(3):159-63.

(12) Granger DN. Role of xanthine oxidase and granulocytes in ischemia- reperfusion injury. Am J Physiol 1988;255(6 Pt 2):H1269-75.

(13) Singal PK, Kapur N, Dhillon KS, Beamish RE, Dhalla NS. Role of free radicals in catecholamine-induced cardiomyopathy. Can J Physiol Pharmacol 1982;60(11):1390-7.

(14) Beckman JS, Beckman TW, Chen J, Marshall PA, Freeman BA. Apparent hydroxyl radical production by peroxynitrite: implications for endothelial injury from nitric oxide and superoxide. Proc Natl Acad Sci U S A 1990;87(4):1620-4. 
(15) Kukreja RC, Kontos HA, Hess ML, Ellis EF. PGH synthase and lipoxygenase generate superoxide in the presence of NADH or NADPH. Circ Res 1986;59(6):6129.

(16) Kubes P, Ibbotson G, Russell J, Wallace JL, Granger DN. Role of platelet-activating factor in ischemia/reperfusion- induced leukocyte adherence. Am 」 Physiol 1990;259:G300-5.

(17) Palmblad J, Malmsten CL, Uden AM, Radmark O, Engstedt L, Samuelsson B. Leukotriene $\mathrm{B}_{4}$ is a potent and stereospecific stimulator of neutrophil chemotaxis and adherence. Blood 1981;58(3):658-61.

(18) Kourembanas S, Marsden PA, McQuillan LP, Faller DV. Hypoxia induces endothelin gene expression and secretion in cultured human endothelium. I Clin Invest 1991;88(3):1054-7.

(19) Lefer AM, Tsao PS, Lefer DJ, Ma XL. Role of endothelial dysfunction in the pathogenesis of reperfusion injury after myocardial ischemia. FASEB I 1991;5(7):2029-34.

(20) Grace PA. Ischaemia-reperfusion injury. Br J Surg 1994;81(5):637-47.

(21) Nowicki PT, Miller CE, Edwards RC. Effects of hypoxia and ischemia on autoregulation in postnatal intestine. Am J Physiol 1991;261(1 Pt 1):G152-7.

(22) Crissinger KD, Grisham MB, Granger DN. Developmental biology of oxidantproducing enzymes and antioxidants in the piglet intestine. Pediatr Res $1989 ; 25(6): 612-6$.

(23) Blank ML, Lee T, Fitzgerald V, Snyder F. A specific acetylhydrolase for 1-alkyl-2acetyl-sn-glycero-3- phosphocholine (a hypotensive and platelet-activating lipid). J Biol Chem 1981;256(1):175-8.

(24) Caplan $M$, Hsueh W, Kelly $A$, Donovan M. Serum PAF acetylhydrolase increases during neonatal maturation. Prostaglandins 1990;39(6):705-14. 


\section{Chapter 4}

\section{Effects of different durations of total warm ischemia of the} gut on rat mesenteric microcirculation

Roland J. Beuk, Erik Heineman, Geert-Jan Tangelder, Harrie A.J.M. Kurvers, Harm-Jan Bonke, and Mirjam G.A. oude Egbrink 


\section{Abstract}

Background: Gut injury due to ischemia and reperfusion (I/R) plays a pivotal role in many clinical conditions, such as small bowel transplantation, heart or aortic surgery in adults, and necrotizing enterocolitis in neonates. The influence of ischermic events on microcirculatory mechanisms is not well understood. Therefore, we studied, in vivo, local perfusion and leukocyte-vessel wall interactions before and after different periods of total warm ischemia of the whole gut and subsequent reperfusion in mesenteric microvessels.

Materials and Methods: Groups of pentobarbital-anaesthetized Lewis rats were subjected to $15(n=9), 30(n=12)$, or $60 \min (n=5)$ of total warm gut ischemia and $2 h$ reperfusion. As control a sham group $(n=10)$ was included. After ligating the inferior mesenteric artery, total warm ischemia was induced by clamping the superior mesenteric artery. Before and at different time periods after start of reperfusion intravital video microscopic measurements were performed.

Results: Rats subjected to $60 \mathrm{~min}$ ischemia died during the early reperfusion phase. Fifteen, 30 , and 60 min ischemia induced in venules a significant decrease in blood flow, while diameter changes were not observed. This flow decrease was severe in the 15" and 30 -min ischemia groups, dropping to 40 and $25 \%$ of control, respectively. Following 60 min ischemia blood flow did not exceed $10 \%$ of control. The total number of interacting leukocytes, a parameter which includes both leukocyte rolling and adhesion in venules, increased up to 5 or 10 times its control value following 15 or $30 \mathrm{~min}$ ischemia, respectively. Leukocyte-vessel wall interactions could not be studied in the 60-min ischemia group, due to the low blood flow.

Conclusions: Even short periods of total warm ischemia of the whole gut induce severe attenuation of venular blood flow with an increase in leukocyte-vessel wall interactions. These changes increase with prolongation of the ischemic period. A 60-min period of total warm ischemia is fatal during the early reperfusion phase. 


\section{Effects of different durations of total warm ischemia of the gut on rat mesenteric microcirculation}

\section{Introduction}

Gut injury as a result of ischemia and subsequent reperfusion (l/R) plays a pivotal role in a variety of clinical conditions, such as small bowel transplantation(1-3), heart or aortic surgery in adults $\left(4^{-6}\right)$, and necrotizing enterocolitis in neonates $(7 ; 8)$. Although the damaging mechanisms remain unclear, $I / R$ of the small bowel has been reported to result in increased microvascular permeability( 9 ) and intestinal mucosal lesions(10).

It has been suggested that activated polymorphonuclear leukocytes (PMNs) are important contributors to l/R-induced tissue injury, among others by the release of reactive oxygen metabolites and by the secretion of certain proteases(11-13). The importance of the role of PMNs is corroborated by the finding that treating animals with antineutrophil serum(14) or monoclonal antibodies interfering with PMN adhesion(9) significantly attenuated the extent of tissue injury in the reperfused gut. Furthermore, neutrophil depletion attenuates intestinal reperfusion injury in humans(15). Reactive oxygen species may also amplify expression of adhesion molecules(13). An increase in vascular resistance, as a result of leukocyte adhesion, may further exaggerate tissue damage(16). Before leukocytes are able to adhere to the venular vessel wall and, subsequently, migrate into the postischemic tissue, they must marginate from the central blood stream and roll along the vascular endothelium(17-20). Therefore, rolling of leukocytes along the venular wall seems to be a prerequisite step in the development of I/R injury. Using intravital video microscopy it is possible to study and quantify this multiple-step process in vivo(21-24).

Although several intravital microscopic studies on the consequences of $I / R$ of the gut have been published recently, to our best knowledge none of these studies were performed with total warm ischemia of the whole small bowel, whereas this situation has great clinical relevance with respect to, e.g., small bowel transplantation and thoracic aorta surgery. In most studies partial ischemia is induced by a reduction of blood flow to about $20 \%$ of baseline (25-28). According to Megison and colleagues, a methodological disadvantage of induction of partial ischemia is that mesenteric collateral flow can be a significant variable leading to inconsistent results(29). In another study total ischemia of only a small region of the small bowel was induced(30). In clinical situations such as heart or aortic surgery and necrotizing enterocolitis it is mostly a matter of ischemia of the whole gut. In addition, the influence of different duration of ischemic periods on gut microcirculation has not yet been elucidated. 
Therefore, we developed a rat model to study in the mesenteric microcirculation the effects of different periods of total warm ischemia of the whole gut with subsequent reperfusion. A study by Kurtel and colleagues indicates that $I / R$ of the small bowel results in similar increases in PMN accumulation in both mucosa and mesentery, as determined by myeloperoxidase activity(31). With the use of intravital video microscopy, we studied the effects of 15,30 , or 60 min of total warm ischemia and $2 \mathrm{~h}$ of reperfusion on blood flow and leukocyte-vessel wall interactions in mesenteric venules.

\section{Moterials and methods}

\section{Animal preparation}

All experiments were approved by the local ethical committee on the use of laboratory animals. Thirty-six male Lewis rats, with a mean weight of $274 \mathrm{~g}$ (range: 210-320 g), were used. They were fasted for $24 \mathrm{~h}$ before the experiments started. Anesthesia was induced by an intraperitoneal injection of sodium pentobarbital $(6.6 \mathrm{mg} / 100 \mathrm{~g}$ body wt). A steadystate anesthetic depth was achieved by continuous infusion of sodium pentobarbital ( 2.6 $\mathrm{mg} / 100 \mathrm{~g}$ body $\mathrm{wt} / \mathrm{h}$ ) through a catheter (PE 10) in the right femoral vein, starting $1 \mathrm{~h}$ after the bolus injection. Sodium pentobarbital was used, because it does not influence leukocyte-vessel wall interactions in rat venules(32). To measure arterial blood pressure (Uniflow external pressure transducer, Baxter, Santa Ana, $C A$ ) and heart rate, a second catheter ( $P E$ 10) was placed in the right femoral artery. This catheter was continuously perfused with physiological saline $(1 \mathrm{ml} / \mathrm{h})$ to prevent blockage of the catheter tip. Throughout the experiments body temperature was kept at $37^{\circ} \mathrm{C}$ using an infrared heating lamp controlled by a thermoanalyzer system connected to a rectal probe.

A midline laparotomy was performed, and the superior mesenteric artery (SMA) was identified, dissected free, and marked by a vessel loop. The inferior mesenteric artery was ligated (Ethicon 3-0). Imodium ( $0.5 \mathrm{ml}, 0.2 \mathrm{mg} / \mathrm{ml}$; Janssen Pharmaceutica B.V., Tilburg, The Netherlands) was administered directly into the duodenum. Subsequently, a right flank incision was made and a segment of the distal ileum was exteriorized. An additional dose of imodium was injected locally $(0.5 \mathrm{ml})$ into the ileum. The mesentery was carefully spread over a siliconized glass plate mounted in the electrically heated table $\left(37^{\circ} \mathrm{C}\right)$ of an intravital microscope and continuously superfused with a buffered Tyrode's solution $\left(37^{\circ} \mathrm{C}, \mathrm{pH} 7.35\right.$ to 7.40 ) that was bubbled with a mixture of $\mathrm{N}_{2}(95 \%)$ and $\mathrm{CO}_{2}(5 \%)$. The ileum was kept moist with overlying wet gauze. During the entire procedure, the utmost precaution was taken not to manipulate the abdominal contents, and in particular the mesentery, any more than strictly necessary. Following surgery, preparations were allowed to stabilize for $30 \mathrm{~min}$.

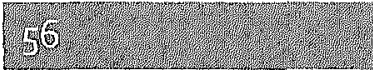


Intravital video microscopy and hemodynamic measurements

Mesenteric microvessels were observed using a Leitz intravital microscope adapted to telescopic imaging(33), equipped with a Leitz x25 saltwater immersion objective (numerical aperture 0.6 ). Under transillumination with a $60-\mathrm{W}$ tungsten lamp, images were projected on a TV camera (Ultricon 4532, Bosch, Darmstadt, Germany), displayed on a monitor screen, and recorded for off-line analysis on videotape (Betamax SL-C9, Sony, Tokyo, Japan). The final optical magnification at the front plane of the TV camera was $\times 51.6$.

In all experiments the midplane of the vessel was kept in focus. Vessel diameters were measured off-line, using a home-built image-shearing device(34). Online, mean red blood cell velocity (RBCV) was measured using a three-stage prism grating system with the slit covering the whole vessel width(35). Mean arterial pressure (MAP) and heart rate (HR) were determined continuously and recorded on a computer hard disk using a data acquisition system.

\section{Experimental protocol (Fig. 1)}

In each experiment, one venule was selected with a diameter between 21 and $53 \mu \mathrm{m}$. Contiguous to the acclimatization period, the image of the selected venule was recorded on video and RBCV was measured (control).

In one group of rats $(n=9) 15$ min of total warm ischemia was induced by occlusion of the SMA with a nontraumatic vessel clamp. In the second group $(n=12)$ this ischemic period lasted $30 \mathrm{~min}$. In a third group $(n=5) 60 \mathrm{~min}$ of total warm ischemia was induced. A sham-operated control group $(n=10)$ was also included; after a period of $15 \mathrm{~min}(\mathrm{sham})$, data collection was identical to the ischemia groups.

Video recordings were made, lasting 5 min each, and RBCV was measured during at least $30 \mathrm{~s}$, at 10, 20, 30, 60, 90, and 120 min after start of reperfusion (5ee Fig. 1). From each video recording of $5 \mathrm{~min}$ data on leukocyte behavior and vessel diameter were gathered before and after RBCV was measured; these data were averaged. At the end of the last observation period, the animals were sacrificed using an overdose of sodium pentobarbital. Through the midline incision, the small bowel and the SMA near the clamp site were inspected macroscopically. Subsequently, the SMA was taken out and immediately fixed in $10 \%$ formaldehyde-saline solution. To study the clamp site microscopically, the fixed SMA was embedded in paraffin, sectioned, and stained with hematoxylin and eosin. 


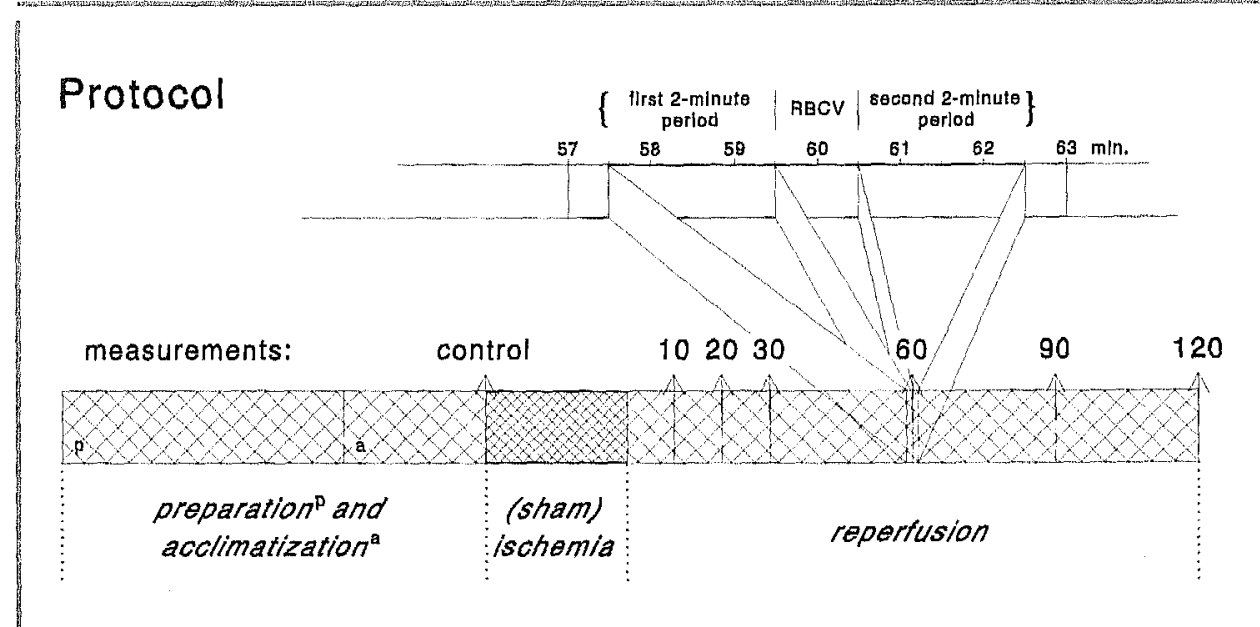

Figure : Experimental protocol: Following preparation of the mesentery and acclimatization ischemia was induced or sham was performed. When in the former the vessel clamp was relieved, the reperfusion phase started. Measurements were performed in all groups before ischemia or sham (control) and 10, 20,30,60, 90, and $120 \mathrm{~min}$ after the end of ischemia or sham period. At each time point a 5 -min video recording was made. During the third minute RBCV was measured online. The data on leukocyte behavior and vessel diameter obtained during the 2-min periods before and after the RBCV measurement were averaged.

\section{Experimental parameters}

All experiments were analyzed off-line from video tape. Leukocytes are considered to be rolling if they can be seen moving along the venular wall by eye. Rolling leukocytes move at least an order of magnitude slower than free-flowing leukocytes. Because the latter have the same velocity as the surrounding red blood cells, they cannot be detected in this way. The degree of leukocyte rolling was quantified by counting the number of rolling leukocytes (nRL) passing an imaginary line perpendicular to the venular axis per minute. The velocity of the rolling leukocytes (VRL) was determined by measuring the time needed for to randomly chosen cells to travel a certain distance on the video screen. Leukocytes are considered to be adherent (sticking) when they remain stationary for $\geq 30$ s. The number of adherent leukocytes ( $\mathrm{nAL}$ ) was determined in a 100- $\mu \mathrm{m}$ segment of the venule. As an overall parameter of leukocyte-vessel wall interactions the total number of leukocytes interacting with the venular wall (tnIL) at a particular moment was determined per $100-\mu \mathrm{m}$ vessel segment. This parameter includes not only the number of adherent and rolling leukocytes, but also the velocity of the latter. To determine tnll, a frozen video frame was employed and the number of visible leukocytes within a $100-\mu \mathrm{m}$ vessel 
segment was counted. At each time point this count was performed four times on randomly chosen video frames; the data were averaged.

Reduced velocity $(\bar{U})$, which is proportional to wall shear rate, and blood flow $(Q)$ were calculated using the RBCV and diameter (D) data, according to the equations

$$
\bar{U}=\frac{\mathrm{RBCV}}{D} \text { and } Q=\pi \cdot\left(\frac{1}{2} D\right)^{2} \cdot \mathrm{RBCV} \text {. }
$$

\section{Statistics}

Because of their asymmetrical distribution, data are presented as medians with their interquartile ranges (i.e., the spread from 25 th to 75 th percentile). To enable comparisons between groups, most data were normalized to their preischemic control values. Because in 12 of 31 venules there were no adherent leukocytes present during the control period, nAL must be presented in absolute numbers to avoid a division by zero.

Nonparametric statistical analysis was performed within the sham group using the Friedman two-way ANOVA. The Mann-Whitney $U$ test was used to compare data from the ischemia groups with those of the sham group at each time point. We considered $P<$ 0.05 to be statistically significant.

\section{Results}

Simultaneous occlusion of both the superior and inferior mesenteric artery indeed resulted in complete ischemia of the mesentery and the bowel in all rats of the ischemic groups, as verified through the microscope by flow cessation in all observed vessels of the mesentery and the whole small bowel.

Histologic examination of the superior mesenteric artery at the clamp site did not show any obstruction (i.e., thrombus formation) capable of reducing blood flow to the small bowel during the reperfusion phase.

\section{Survival}

In the sham, 15-min, and $30-\mathrm{min}$ ischemia groups, $100 \%$ survival was achieved throughout the 2 -h h reperfusion period. However, all rats that were subjected to $60 \mathrm{~min}$ ischemia died during the early reperfusion phase, between 30 and $90 \mathrm{~min}$ after start of reperfusion. Macroscopic analysis of the small bowel of these rats showed several necrotic (black) spots, whereas in the other groups no such abnormality was observed.

\section{Systemic hemodynamics}

During control measurements, mean HR was $360 \mathrm{bpm}$ and MAP $95 \mathrm{~mm} \mathrm{Hg}$ (average values, all groups pooled); no initial differences existed in HR or MAP between the groups. 


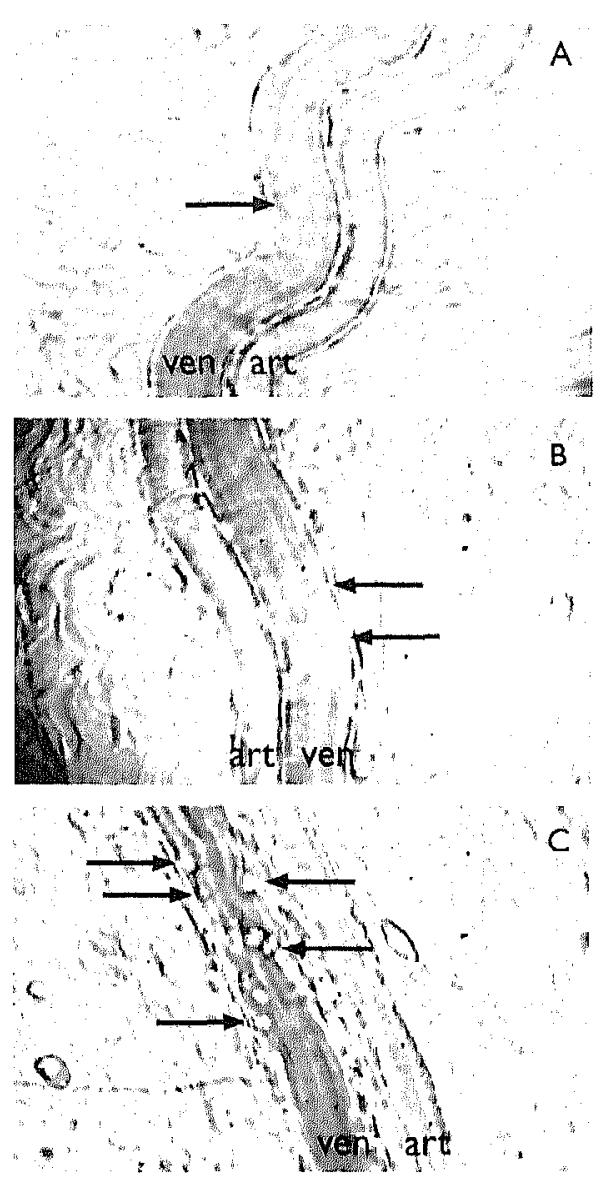

Figure $2:$ Frozen video frames of rat mesenteric arterioles (art) and venules (ven) at $120 \mathrm{~min}$ following start of reperfusion in the sham (A), 15- $\mathrm{min}$ ischemia (B), and 30 min ischemia groups $(C)$ in the $60-\mathrm{min}$ ischemia group all rats had died at this time point. Some leukocytes interacting with venular endothelium are indicated by arrows. Compared with sham, a period of total warm ischemia and $120 \mathrm{~min}$ reperfusion increased the number of leukocytes interacting with the vessel wall, while the flow decreased (as illustrated by the more sluggish flow pattern). These changes increase with increasing length of the ischemic period. $C$ also illustrates a regional decrease in arteriolar diameter as a result of vasomotion (rhythmic changes in diameter) in the 30-min ischemia group. Two of four observed arterioles subjected to $30 \mathrm{~min}$ ischemia showed vasomotion during reperfusion, whereas in the sham and 15 -min ischemia groups no vasomotion was observed. 
Throughout the experiments HR remained constant in all groups, except for the 60-min ischemia group. Following $1 \mathrm{~h}$ ischemia HR increased significantly to $110 \%$ of control during the first $30 \mathrm{~min}$ of reperfusion $(P<0.01)$ and to $117 \%$ thereafter $(P<0.05)$. Table 1 shows the normalized MAP during the experiments in the four different groups. Absolute MAP control values and their interquartile ranges in the sham, 15-, 30-, and 60-min ischemia groups were 107 (94-125), 92 (79-96), 87 (80-103), and $72(68-96) \mathrm{mm} \mathrm{Hg}$, respectively. During (sham) ischemia MAP remained at the same level in all four groups. MAP was not affected in the sham group, but dropped transiently to $50-60 \%$ of control at I min of reperfusion in the $15 \%, 30-$, and $60-$ min ischemia groups. It returned to about $90 \%$ of control after $10 \mathrm{~min}$ of reperfusion in both the 15- and 30-min ischemia groups. Following this recovery MAP slowly dropped in the 30-min ischemia group to about $66 \%$ of control at $120 \mathrm{~min}(P<0.05)$. In contrast, in the 60-min ischemia group MAP did not recover from the initial drop at $1 \mathrm{~min}$ reperfusion and dropped even further until these rats died.

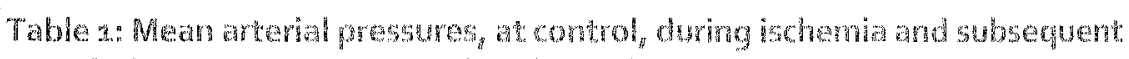
reperfusion (mediar values and interquantes; normalized to controb)

\begin{tabular}{|c|c|c|c|c|c|c|c|c|c|c|}
\hline Group & Control & $\begin{array}{c}\text { Start } \\
\text { ischemia }\end{array}$ & $\begin{array}{l}\text { End } \\
\text { ischemia }\end{array}$ & $1 \mathrm{~min}$ & $10 \mathrm{~min}$ & $20 \mathrm{~min}$ & $30 \mathrm{~min}$ & $60 \mathrm{~min}$ & $90 \mathrm{~min}$ & $2.20 \mathrm{~min}$ \\
\hline Sham & 1 & $\begin{array}{c}1.04 \\
(0.93- \\
1.06)\end{array}$ & $\begin{array}{c}1.02 \\
(0.99-1.06)\end{array}$ & $\begin{array}{c}1.00 \\
(0.99- \\
1.05)\end{array}$ & $\begin{array}{c}1.01 \\
(0.98 \\
1.09)\end{array}$ & $\begin{array}{l}1.00 \\
(0.90 \\
1.02)\end{array}$ & $\begin{array}{c}0.94 \\
(0.89 \% \\
\left.0.9^{6}\right)\end{array}$ & $\begin{array}{c}0.92 \\
(0.86- \\
0.98)\end{array}$ & $\begin{array}{c}0.91 \\
(0.71- \\
1.04)\end{array}$ & $\begin{array}{c}0.95 \\
(0.80- \\
1.04)\end{array}$ \\
\hline $\begin{array}{l}25-\mathrm{min} \\
\text { ischemia }\end{array}$ & 1 & $\begin{array}{c}0.99 \\
(0.95 \\
1.02)\end{array}$ & $\begin{array}{c}0.97 \\
(0.85-1.10)\end{array}$ & $\begin{array}{c}0.59^{*} \\
(0.58= \\
0.75)\end{array}$ & $\begin{array}{c}0.88 \\
(0.85- \\
0.99)\end{array}$ & $\begin{array}{l}0.87 \\
(0.79- \\
0.98)\end{array}$ & $\begin{array}{c}0.86 \\
\left(0.77^{-}\right. \\
0.97)\end{array}$ & $\begin{array}{c}0.80 \\
(0.68 \\
0.89)\end{array}$ & $\begin{array}{c}0.87 \\
(0.69- \\
0.92)\end{array}$ & $\begin{array}{c}0.86 \\
(0.78 \\
1.01)\end{array}$ \\
\hline $\begin{array}{l}30 \cdot \text { min } \\
\text { ischemia }\end{array}$ & 1 & $\begin{array}{l}1.01 \\
(0.76 \\
1.14)\end{array}$ & $\begin{array}{c}0.95 \\
(0.73-1.07)\end{array}$ & $\begin{array}{c}0.59 \text { \#\#\# } \\
(0.50 \\
0.65)\end{array}$ & $\begin{array}{c}0.88 \\
(0.83- \\
0.94)\end{array}$ & $\begin{array}{c}0.86 \\
(0.77 \\
0.93)\end{array}$ & $\begin{array}{c}0.79 \\
\left(0.74^{-}\right. \\
0.94)\end{array}$ & $\begin{array}{c}0.72 \# \# \\
(0.68- \\
0.79)\end{array}$ & $\begin{array}{c}0.79 \\
(0.58 \\
0.87)\end{array}$ & $\begin{array}{l}0.66 \# \\
(0.57 * \\
0.79)\end{array}$ \\
\hline $\begin{array}{l}\text { 6o-min } \\
\text { ischemia }\end{array}$ & 1 & $\begin{array}{c}1.07 \\
(1.01- \\
1.12)\end{array}$ & $\begin{array}{c}1.11 \\
(1.01-1.12)\end{array}$ & $\begin{array}{l}0.60 t \\
(0.58 \\
0.68)\end{array}$ & $\begin{array}{c}0.63^{+} \\
(0.59- \\
0.74)\end{array}$ & $\begin{array}{c}0.57^{4} \\
\left(0.49^{*}\right. \\
0.74)\end{array}$ & $\begin{array}{c}0.43^{+\dagger} \\
\left(0.41^{-}\right. \\
0.53)\end{array}$ & $\begin{array}{c}0.29 \dagger^{a} \\
(0.28 \\
0.31)\end{array}$ & $b$ & \\
\hline
\end{tabular}

a In the 60-min ischemia group, two rats died between 30 and 60 min after start of reperfusion

${ }^{b}$ The three remaining rats had died

* $P<0.05$ for 15 -min ischemia group versus sham group

$\# P<0.05$, \#\#P<0.01, and \#\# $P<0.001$ for 30 -min ischemia group versus sham group

$+P<0.05$ and $+t P<0.01$ for 60 -min ischemia group versus sham group

\section{Microcirculation}

Figure 2 shows video images of mesenteric venules from different groups at $120 \mathrm{~min}$ after the end of the ischemia or sham period. These images illustrate typical reactions to 
ischemia and subsequent reperfusion: an increase in leukocyte-vessel wall interactions with longer periods of ischemia and a decrease in blood flow.

\section{Leukocyte-vessel wall interactions}

Within the 6o-min ischemia group leukocyte-vessel wall interactions could not be quantified during the reperfusion phase, because of very low flow conditions (see below) in which it is impossible to distinguish interacting leukocytes from free-flowing leukocytes.

The control values of all leukocyte-vessel wall interaction parameters as measured in the other groups just before the start of ischemia are shown in Table 2 . These parameters were not significantly different between the three groups. Figure 3 illustrates the effect of 15 (broken line) and $30 \mathrm{~min}$ (dotted line) ischemia and subsequent reperfusion on leukocyte rolling; in the sham group (solid line), no changes occurred in number (top) or velocity (bottom) of the rolling leukocytes. This also holds for the number of rolling leukocytes (nRL) in the 15 -min ischemia group. In contrast, 30 min ischemia induced a transient increase by $50-70 \%$ in nRL during the first half hour of reperfusion. Thereafter, $\mathrm{nRL}$ rapidly decreased until the baseline level was achieved. Both 15 and $30 \mathrm{~min}$ ischemia induced a significant decrease in velocity of the rolling leukocytes (VRL) during reperfusion. In the 30-min ischemia group VRL was attenuated earlier and stronger: it had decreased to about $25 \%$ of its control velocity from 10 min reperfusion onward.

Table z: Control values of leukocyte-vessel wall interaction parameters

\begin{tabular}{|c|c|c|c|}
\hline \multirow[b]{2}{*}{ Parameter } & \multirow[b]{2}{*}{ Group } & \multicolumn{2}{|c|}{ Control values } \\
\hline & & Median & Interquartiles \\
\hline Number of rolling leukocytes & Sham & $5^{8}$ & $45-73$ \\
\hline \multirow[t]{2}{*}{$\left(\min ^{-1}\right)$} & 15-min ischemia & 45 & $19-89$ \\
\hline & 30-min ischemia & 82 & $65-120$ \\
\hline Velocity of the rolling leukocytes & Sham & 52 & $40-66$ \\
\hline \multirow[t]{2}{*}{$\left(\mu m \cdot s^{-1}\right)$} & 15-min ischemia & $4^{8}$ & $36-59$ \\
\hline & 30-min ischemia & 55 & $45-66$ \\
\hline Number of adherent leukocytes & Sham & 1 & $1-2$ \\
\hline \multirow[t]{2}{*}{ (per $100 \mu \mathrm{m})$} & 15-min ischemia & 0 & $0-1$ \\
\hline & 30-min ischemia & 1 & $0-1$ \\
\hline Total number of interacting leukocytes & Sham & 2 & $2-4$ \\
\hline \multirow[t]{2}{*}{$($ per $100 \mu \mathrm{m})$} & 15-min ischemia & 3 & $0-3$ \\
\hline & 30-min ischemia & 2 & $1-3$ \\
\hline
\end{tabular}


The effect of 15 or 30 min ischemia and subsequent reperfusion on the number of adherent leukocytes ( $n A L$ ) is shown in Fig. 4. Compared to the sham group, 15 min ischemia did not significantly affect $n A L$ during reperfusion. However, following 30 min ischemia $\mathrm{nAL}$ significantly increased during reperfusion, on average to four to six cells per 100- $\mu m$ venule segment.

The total number of interacting leukocytes, which in the preischemic control period was two to three cells per $100-\mu \mathrm{m}$ vessel length, did not change in the sham group (Fig. 5). However, in both the 15- and 30-min ischemia groups this parameter increased significantly. Fifteen minutes of ischemia induced an increase of already more than 2 times at $10 \mathrm{~min}$ after start of reperfusion to more than 5 times at the end of the reperfusion period. Thirty minutes of ischemia induced an increase of about 10 times during the entire reperfusion period.

Table 3: Control values of local hemodymamic parameters

\begin{tabular}{|c|c|c|c|}
\hline \multirow[b]{2}{*}{ Parameter } & \multirow[b]{2}{*}{ Group } & \multicolumn{2}{|c|}{ Control values } \\
\hline & & Median & Interquartiles \\
\hline Diameter & Sham & 32 & $31-37$ \\
\hline \multirow[t]{3}{*}{$(\mu \mathrm{m})$} & 15-min ischemia & 31 & $26-34$ \\
\hline & 30-min ischemia & 34 & $31-37$ \\
\hline & 6o-min ischemia & 25 & $22-27$ \\
\hline Mean red blood cell velocity & Sham & 1.27 & $1.13-2.22$ \\
\hline \multirow[t]{3}{*}{$\left(\mathrm{mm} \cdot \mathrm{s}^{-1}\right)$} & 15-min ischemia & 1.20 & $1.06-1.41$ \\
\hline & 30-min ischemia & 1.66 & $1.13-2.27$ \\
\hline & 60-min ischemia & 1.41 & $1.26-1.72$ \\
\hline Reduced velocity & Sham & 42 & $33-73$ \\
\hline \multirow[t]{3}{*}{$\left(s^{-1}\right)$} & 15-min ischemia & 39 & $33-44$ \\
\hline & 30-min ischemia & 39 & $33-70$ \\
\hline & 6o-min ischemia & 57 & $57-65$ \\
\hline Blood flow & Sham & 1.40 & $0.97-1.61$ \\
\hline \multirow[t]{2}{*}{$\left(\mathrm{nl} \cdot \mathrm{s}^{-1}\right)$} & $15^{-m i n}$ ischemia & 0.87 & $0.59-1.79$ \\
\hline & $\begin{array}{l}30-\mathrm{min} \text { ischemia } \\
60-\mathrm{min} \text { ischemia }\end{array}$ & $\begin{array}{l}1.29 \\
0.69\end{array}$ & $\begin{array}{l}0.97-2.35 \\
0.61-0.69\end{array}$ \\
\hline
\end{tabular}

\section{Local hemodynamics}

The absolute control values of the local hemodynamic parameters in all four groups are given in Table 3. In the control period no differences in hemodynamic parameters existed between the four groups. During the experiments the venular diameter remained constant in all groups. Therefore, changes in RBCV, reduced velocity $(U)$, and blood flow 
(Q), if any, showed a similar pattern. Figure 6 illustrates blood flow changes in the different groups. Blood flow did not change in the sham group. However, 15 as well as 30 min ischemia induced a severe decrease in blood flow during the reperfusion period, which started earlier in the 30-min ischemia group. The decrease in the 60-min ischemia group was very dramatic from the beginning of the reperfusion phase (Fig. 6).

\section{Arterioles}

In 10 experiments not only a venule but also an arteriole could be noticed in the recorded video images. The median diameter of these arterioles during the control period was 18 $\mu \mathrm{m}$ (range: 13 to $34 \mu \mathrm{m}$ ). In the sham group $(n=2)$ and the 15 -min ischemia group $(n=4)$ this diameter did not change during the experiment. In contrast, in the $30 \cdot \mathrm{min}$ ischemia group $(n=4)$ the arteriolar diameter tended to decrease to about $75 \%$ of its control value during the reperfusion period. Surprisingly, in two of the four arterioles in the $30-\mathrm{min}$ ischemia group vasomotion started during the reperfusion period. One arteriole showed vasomotion during the whole reperfusion phase, with a constant frequency of $2.4 \mathrm{cycles}$ per minute and a peak-to-valley amplitude, relative to the mean vessel diameter, of 0.06 at $10 \mathrm{~min}$ reperfusion increasing to 1.16 after $120 \mathrm{~min}$ reperfusion. The other arteriole started its vasomotion after 90 min reperfusion, with a constant frequency of 1.8 cycles per minute. Its peak-to-valley amplitudes, relative to the mean vessel diameter, were 0.61 and 0.73 following go and $120 \mathrm{~min}$ reperfusion, respectively. In the 60-min ischemia group no arterioles were recorded.

\section{Discussion}

The results of the present study indicate that even a short period of total warm ischemia and subsequent reperfusion of the rat small bowel results in significant microcirculatory impairment: blood flow decreases significantly, while leukocyte-vessel wall interactions increase. As the reperfusion phase continues these effects become more pronounced.

Whereas periods of 15 or 30 min of total warm ischemia had no direct consequences for survival during the experiment, a 6o-min ischemic period was fatal in all rats. The finding that such a short period of total warm ischemia of the small bowel has devastating systemic effects is in agreement with findings in different clinical studies. Especially in the elderly acute mesenteric ischemia following a cardiopulmonary bypass procedure, which is a relatively common complication, has mortality rates varying from 60 to $100 \%(5 ; 6)$. In neonates it has been suggested that ischemia and reperfusion plays a role in the pathogenesis of necrotizing enterocolitis (NEC), with mortality rates varying from 20 to $35 \%(7 ; 8 ; 36)$. Several previous studies on the effect of ischemia and reperfusion of the small bowel demonstrated an increase in leukocyte-vessel wall interactions in mesenteric

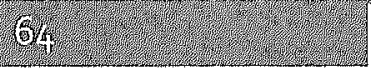



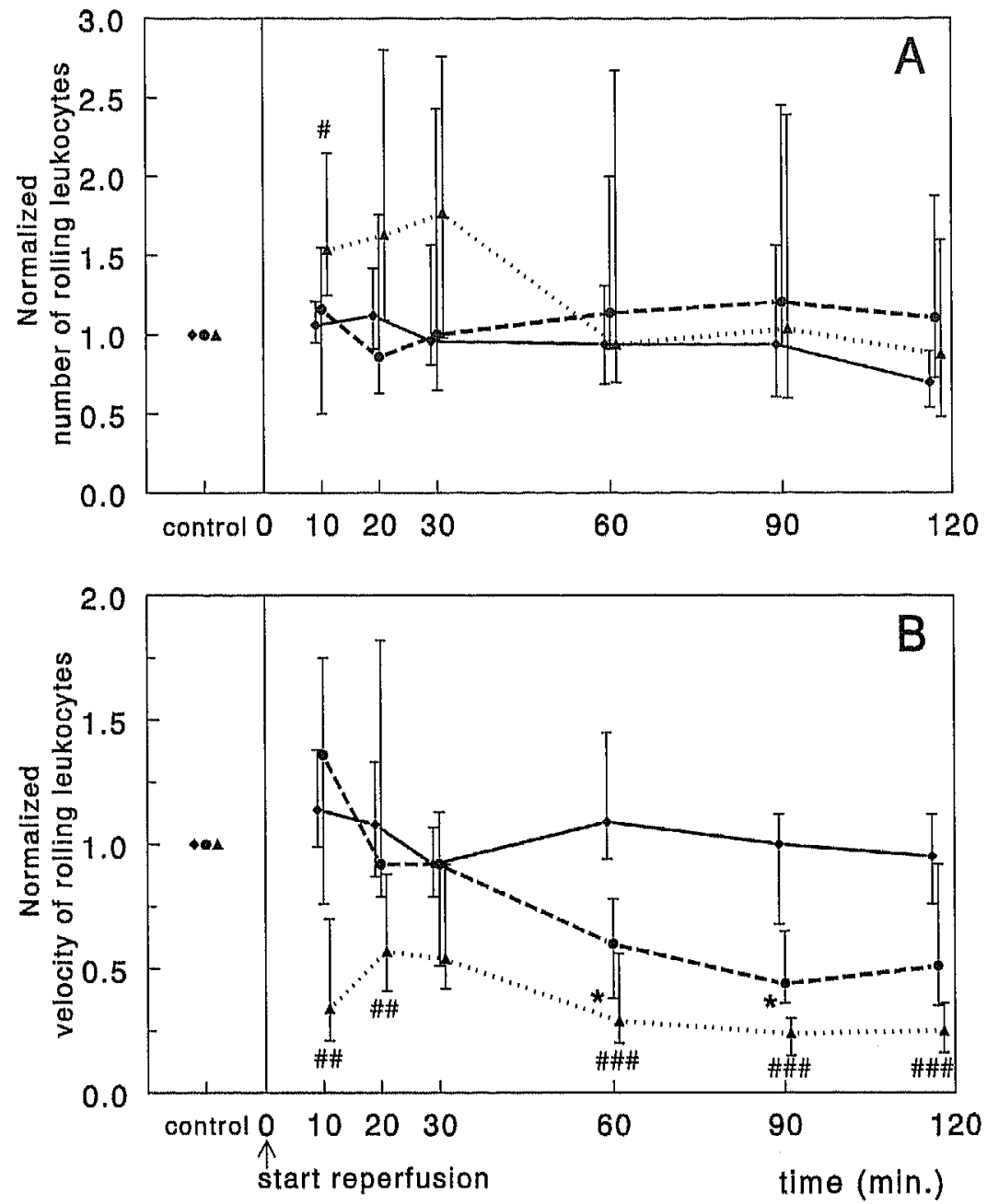

Figugre 3. Effect of ischemia and subsequent reperfusion, or sham, on leukocyte rolling (normalized to control). (A) The median number of rolling leukocytes; (B) the median velocity of the rolling leukocytes in the sham group (solid line, $), 15$-min ischemia group (broken line, $\bullet$ ), and 30 -min ischemia group (dotted line, $\mathbf{\Delta}$ ). Bars denote interquartile ranges. Times shown along the $x$ axis indicate the number of minutes after start of reperfusion (vertical line). The left side of the vertical line represents the control period before total warm ischemia (or sham period). $* P<0.05$ for 15-min ischemia group versus sham group. $\# P<0.05$ \# \#P<0.01, and \#\#\#P< 0.001 for $30-\mathrm{min}$ ischemia group versus sham group. In the sham group, no significant changes were observed over time. 
venules, but no mortality was reported in the case of a 60-min duration of the ischemia(25-28), whereas in our study all rats died between 30 and 90 min reperfusion. This probably results from the fact that these previous studies employed either partial ischemia, in which there was still approximately $20 \%$ flow, or only regional ischemia. In addition, it is remarkable that during these previous studies a 1 - $h$ ischemic period was used to study reperfusion injury and not any shorter periods.

Determination of the effects of total warm ischemia of the whole small bowel has great clinical relevance with respect to situations like small bowel transplantation, which is a developing therapeutic option for patients with irreversible intestinal failure or short bowel syndrome(37), or thoracic aorta surgery. In addition, using our model, we are certain there is no variation in intestinal flow during the ischemic period. By clamping the superior mesenteric artery and ligating the inferior mesenteric artery we are able to stop flow completely in the whole small bowel and the mesentery, as verified through the intravital microscope. In partial ischemic models it is much more complicated to achieve little or no variation. Different intestinal flow patterns between animals can be created due to a variation in collateral flow during partial ischemia. Megison and colleagues(29) took notice of this phenomenon and discovered that superior mesenteric artery occlusion alone does not yield reproducible ischemia or mortality in the rat. By ligating other vessels and thereby interrupting collateral flow they managed to take care of this problem, which indicates that achieving total ischemia is of great importance.

Thirty minutes of total warm ischemia of the small bowel was required to induce during reperfusion an increase in the number of rolling leukocytes along the endothelium. The number of rolling leukocytes significantly increased at $10 \mathrm{~min}$, but had returned to baseline after $1 \mathrm{~h}$ of reperfusion. Although in the $30-\mathrm{min}$ ischemia group during that second hour of reperfusion the number of rolling leukocytes did not differ from the other groups, the velocities of the rolling leukocytes were still sufficiently lower to cause an increase in adherence or sticking of leukocytes. Similar to the present study, Davenpeck et al. found a transient increase in the number of rolling leukocytes during the first hour of reperfusion following a 1 -h occlusion of the celiac and superior mesenteric artery in rats(38). When these rats were treated with monoclonal antibodies blocking the interaction between the endothelial adhesion molecule P-selectin and its ligand on leukocytes, sialyl Lewis ${ }^{x}$, this transient increase did not occur. Whereas in our study the number of rolling leukocytes was increased only during the first 30 min of reperfusion, blood flow continued to decrease. If the reduced blood flow during the second hour of reperfusion is among other mechanisms mediated by leukocyte-vessel wall interactions such as a further significant slowing down of the velocity of rolling cells following both 1.5 and $30 \mathrm{~min}$ ischemia, these interactions must probably have been based on adhesion 


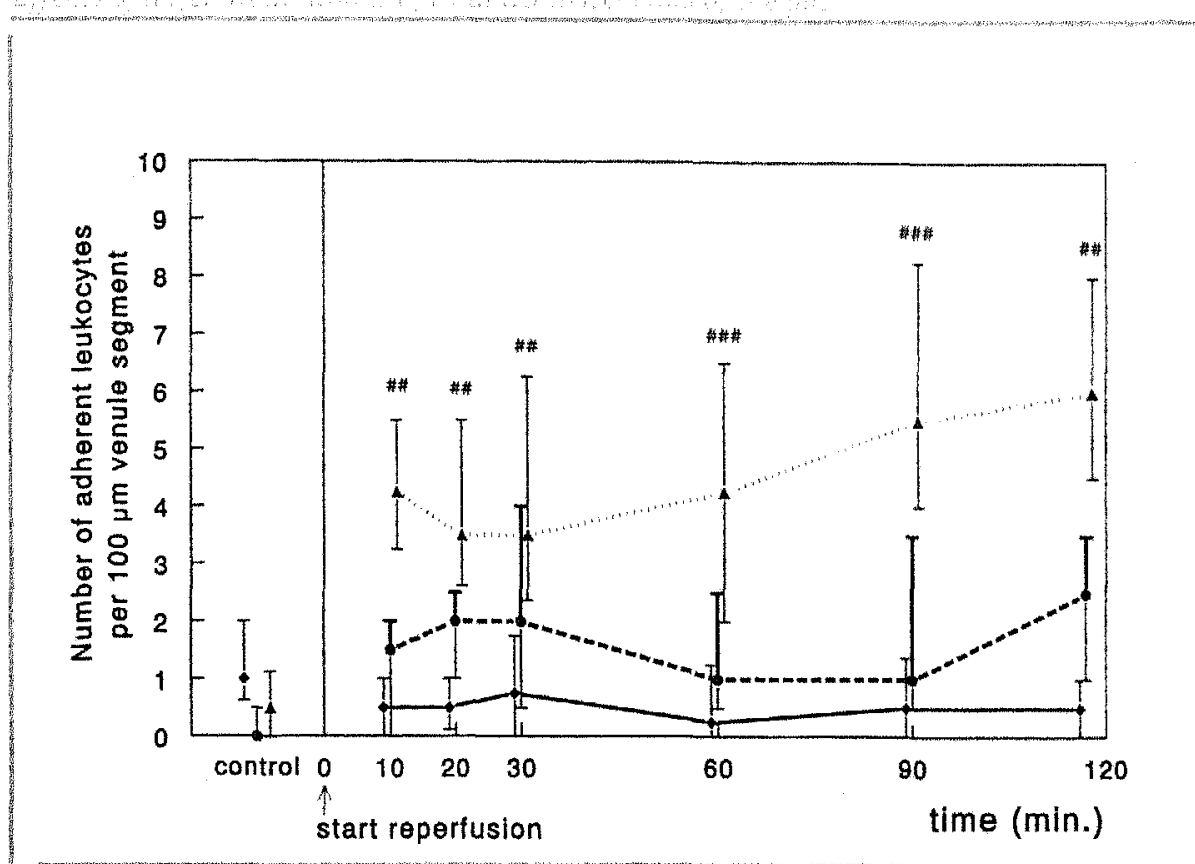

wigure 4 : Median number of adherent leukocytes per 100 $\mu \mathrm{m}$ venule segment (absolute numbers) in three groups: sham (solid line, $\$$ ), 15-min ischemia (broken line, $\bullet$ ), and $3^{0-m i n}$ ischemia (dotted line, $\mathbf{A}$ ). Bars denote interquartile ranges. Times shown along the $x$ axis indicate the number of minutes after start of reperfusion (vertical line). The data on the left side of the vertical line represent the control values before total warm ischemia (or sham period). \#\#P<0.01 and \#\#\#P< 0.001 for $30-\mathrm{min}$ ischemia group versus sham group. In the sham group, no significant changes were observed over time.

molecules other than P-selectin. The velocity of rolling leukocytes is believed to depend on expression of selectins and their ligands as well as on hydrodynamic drag(39). In the 15-min ischemia group both rolling velocity and red blood cell velocity attenuated from 1 $\mathrm{h}$ reperfusion onward. Following $30 \mathrm{~min}$ ischemia rolling velocity and red blood cell velocity were significantly attenuated during the early reperfusion phase as well. These findings cannot rule out a possible involvement of adhesion molecules, such as selectins, in the decrease of leukocyte rolling velocity following ischemia and reperfusion, but they strongly suggest that in both groups after $1 \mathrm{~h}$ of reperfusion an attenuated hydrodynamic drag as a result of a two to five times decreased red blood cell velocity comes into prominence.

Leukocyte adherence increased during the reperfusion phase following $30 \mathrm{~min}$ ischemia, whereas $15 \mathrm{~min}$ ischemia did not significantly affect firm adhesion. Firm adhesion or sticking is mainly an interaction of $\beta_{2}$ integrins (i.e., $C D_{11} / C_{1} 8$ ) on 


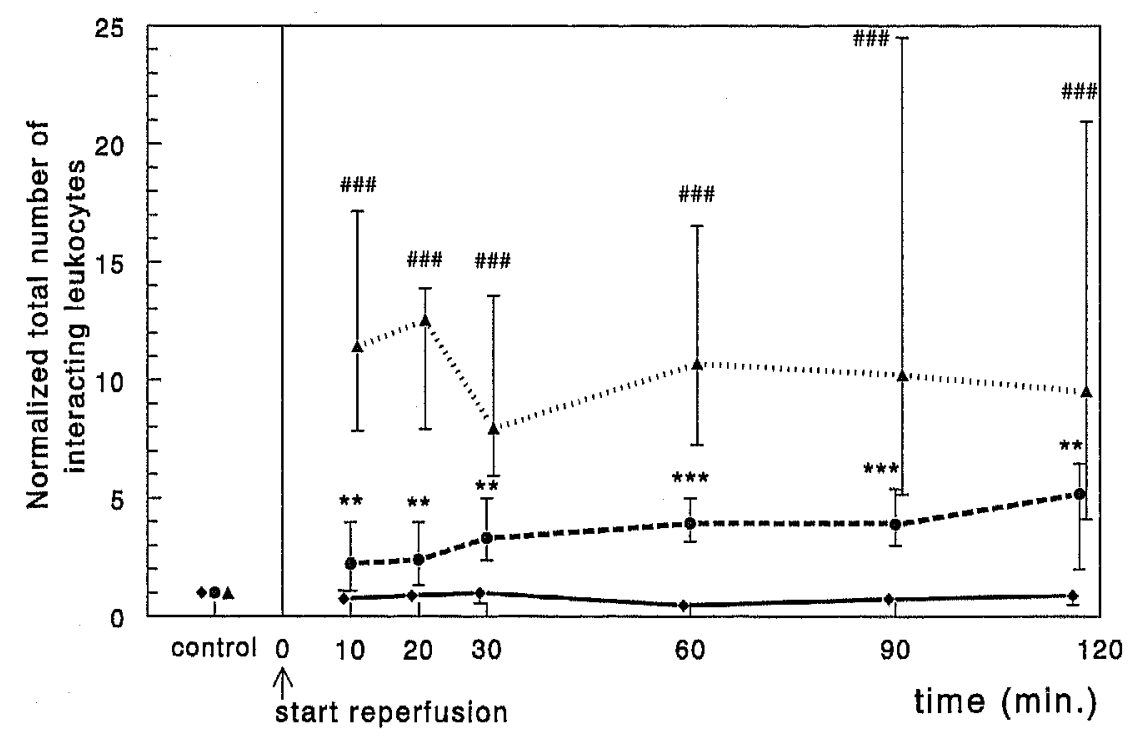

Figure 5: Median total number of leukocytes interacting with the vessel wall per $100-\mu \mathrm{m}$ venule segment (normalized to control) in three groups: sham (solid line, $\downarrow$ ), 15-min ischemia (broken line, $\bullet$ ), and 30-min ischemia (dotted line, $\mathbf{\Delta}$ ). Bars denote interquartile ranges. Times shown along the $x$ axis indicate the number of minutes after start of reperfusion (vertical line). The left side of the vertical line represents the control period before total warm ischemia (or sham period). $* * P<0.01$ and $* * * P<0.001$ for 15 -min group versus sham group. \#\#\#P<0.001 for $30-\mathrm{min}$ ischemia group versus sham group. In the sham group, no significant changes were observed over time.

neutrophils with their endothelial counterreceptors [i.e., intercellular adhesion molecule1 (ICAM-1), ICAM-2, and ICAM-3](31;40). Once neutrophils adhere they are able to damage the endothelial cell or, after transendothelial migration, the intestinal tissue by releasing free radicals and proteolytic enzymes(17;27). Because firm adhesion is a prerequisite for migration, the number of adherent leukocytes may also represent a measure of the extent of neutrophil-mediated tissue injury. This insinuates that an ischemic period of more than $15 \mathrm{~min}$ is required to induce neutrophil-mediated tissue injury during the first $2 \mathrm{~h}$ of reperfusion.

After release of the vessel clamp a distinct and ongoing decline in blood flow occurred in both the 15- and 30-min ischemia groups, being most pronounced following $30 \mathrm{~min}$ ischemia. Following $60 \mathrm{~min}$ ischemia blood flow hardly managed to recover to $10 \%$ of its 


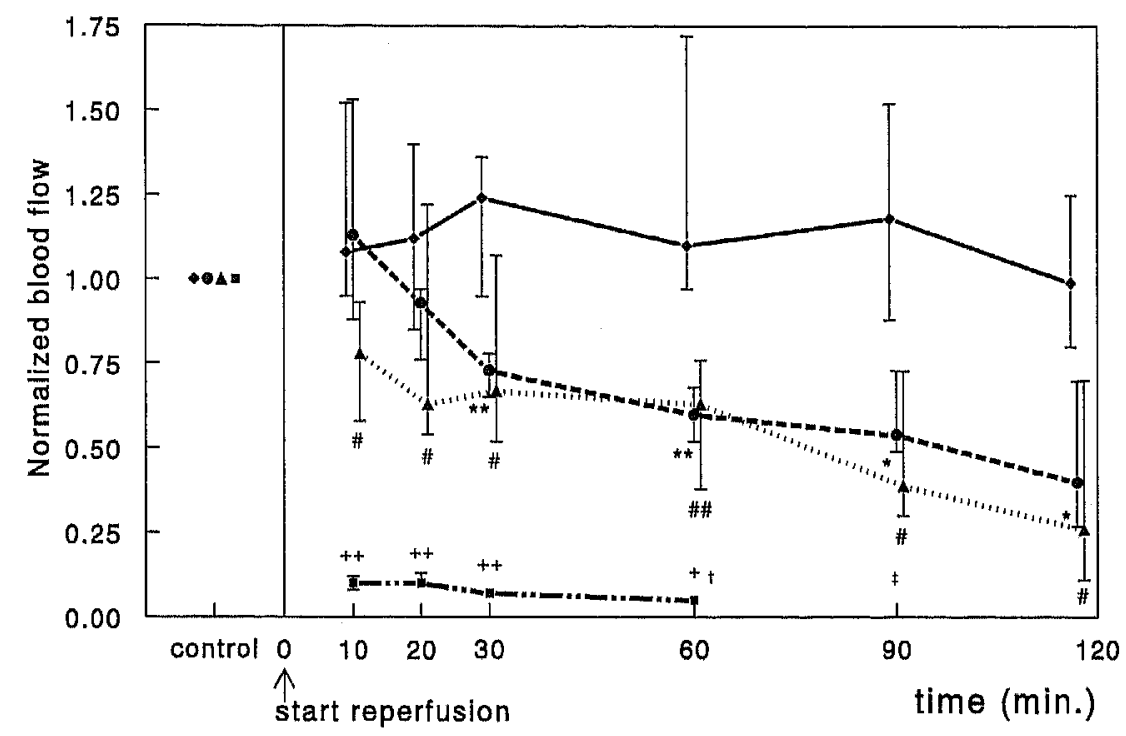

Figure 6: Median blood flow values (normalized to control) in the four groups: sham (solid line, $\bullet$ ), 15 -min ischemia (broken line, $\bullet$ ), 30 -min ischemia (dotted line, $\mathbf{4}$ ), and 6o-min ischemia (alternately solid and broken line, $\boldsymbol{m}$ ). Bars denote interquartile ranges. Times shown along the $x$ axis indicate the number of minutes after start of reperfusion (vertical line). The left side of the vertical line represents the control period before total warm ischemia (or sham period). $* P<0.05$ and $* * P<0.01$ for $15^{-}$ min group versus sham group. $\# P<0.05$ and $\# \# P<0.01$ for $30-\mathrm{min}$ ischemia group versus sham group. $+P<0.05$ and $++P<0.01$ for $60-\mathrm{min}$ ischemia group versus sham group. In the sham group, no significant changes were observed over time. th the 60 -min ischemia group two of the five rats died between 30 and 60 min after start of reperfusion. $¥$ All rats died in the 60 - $\mathrm{min}$ ischemia group.

control value. Because no thrombotic structures, capable of obstructing blood flow, were found at the clamping site of the superior mesenteric artery, other mechanisms must have been responsible for this dramatic decline. The impaired blood flow following 60 min ischemia is probably due to the extremely low MAP and other unknown systemic effects. However, in the 15- and 30-min ischemia groups, the decrease in mean arterial pressure can only partly be held responsible for the observed change in blood flow. The fact that blood pressure only decreased in the $30-\mathrm{min}$ ischemia group while blood flow decreased in the 15 -min ischemia group as well indicates that under these circumstances the involvement of blood pressure is not of eminent importance. An increase in arteriolar resistance could also play a role in reducing venular blood flow. However, arteriolar 
diameter decreases as well as arteriolar vasomotion were found in the 30 -min ischemia group but not in the 15 -min ischemia group (in the 60-min ischemia group no arterioles were observed). This strongly suggests that the decrease in venular blood flow was also only partially related to a change in arteriolar resistance, at least after 15 min of ischemia and probably also after $30 \mathrm{~min}$ of ischemia.

Another mechanism that could have contributed to the decrease in venular blood flow is an increased vascular resistance in the venules themselves as a result of leukocytevessel wall interactions. The total number of leukocytes interacting with the venular endothelium, i.e., rolling as well as adhering leukocytes, increased to about 15 and 20 leukocytes per 100- $\mu \mathrm{m}$ vessel segment after 15 and 30 min of ischemia, respectively. The presence of an increasing number of sticking or slowly rolling leukocytes has undoubtedly led to a local increase in vascular resistance. In addition, one should realize that once a significant amount of leukocytes interacts with the endothelium, they will collide with red blood cells, which probably disturbs the low resistant plasma sleeve along the luminal borders of the vessel; this will also contribute to an increase in resistance to flow. An increased vascular resistance due to leukocyte-vessel wall interactions has been described before(41-44); especially during low flow states these interactions could result in a twofold rise in the resistance to flow(45). In our study the total number of interacting leukocytes increased from 2 to about 20 per $100-\mu \mathrm{m}$ vessel segment within $10 \mathrm{~min}$ of reperfusion after $30 \mathrm{~min}$ ischemia, while the red blood cell velocity decreased by $30 \%$ within the same time period. In the 15-min ischemia group there was at this early stage of reperfusion only a small rise in leukocyte-vessel wall interactions, whereas red blood cell velocity was not yet decreased. When the total number of interacting leukocytes became greater, also in this latter group red blood cell velocity reduced. Because the resistance in a microvessel depends on blood flow velocity as well, the relationship between leukocytevessel wall interactions and vascular resistance seems to be nonlinear.

In conclusion, we illustrated that in postcapillary venules of the rat mesentery relative short periods of total warm ischemia of the small bowel result in severe attenuation of blood flow, with an increase in leukocyte-vessel wall interactions. These changes increase with prolongation of the ischemic period. A 60-min period of total warm ischemia is fatal; the rats die during the early reperfusion phase. The decreasing blood flow during reperfusion may at least partially be explained by the increase in leukocyte-vessel wall interactions. Other mechanisms involved still must be elucidated.

\section{Acknowledgement}

The authors express their appreciation for the technical assistance of Sabrina van Velzen.

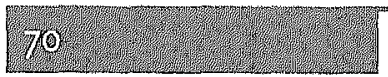




\section{Refirences}

(1) Grant D, Wall W, Mimeault R, Zhong R, Ghent C, Garcia B, et al. Succesful smallbowel/liver transplantation. Lancet 1990;335:181-4.

(2) Schroeder P, Goulet O, Lear PA. Small-bowel transplantation: European experience. Lancet 1990;336:110-1.

(3) Grant D. Current results of intestinal transplantation. The International Intestinal Transplant Registry. Lancet 1996;347(9018):1801-3.

(4) Soong CV, Blair PH, Halliday MI, McCaigue MD, Hood JM, Rowlands BJ, et al. Bowel ischaemia and organ impairment in elective abdominal aortic aneurysm repair [see comments]. Br J Surg 1994;81(7):965-8.

(5) Gennaro M, Ascer E, Matano R, Jacobowitz IJ, Cunningham JN, Jr., Uceda P. Acute mesenteric ischemia after cardiopulmonary bypass. Am J Surg 1993;166(2):231-6.

(6) Huddy SP, Joyce WP, Pepper JR. Gastrointestinal complications in 4473 patients who underwent cardiopulmonary bypass surgery. Br J Surg 1991;78(3):293-6.

(7) Nowicki PT, Nankervis CA. The role of the circulation in the pathogenesis of necrotizing enterocolitis. Clin Perinatol 1994;21(2):219-34.

(8) Kliegman RM, Walker WA, Yolken RH. Necrotizing enterocolitis: research agenda for a disease of unknown etiology and pathogenesis. Pediatr Res 1993;34(6):701-8.

(9) Hernandez LA, Grisham MB, Twohig B, Arfors KE, Harlan JM, Granger DN. Role of neutrophils in ischemia-reperfusion-induced microvascular injury. Am J Physiol 1987;253(3 Pt 2):H699-703.

(10) Fujimoto K, Price VH, Granger DN, Specian R, Bergstedt S, Tso P. Effect of ischemia-reperfusion on lipid digestion and absorption in rat intestine. Am J Physiol 1991;260:G595-602.

(11) Gaboury J, Woodman RC, Granger DN, Reinhardt P, Kubes P. Nitric oxide prevents leukocyte adherence: role of superoxide. Am J Physiol 1993;265:H862-7.

(12) Grisham MB, Granger DN. Neutrophil-mediated mucosal injury. Role of reactive oxygen metabolites. Dig Dis Sci 1988;33(3 Suppl):65-15S.

(13) Inauen W, Suzuki M, Granger DN. Mechanisms of cellular injury: potential sources of oxygen free radicals in ischemia/reperfusion. Microcirc Endothelium Lymphatics $1989 ; 5(3-5): 143-55$.

(14) Kurtel $H$, Fujimoto $K$, Zimmerman BJ, Granger DN, Tso P. Ischemia-reperfusioninduced mucosal dysfunction: role of neutrophils. Am J Physiol 1991;261:G490-6.

(15) Sisley AC, Desai T, Harig JM, Gewertz BL. Neutrophil depletion attenuates human intestinal reperfusion injury. J Surg Res 1994;57(1):192-6. 
(16) Engler RL, Dahlgren MD, Morris DD, Peterson MA, Schmid Schonbein GW. Role of leukocytes in response to acute myocardial ischemia and reflow in dogs. Am $J$ Physiol 1986;251(2 Pt 2):H314-23.

(17) Granger DN. Role of xanthine oxidase and granulocytes in ischemia- reperfusion injury. Am J Physiol 1988;255(6 Pt 2):H1269-75.

(18) Welbourn CR, Goldman G, Paterson IS, Valeri CR, Shepro D, Hechtman HB. Pathophysiology of ischaemia reperfusion injury: central role of the neutrophil. $\mathrm{Br} J$ Surg 1991;78(6):651-5.

(19) Arndt $H$, Kubes $P$, Granger DN. Involvement of neutrophils in ischemia-reperfusion injury in the small intestine. Klin Wochenschr 1991;69:1056-60.

(20) Zimmerman BJ, Granger DN. Mechanisms of reperfusion injury. Am J Med Sci 1994;307:284-92.

(21) von Andrian UH, Arfors KE. Neutrophil-endothelial cell interactions in vivo: a chain of events characterized by distinct molecular mechanisms. Agents Actions Suppl 1993:41:153-64.

(22) Adams DH, Shaw S. Leucocyte-endothelial interactions and regulation of leucocyte migration [see comments]. Lancet 1994;343(8901):831-6.

(23) Springer TA. Traffic signals for lymphocyte recirculation and leukocyte emigration: the multistep paradigm. Cell 1994;76(2):301-14.

(24) Tangelder GJ, Janssens CJ, Slaaf DW, Oude Egbrink MG, Reneman RS. In vivo differentiation of leukocytes rolling in mesenteric postcapillary venules. Am J Physiol 1995; 268(2 Pt 2):Hgog-15

(25) Granger $D N$, Benoit $\perp N$, Suzuki $M$, Grisham MB. Leukocyte adherence to venular endothelium during ischemia- reperfusion. Am J Physiol 1989;257(5 Pt 1):G683-8.

(26) Grisham MB, Hernandez LA, Granger DN. Adenosine inhibits ischemiareperfusion-induced leukocyte adherence and extravasation. Am 」 Physiol 1989;257(5 Pt 2):H1334-9.

(27) Zimmerman BJ, Granger DN. Reperfusion-induced leukocyte infiltration: role of elastase. Am J Physiol 1990;259:H390-4.

(28) Kubes P, Ibbotson G, Russell J, Wallace JL, Granger DN. Role of platelet-activating factor in ischemia/reperfusion- induced leukocyte adherence. Am J Physiol 1990;259: G300-5.

(29) Megison SM, Horton JW, Chao H, Walker PB. A new model for intestinal ischemia in the rat. J Surg Res 1990;49(2):168-73.

(30) Boyd AJ, Sherman IA, Saibil FG. Intestinal microcirculation and leukocyte behavior in ischemia- reperfusion injury. Microvasc Res 1994;47:355-68.

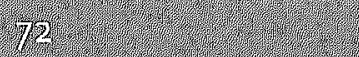


Efects of different duations of total wam ischentia of the gut

(31) Kurtel H, Tso P, Granger DN. Granulocyte accumulation in postischemic intestine:

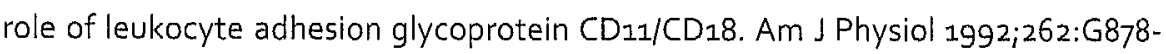
82.

(32) Janssen GHGW, Tangelder GJ, oude Egbrink MGA, Reneman RS. Different effects of anesthetics on spontaneous leukocyte rolling in rat skin. Int.J.Microcirc.Clin.Exp. 17, 305-313. 1997.

(33) Slaaf DW, Alewijnse $R$, Wayland $H$. Use of telescopic imaging in intravital microscopy: a simple solution for conventional microscopes. Int J Microcirc Clin Exp 1982;1(2):121-34.

(34) Intaglietta $M$, Tompkins WR. Microvascular measurements by video image shearing and splitting. Microvasc Res 1973;5(3):309-12.

(35) Slaaf DW, Rood JP, Tangelder GJ, Jeurens TJ, Alewijnse R, Reneman RS, et al. A bidirectional optical (BDO) three-stage prism grating system for on-line measurement of red blood cells velocity in microvessels. Microvasc Res 1981;22(1):110-22.

(36) Caplan MS, MacKendrick W. Necrotizing enterocolitis: a review of pathogenetic mechanisms and implications for prevention. Pediatr Pathol 1.993:13(3):357-69.

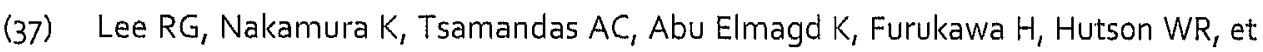
al. Pathology of human intestinal transplantation [see comments]. Gastroenterology 1996;110(6):1820-34.

(38) Davenpeck KL, Gauthier TW, Albertine $\mathrm{KH}$, Lefer AM. Role of P-selectin in microvascular leukocyte-endothelial interaction in splanchnic ischemiareperfusion. Am J Physiol 1994; 267(2 Pt 2):H622-30.

(39) Finger EB, Puri KD, Alon $R$, Lawrence $M B$, von Andrian $U H_{1}$ Springer TA. Adhesion through L-selectin requires a threshold hydrodynamic shear. Nature 1996;379(6562):266-9.

(40) Lawrence MB, Springer TA. Leukocytes roll on a selectin at physiologic flow rates: distinction from and prerequisite for adhesion through integrins. Cell 1991;65(5):859-73.

(41) House SD, Lipowsky HH, In vivo determination of the force of leukocyteendothelium adhesion in the mesenteric microvasculature of the cat. Circ Res 1988;63:658-68.

(42) House SD, Lipowsky HH. Leukocyte-endothelium adhesion: Microhemodynamics in mesentery of the cat. Microvasc Res 1987;34:363-79.

(43) Sutton DW, Schmid Schonbein GW. Elevation of organ resistance due to leukocyte perfusion. Am J Physiol 1992;262(6 Pt 2):H1646-50. 
(44) Chien S. The Benjamin W. Zweifach Award Lecture. Blood cell deformability and interactions: from molecules to micromechanics and microcirculation. Microvasc Res 1992;44(3):243-54.

(45) Eppihimer MJ, Lipowsky HH. Leukocyte sequestration in the microvasculature in normal and low flow states. Am J Physiol 1994; 267(3 Pt 2):H11.22-34. 
Chapter 5

\section{An evaluation of methods for grading histologic injury following ischemia/reperfusion of the small bowel}

Josine S.L.T. Quaedackers, Roland J. Beuk, Laura Bennet, Amanda Charlton, Mirjam G.A. oude Egbrink, Alistair J. Gunn and Erik Heineman 


\section{An evaluatur of methods ror grading histologic injury following ischemialreperusion of the small bowel}

\section{Introduction}

Intestinal injury following ischemia and reperfusion $(I / R)$ of the gut is a common clinical complication that is most often assessed by histologic evaluation of standard hematoxylin and eosin $(H \& E)$ stained tissue sections. For this purpose, many different grading systems for bowel injury have been described in the literature. Unfortunately, there is no consensus on how this injury should be graded. Instead, most studies have used their own systems, which often amount to qualitative or semiquantitative descriptions. Thus, it is difficult to compare the results of studies that were evaluated using different grading systems. However, quantitative comparison of results is essential for the development of an understanding of the mechanisms of $1 / R$ injury and the development of treatment strategies.

The overall goal of this preliminary study was to determine whether it is possible to recommend a standard histologic grading system that would be broadly suitable for use in typical experimental studies of I/R of the gut. The specific aims of this study were first to identify the histologic grading systems available for assessment of intestinal $/ / R$ injury; and second, to examine the validity, reliability, and ease of use of the most commonly used or representative grading systems using tissue sections from a study of I/R of the rat small bowel.

\section{Materials and methods}

\section{Literature study}

Using MEDLINE (Ovid Technologies, NY) from 1966 to the present, we searched the literature for articles reporting on histologic intestinal $1 / R$ injury. A large number and variety of grading systems were identified. In many of these studies, however, histologic damage was either just described, with or without semiquantitative grades attached to this description, or the authors developed entirely new grading systems to suit their needs. From this literature we selected three systems that were most representative of the different types of grading systems. These were the systems developed by Parks(1), Sonnino(2), Chiu(3) and Park(4). These systems are described briefly below and in table 1.

Parks' system scores mucosal injury in intestinal villi and in crypts separately from grade o to 4 , according to the number of villi and crypts affected by epithelial necrosis.(1) 
Sonnino's system also grades only mucosal injury using a large number of different, cumulative criteria, each of which are scored o for a normal or 1 for an abnormal finding.(2) The system developed by Park encompasses a system that was earlier developed by Chiu and scores by progression of intestinal injury from the tips of the villi into the deeper layers of the gut wall in 8 grades. $(3 ; 4)$ The present study refers to this system as the Park/Chiu system to avoid any confusion due to the names of the authors.

\section{Experimental procedures}

Using the three selected grading systems, we reevaluated histologic damage in tissue sections from a previous study of $I / R$ of the rat small intestine.(5) This study compared two groups of adult male Lewis rats. The first group of rats $(n=10)$ was subjected to 30 minutes of total warm ischemia of the small bowel by occlusion of the superior and inferior mesenteric arteries, followed by 60 minutes of reperfusion, as previously described.(6) The second group $(n=11)$ received sham occlusion. At the end of the reperfusion period the rats were sacrificed and the terminal ileum was removed and processed for histological analysis. The tissues were processed using standard histologic techniques including formalin fixation, dehydration and paraffin embedding, then cut in 4- $\mu \mathrm{m}$ sections and stained with H\&E.(6) The sections of both groups were coded, and evaluation was carried out by two independent, experienced observers blinded to the treatment groups. The correlation coefficients between the scores of the independent. observers were calculated separately for each of the three grading systems. The mean of the scores for each section obtained by the two observers were used to compare the three systems together.

\section{Results}

The literature search identified 60 papers in which intestinal damage caused by I/R of the gut was assessed using histologic evaluation. In $18(30 \%)$ of these papers intestinal injury was described without grading. Park's system was used in 5 papers ( $8 \%$ of all papers) Sonnino's system in $2(3 \%)$; Chiu's system in $13(22 \%)$, and the system of Park/Chiu was used in $7(12 \%)$. The remaining 15 papers used other grading systems, usually reported only by one research group.

The evaluation of intestinal injury in the two experimental rat groups by the two independent observers using the three selected systems demonstrated that the Park/Chiu system had the best correlation between the two observers $\left(r^{2}=.86\right)$. Parks's system produced a relatively good correlation for the grading of villus damage $\left(r^{2}=.74\right)$; however, the crypt scores showed much greater discrepancies $\left(r^{2}=.26\right)$. Finally, Sonnino's system showed the least overall correlation between the observers $\left(r^{2}=.41\right)$.

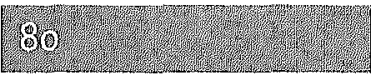


An rvaluation of methods for grading histologic injury following lR of the small bowel

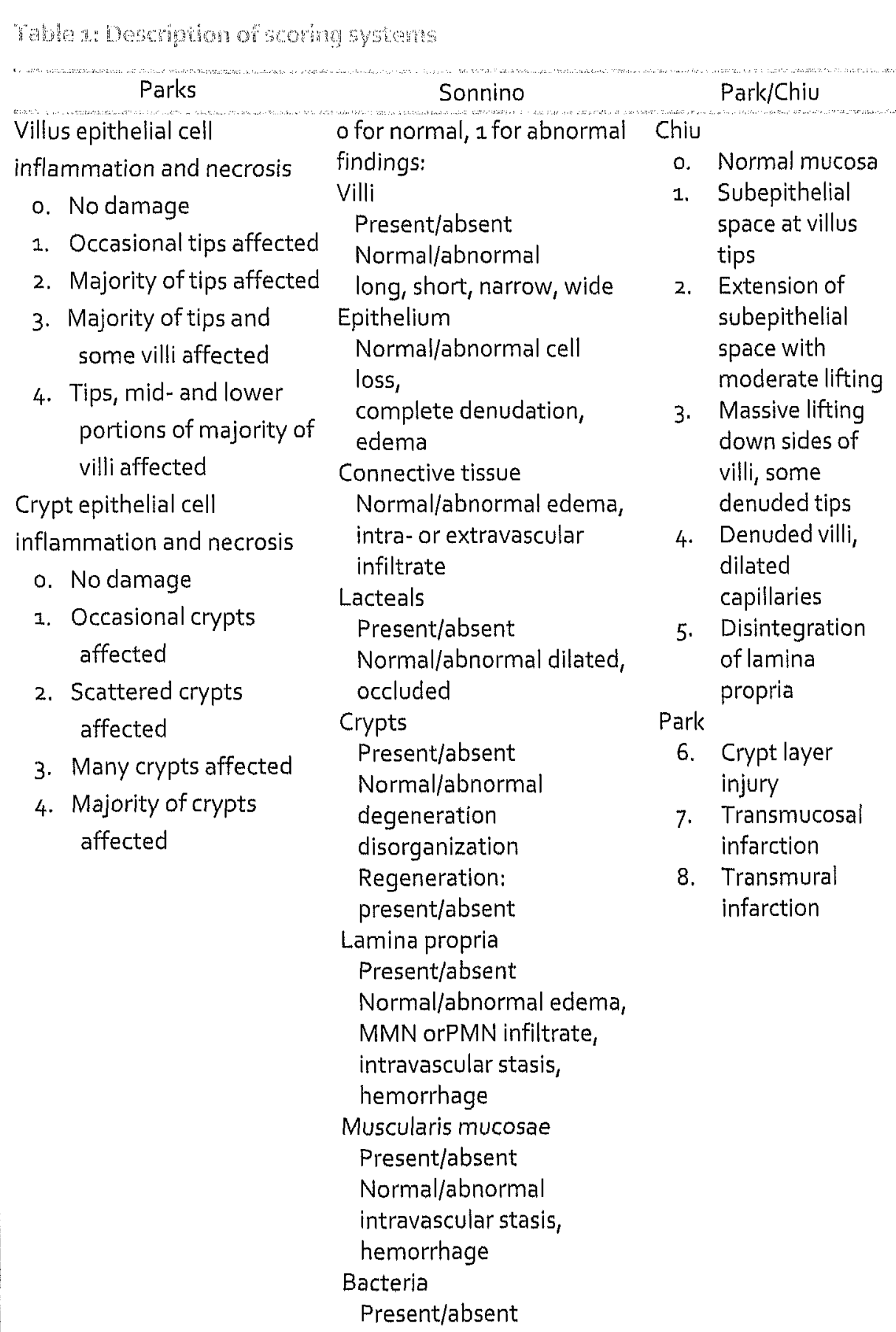

o. Normal mucosa

1. Subepithelial space at villus tips

2. Extension of subepithelial space with moderate lifting

3. Massive lifting down sides of villi, some denuded tips

4. Denuded villi, dilated capillaries

5. Disintegration of lamina propria

Park

6. Crypt layer injury

7. Transmucosal infarction

8. Transmural infarction 
To better examine the pattern of differences in scoring, we related the differences between scores to the mean scores as shown in figure 1.(7) The systems by Park/Chiu and Parks showed relatively greater variation between the observers at moderate levels of damage than in the sections with little damage or those with severe damage; however, the overall differences between the observers were linear. The mean \pm SD differences were $0.64 \pm 1.03$ for the Park/Chiu and $0.52 \pm 1.0$ for the Parks system for villi. The Sonnino system showed much greater discrepancies, particularly in the sham control sections, with a mean difference of $4.14 \pm 3.1$.

When the results of the Park/Chiu system were correlated with the other two systems, it was apparent that Soninno's system, as used by the two experienced observers, suggested that there were significant levels of damage in sham control sections. These were scored as zero with either of the other systems (figure 2). The correlation between the Park/Chiu and Parks (villi) systems was excellent $\left(r^{2}=.99\right)$, whereas the correlation with the Sonnino system was weaker $\left(r^{2}=.83\right)$.

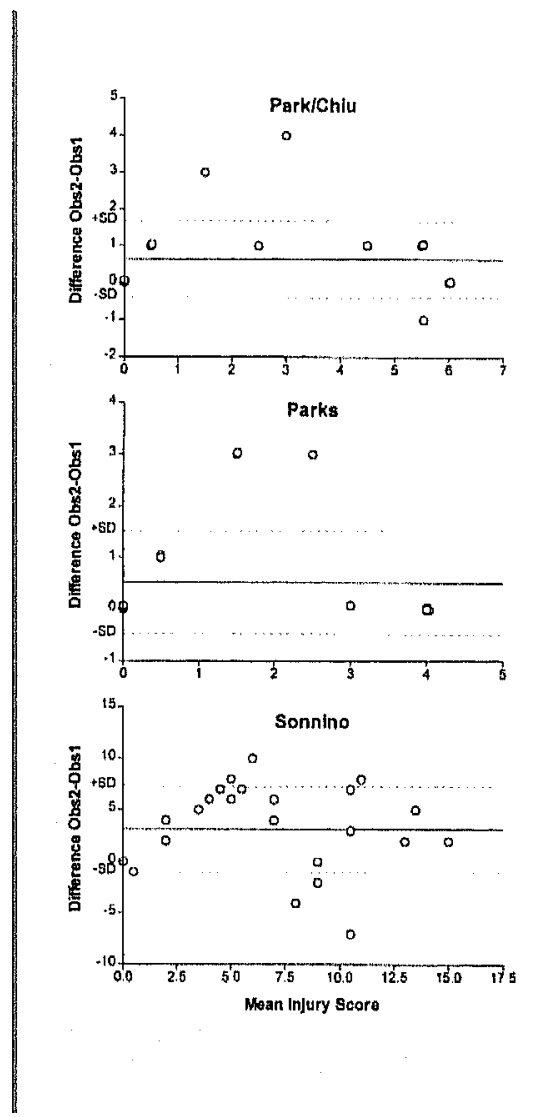

Figure 1: Relationship between the differences between the scores by the two masked observers, and the mean scores for the Park/Chiu, Parks, and Sonnino systems of grading injury, in 21 sections of the small intestine of rats subjected to either sham ischemia or 30 minutes of warm ischemia, followed by 60 minutes of reperfusion. The mean differences are shown by solid lines and the \pm 1 SD ranges by dotted lines. 


\section{Discussion}

l/R of the small intestine is a common clinical problem, seen for example in neonatal necrotizing enterocolitis and small bowel transplantation, and is thus the subject of considerable ongoing research. The degree of injury caused by intestinal $/ / R$ is routinely assessed by histologic evaluation. A commonly used and readily available process for tissue preparation is formalin fixation, dehydration and paraffin embedding, after which sections of $4 \mu \mathrm{m}$ thickness are cut and stained with H\&E. Intestinal damage may be assessed either by choosing the most affected area for grading or by averaging the scores from sections at standard areas.

Ideally, to allow comparisons between different studies of $y / R$ of the bowel, the tissue damage would be quantified using a single standard system, applied to sections that are prepared using this standard method. Our literature search has demonstrated that currently there is no consensus on such a standard grading system making comparisons between studies difficult. Yet comparison between studies that is quantitative as well as qualitative is essential for the determination of potential mechanisms underlying injury and for the development of treatment strategies.

An ideal standard grading system should include the following features. The grades should parallel the morphologic appearance of injury with increasing severity of the insult, and be reliable, producing consistent results within and between observers. Biological validity in this context implies that this hypothetical system should assess both the extent of overall damage to the architectural elements of the bowel wall, including the villi and crypts, as well as more detailed evidence of mucosal and submucosal damage, such as epithelial lifting and mucosal cell debris in the lumen. Typically, ischemic injury leads to progression of damage from the villus tips after the briefest or mildest periods of ischemia, extending to the crypts only after much longer periods of ischemia.(3) Of equal importance is that an ideal grading system should be logically presented, easy to learn, and use and have a low inter-observer variability.

From our literature search we concluded that the Park/Chiu system is the closest to meeting these criteria. This combined system grades the progression of morphologic injury from mild to severe. The grades encompass both architectural and more detailed damage and are well defined, which leads to a low inter-observer variability. The Parks system was equally reliable in the present study; however, it does not include injury beyond the mucosa and its structure, which separates villus and crypt damage, made it more cumbersome to use and interpret. In the present study of $1 / R$-induced intestinal injury in the rat, damage was primarily seen in the villi, and thus there was excellent agreement between the Parks (villi) scores and those of the Park/Chiu system. With a significantly more severe insult, we would have anticipated increasing damage to the 
crypts which would be linearly reflected in the Park/Chiu system, but would require assessment of two scores with the Parks system.

In many grading systems only one aspect of $\mathrm{J} / \mathrm{R}$ damage is singled out and graded according to severity. An example of this is the system by Parks, which only assesses the extent of the epithelial cell necrosis. Other systems, like Sonnino's, are very extensive, scoring a wide range of features; however, this system does not directly assess the progression of injury along the villi and crypts. This is demonstrated in figure 2; although the Sonnino damage scores increased linearly, the most severe damage scored was still only half of the maximum possible, while the Park/Chiu system had reached a very severe score of 6 out of 8 . Further, the sham control sections were rated as having significant damage in Sonnino's system, which was not a feature of the other two scales.

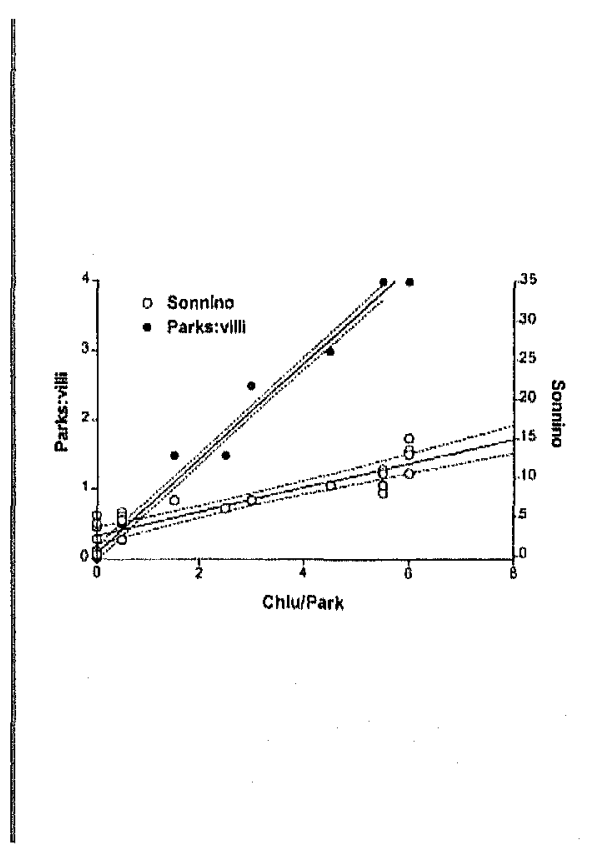

Figure 2: The correlation between the Park/Chiu system with both the Parks and Sonnino systems for the mean scores of the two blinded observers. The Parks score for villi correlated very well with the Park/Chiu system $\left(r^{2}=.99\right)$. However, the Sonnino system showed a less good correlation with the Park/Chiu system $\left(r^{2}=.83\right)$, but also a significant baseline shift, with some apparent damage in sham control sections which was not seen with the other two systems. The solid and dotted lines represent the linear correlation and confidence intervals, respectively.

All of the grading systems would have benefited from more clear and precise descriptions of the grades. This is likely to have contributed to some of the differences between the observers (see figure 1). For example, the system used by Parks grades epithelial cell necrosis, but does not describe which characteristics of necrosis should be assessed. It is not clear whether the system purely grades cytologic evidence of necrosis, such as rounding of the normally cuboid epithelial cells, or whether epithelial lifting is also considered to be evidence of epithelial necrosis. Sonnino's system was the most difficult to implement for both observers. A large number of different criteria are used to assess

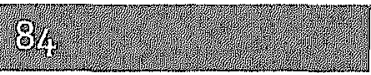


intestinal damage. However, again these criteria are only summarized, and not explained in detail, which leaves the reader to decide what is actually meant by factors such as intravascular stasis, regeneration, and disorganization.

In addition to basic morphologic $1 / R$ damage, more detailed features of intestinal $/ / R$ injury including leukocyte infiltration, apoptosis, and proliferation are a component of many grading systems such as Sonnino's. However, proper evaluation of such detailed objectives is difficult and time consuming. We propose that it would be more appropriate to assess these objectives separately to the basic morphologic assessment and that these criteria should not be incorporated in a standard grading system. Apoptosis and proliferation are better assessed using specialized techniques, such as immunohistochemical staining and TUNEL.

In conclusion a standard quantitative and qualitative histologic scoring system would make it much easier to compare of studies of I/R. However, to date no one system has been consistently supported in the literature. An ideal system should be comprehensive in scope, assessing the evolution of injury from mild to severe damage. It should also be well described and easy to use to ensure low inter-observer variability. From our assessment of the literature and the present evaluation of representative systems, we propose that the combined grading system of Chiu and Park is the most suitable to be recommended as a standard scoring scale for histological evaluation of intestinal $\mathrm{I} R$ damage. However, better description of the last grades of this system would further strengthen its suitability. 


\section{References}

(1) Parks DA, Bulkley GB, Granger DN, Hamilton SR, McCord JM. Ischemic injury in the cat small intestine: role of superoxide radicals. Gastroenterology $1982 ; 82$ (1):915.

(2) Sonnino RE, Riddle JM, Pritchard TJ. Grading system for histologic changes in rat small bowel transplants. Transplant Proc 1992;24(3):1201-2.

(3) Chiu CJ, McArdle AH, Brown R, Scott HJ, Gurd FN. Intestinal mucosal lesion in lowflow states. I. A morphological, hemodynamic, and metabolic reappraisal. Arch Surg 1970;101(4):478-83.

(4) Park PO, Haglund U, Bulkley GB, Falt K. The sequence of development of intestinal tissue injury after strangulation ischemia and reperfusion. Surgery 1990;107(5):574-80.

(5) Beuk RJ, Heineman E, Tangelder GJ, Quaedackers JS, Marks WH, Lieberman JM, et al. Total warm ischemia and reperfusion impairs flow in all rat gut layers but increases leukocyte-vessel wall interactions in the submucosa only. Ann Surg 2000 Jan;231(1):96-104.

(6) Beuk RJ, Heineman E, Tangelder GJ, Kurvers HA, Bonke HJ, Oude Egbrink MG. Effects of different durations of total warm ischemia of the gut on rat mesenteric microcirculation. J Surg Res 1997 Nov;73(1):14-23.

(7) Bland JM, Altman DG. Measuring agreement in method comparison studies. Stat Methods Med Res 1999 Jun;8(2):135-60. 
Total warm ischemia and reperfusion impairs flow in all rat gut layers but increases leukocyte-vessel wall interactions in the submucosa only

Roland J. Beuk, Erik Heineman, Geert-Jan Tangelder, Josine S.L.T. Quaedackers, William H. Marks, Joshua M. Lieberman and Mirjam G.A. oude Egbrink 


\section{Abstract}

Objective: To study the effect of warm ischemia and reperfusion (I/R) on local perfusion and leukocyte-vessel wall interactions in vivo in all small bowel layers, and to quantify small bowel tissue injury histologically and by measuring intestinal fatty acid binding protein (I-FABP) release from the enterocytes.

Summary background data: Gut injury as a result of I/R plays a pivotal role in a variety of clinical conditions, such as small bowel transplantation, heart or aortic surgery, and (septic) shock. The precise mechanism behind I/R injury and the role of microvascular changes remain unclear. The influence of warm $1 / R$ of the gut on microvascular parameters in the different gut layers has not been studied before.

Methods: Anesthetized Lewis rats were either subjected to 30 minutes of ischemia and 1 hour of reperfusion or sham-treated as controls. After ligating the inferior mesenteric artery, total warm ischemia was induced by clamping the superior mesenteric artery. Intravital video microscopic measurements were obtained at intervals. Tissue injury of the small bowel and other organs was histologically evaluated afterward. In addition, plasma levels of I-FABP were determined to measure enterocyte damage.

Results: After ischemia, mean red blood cell velocity decreased significantly in all layers of the small bowel, but no diameter changes were observed. Leukocyte-vessel wall interactions increased in the submucosa but not in the muscle layers. Plasma levels of 1 . FABP significantly increased from 30 minutes of reperfusion onward. The intestinal mucosa was severely injured; no histologic damage was detected in other tissues.

Conclusions: This is the first in vivo study showing that total warm ischemia of the rat gut impairs perfusion in the whole small bowel, whereas leukocyte-vessel wall interactions increase in the submucosal layer only. Therefore, the early inflammatory response to I/R seems to be limited to the submucosa. Both microvascular effects may have contributed to the severe morphologic and functional mucosal injury observed after I/R. 
Total warm ischemua and reperfusion impairs flow un all rat gut layers but increases leukocytewessel wall interactions in the submucosa only

\section{Introduction}

Gut injury as a result of ischemia and subsequent reperfusion (I/R) plays a pivotal role in a variety of clinical conditions, such as small bowel transplantation, $(1 ; 2)$ heart or aortic surgery, $(3 ; 4)$ and (septic) shock. (5-8) l/R of the small bowel has been reported to result in increased microvascular permeability $(9)$ and intestinal mucosal lesions.(10) However, the precise mechanism behind $I / R$ injury and the role of microvascular changes remain unclear.

Recently, we found that 30 minutes of total warm ischemia (complete flow cessation) and subsequent reperfusion of the small bowel led to a significant decrease in blood flow in the microcirculation of the rat mesentery, whereas the number of leukocyte-vessel wall interactions increased; 1 hour of ischemia appeared to be fatal in all rats.(11) It is unknown whether I/R has similar detrimental consequences in the microcirculation of the other splanchnic tissues, such as the different layers of the small bowel wall. It is also not known how such microvascular effects, if any, are related to the development of mucosal injury.

We studied in rats the effect of 30 minutes of total warm ischemia and subsequent reperfusion on the microcirculation of the small bowel. Using intravital video microscopy, we quantified blood flow and leukocyte-vessel wall interactions in the two muscle layers (longitudinal as well as circular) and in the submucosal layer. To evaluate intestinal epithelial injury, we measured in serum the level of intestinal fatty acid binding protein (1FABP). This $15 \mathrm{kd}$ protein constitutes $2 \%$ to $3 \%$ of total enterocyte protein mass.(12) When the membranes of the epithelial cells become more permeable, I-FABP leaks from their cytosol and can be detected in the systemic circulation.(13) Therefore, I-FABP is a useful biochemical marker for epithelial injury in the small bowel.(14) In addition, intestinal histologic changes were examined.

\section{Materials and methods}

Animal preparation

All experiments were approved by the local ethics committee on the use of laboratory animals. Twenty-one male Lewis rats with a mean weight of $280 \mathrm{~g}$ (range 250-300) were used. Anesthesia was induced by sodium pentobarbital $(6.6 \mathrm{mg} / 100 \mathrm{~g}$ given 
intraperitoneally), and from 1 hour on was maintained by continuous infusion $(2.6 \mathrm{mg} / 100$ $g$ per hour) through a PE 10 catheter in the right femoral vein. This anesthetic does not interfere with leukocyte-vessel wall interactions.(15) To measure arterial blood pressure and heart rate with an Uniflow external pressure transducer (Baxter, Santa Ana, CA), a second catheter ( $P E{ }_{10}$ ) was placed in the right femoral artery. This catheter was continuously perfused with physiologic saline $(2 \mathrm{~mL} / \mathrm{hr})$ to prevent blockage. Throughout the experiments, body temperature was kept at $37^{\circ} \mathrm{C}$.

A midline laparotomy was performed, and the superior mesenteric artery (SMA) was identified, dissected free, and marked by a plastic strap. The inferior mesenteric artery was ligated with Ethicon 3-0 sutures. A right flank incision was made and a segment of the distal ileum exteriorized. To decrease peristalsis, $0.5 \mathrm{~mL}$ Imodium $(0.2 \mathrm{mg} / \mathrm{mL}$; Janssen Pharmaceutica B.V., Tilburg, The Netherlands) was injected locally into the ileum. The ileum was then carefully positioned on an electrically heated table $\left(37^{\circ} \mathrm{C}\right)$ of an intravital microscope and continuously superfused with a buffered Tyrode's solution $\left(37^{\circ} \mathrm{C}, \mathrm{pH} 7.35-7.40\right)$ that was bubbled with a mixture of $\mathrm{N}_{2}(95 \%)$ and $\mathrm{CO}_{2}(5 \%)$. The part of the ileum surrounding the observation area was kept moist with overlying wet gauze. To suppress peristalsis further, a catheter ( $\mathrm{PE} 10)$ with a multiple-hole tip was positioned parallel to the exteriorized ileum and was continuously perfused with a solution containing Imodium (20\%) and isoproterenol hydrochloride (1 $\mathrm{mg} / \mathrm{L}$ saline). The concentration of the latter substance was less than doses that can affect the diameter or reactivity of gut microvessels. $(16 ; 17)$ Finally, a thin cover glass was gently placed on top of the ileum to reduce microperistalsis. During the entire procedure, the utmost precaution was taken not to manipulate the abdominal contents any more than strictly necessary. After this procedure, preparations were allowed to stabilize for 30 minutes.

\section{Intravital video microscopy}

Observations were performed under epiillumination with a Leitz intravital microscope (Leitz, Wetzlar, Germany) adapted for telescopic imaging and carrying a 1.25× Leitz Ploemopak 2.2 for interchangeable filter sets. A Leitz $\times 25$ salt-water immersion objective (numeric aperture 0.6 ) and a 100-W mercury lamp were used. Bright-field microscopy was performed with a Leitz Pol-cube, which consists of a $50 \%$ mirror in a $45^{\circ}$ position with respect to the optical axis of the microscope, a polarizer in the illumination pathway, and an analyzer in the observation pathway. For fluorescence microscopy, we used a Leitz N2.1 filter set (excitation filter BP 515-560, dichroic mirror RHP 580, and barrier filter LP 580). Images were projected on a charge-coupled device camera (Hamamatsu Photonics, Hamamatsu (ity, Japan), displayed on a monitor screen, and recorded for off-line analysis

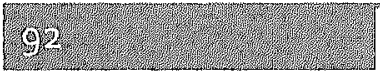


on videotape. The final optical magnification at the front plane of the camera was $\times 31.25$. In all experiments, the midplane of a vessel was kept in focus.



Figure $x$ : The small bowel microvascular bed, showing the six sites of intravital microscopic observation. Arterioles originating from the mesenteric arcade penetrate the muscular layers of the small bowel into the submucosa (C). Here they give rise to arterioles (1), which run mainly longitudinally. Right-angled branches originating from these longitudinal arterioles supply the submucosal capillary plexus (2) and the mucosa (D), whereas other branches ascend through the muscle layers, supplying the capillaries of the $\operatorname{circular}(3, \mathrm{~B})$ and longitudinal $(4, \mathrm{~A})$ muscle layers. Blood from muscle capillaries is collected in venules, which in turn merge between the two muscle layers into larger venules (5). Venules are also formed at the base of the submucosal capillary bed; these in turn become the larger submucosal venules (6). Finally, the blood from the muscle and the submucosal layers is collected in venules, which return to the mesenteric arcade. 
Microvessels observed

In each experiment, we observed six categories of vessels in the different layers of the small bowel. Figure 1 shows the small bowel microvascular bed, indicating the vessels used. These include capillaries in the longitudinal (outer) and circular (inner) muscle layers, as well as in the submucosa, venules located between the two muscle layers, and venules and arterioles within the submucosa. Data obtained from three or four capillaries were averaged.

\section{Experimental protocol}

In one group of rats $(n=10)$, total warm ischemia was induced by a 30-minute occlusion of the SMA with an atraumatic vessel clamp. As controls, a sham-operated group $(n=11)$ was included in which no ischemia was induced. Time protocol and data collection were similar in both groups.

Before each experiment, we randomized the order of observation of the different vessel categories. In both groups, images from all selected vessels were recorded on video before the start of the sham procedure or the induction of ischemia (control), as well as at 10, 20,30, and 60 minutes after the start of reperfusion. Each recording lasted $\geq 1$ minute. To enable leukocyte observation with intravital microscopy, these cells were labeled in vivo with the fluorescent dye Rhodamin-6G (mw 479; Sigma Chemical Co., St. Louis, MO). The venous catheter was used to inject $0.2 \mathrm{~mL}$ Rhodamin-6G (1 mg/mL) before the recordings at baseline and at 10 and 60 minutes after the start of reperfusion. At the end of the last observation period, the animals were killed with an overdose of sodium pentobarbital and organs were harvested for histologic examination.

Blood samples were taken from the arterial catheter placed in the right femoral artery to determine the systemic leukocyte count in a Bürker chamber $(20 \mu \mathrm{L}$ collected in $20 \mu \mathrm{L}$ Türk's solution) and hematocrit ( $20 \mu \mathrm{L}$ ), both at baseline and 60 minutes after the start of reperfusion. 1-FABP was determined at baseline and at 30 and 60 minutes after the start of reperfusion $(0.5 \mathrm{~mL})$.

\section{Microvascular parameters}

Vessel diameters were measured off-line using a home-built image-shearing device.(18) Mean red blood cell velocity(mRBCV) in the muscle layers was measured with a flying spot device. In venules and arterioles in the submucosal layer, the centerline velocity was determined by frame-to-frame analysis using the fastest passing fluorescent leukocyte as a marker. This centerline velocity was divided by $1.5(19)$ to calculate MRBCV. Using this technique, we were able to measure centerline velocities up to $10 \mathrm{~mm} / \mathrm{sec}$; higher centerline velocities were designated as beyond this value (i.e., $\mathrm{mRBCV}>6.7 \mathrm{~mm} / \mathrm{sec}$ ).

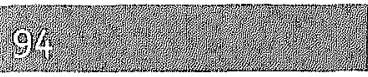


Red blood cell velocity in submucosal capillaries could not be measured on an ordinal scale but was scored using an arbitrary velocity index (4: cell images were seen as solid streaks, 3: cell images appeared as interrupted streaks, 2: individual cells were visible but fast-flowing, 1 : individual cells were visible but slow-flowing, and o: complete flow cessation). However, because of the direct visualization of these capillaries, a velocity index of o could be established without any doubt and is therefore not arbitrary. Each capillary visible in one field of view was scored separately; the median value was used for further analysis.

Leukocyte-vessel wall interactions were observed in muscular and submucosal venules. Rolling leukocytes move along the venular wall at least an order of magnitude slower than free-flowing leukocytes and therefore can easily be identified by eye. The degree of leukocyte rolling was quantified by counting the number of rolling leukocytes passing an imaginary line perpendicular to the venular axis during a 1-minute period. Leukocytes were considered to be firmly adherent (sticking) when they remained stationary for $\geq 30$ seconds. The number of adherent leukocytes was determined in a 100$\mu \mathrm{m}$ segment of the venule. We also determined the total number of leukocytes interacting with the venular wall at a particular moment. This parameter includes not only the number of adherent and rolling leukocytes but also the velocity of the latter; it is important to assess possible leukocyte-mediated changes in vascular resistance.(11) To determine this parameter, we counted in a frozen video frame the total number of rolling and adhering leukocytes in a 100- $\mu \mathrm{m}$ vessel segment. Because during low-flow conditions distinction between interacting and free-flowing fluorescently labeled leukocytes can become complicated, we also checked the preceding and sequential video frames. At each time point, this count was performed four times and the data were averaged.

\section{Intestinal fatty acid binding protein}

Blood samples were collected in micro test tubes (Eppendorf, Hamburg, Germany) and centrifuged at $12,000 \mathrm{rpm}$ for 20 minutes. Serum was extracted and stored at $-70^{\circ} \mathrm{C}$. IFABP content of serum was determined with a radioimmunoassay, as described previously. $(12 ; 20)$ In brief, the assay uses a polyclonal antibody developed in rabbits against a recombinant I-FABP and ${ }^{125}$ I-labeled recombinant I-FABP as a tracer. The assay is specific for rat I-FABP and is sensitive for I-FABP in concentrations of 4 to $125 \mathrm{ng} / \mathrm{mL}$ in dilute serum. Samples of serum $(100 \mu L)$ diluted $1: 2$ with phosphate buffer were assayed in duplicate. 


\section{Histology}

After the rats had been killed, the clamp site of the SMA, terminal ileum, liver, kidneys, lungs, heart, and left gastrocnemius muscle were removed and immediately fixed in 10\% formaldehyde-saline solution. The fixed tissue was embedded in paraffin, sectioned in 4$\mu \mathrm{m}$ slides, and stained with hematoxylin and eosin for observation. The degree of intestinal injury was evaluated on a scale of 0 to 8 , as described by Park et al(21) (0: normal mucosa, 1: subepithelial space at the tips of the villi, 2: more extended subepithelial space, 3 : massive epithelial lifting down the sides of the villi, 4 : villi denuded of epithelium, 5: loss of villi themselves, 6: the intestinal crypt layer is also affected, 7: transmucosal infarction is present, 8 : transmural infarction).

\section{Statistical analysis}

Because of their asymmetric distribution, data are presented as medians with their interquartile ranges (25th to $75^{\text {th }}$ percentile). Nonparametric statistical analysis was performed within the sham group using the Friedman two-way analysis of variance. The Mann-Whitney $U$ test was used to compare data from the ischemia groups with those of the sham group at each time point. These tests also allow handling of categorical data and of those values that exceed a measuring limit (e.g., some mRBCV data). $P<.05$ was considered statistically significant.

\section{Resultes}

Simultaneous occlusion of both the superior and inferior mesenteric arteries resulted in complete ischemia of the small bowel, as verified through the microscope by flow cessation in all vessels observed in the various layers of this organ. All rats survived throughout the observation period and were killed after 1 hour of reperfusion. Histologic examination of the SMA at the clamp site did not show any obstruction (i.e., thrombus formation) capable of reducing blood flow to the small bowel during the reperfusion phase.

\section{Systemic hemodynamics}

During control measurements, heart rate and mean arterial pressure were the same in both groups, with an average value for all animals of $339 \mathrm{bpm}$ and $84 \mathrm{mmHg}$. In the sham group, the heart rate and mean arterial pressure remained constant during the whole experimental protocol. The same held for the ischemia group, except for a small rise in heart rate ( $348 \mathrm{vs} .327 \mathrm{bpm}$ ) for the ischemia group compared with the sham group ( $P<$ $.05)$ at 30 minutes and a short drop in mean arterial pressure to $57 \mathrm{mmHg}$ at 1 minute $(P<$ .01) after the start of reperfusion.

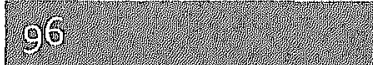


Neither hematocrits nor systemic leukocyte counts were significantly affected; they remained on average between $45 \%$ and $50 \%$ and 11 to $12 \times 10^{6}$ leukocytes $/ \mathrm{mL}$.

\section{Microcirculatory flow parameters}

Small bowel submucosa

Diameters of the submucosal arterioles and venules did not change significantly throughout the experiment, remaining at their median control values of 35 to $38 \mu \mathrm{m}$ and 45 to $49 \mu \mathrm{m}$, respectively, in both groups. Figure 2 shows that in the ischemia group, mRBCV decreased significantly in both the submucosal arterioles and venules during the entire reperfusion phase, compared with the sham group. In addition, the arbitrary velocity index of the submucosal capillaries after ischemia was significantly lower than in the sham group, showing a continuous decline until almost complete flow cessation at 60 minutes after the start of reperfusion $(P<.001)$. In the sham group, no significant flow changes were observed.

\section{Small bowel muscle layers}

None of the three vessel categories investigated showed significant changes in diameter. Median control values were similar in both groups (venules: $13 \mu \mathrm{m}$; capillaries in both muscle layers: $4 \mu \mathrm{m}$ ). Figure 3 shows the significant decrease in mRBCV in venules and capillaries to at the most one third of sham values in all vessels observed in the muscle layers during the entire reperfusion phase. In the sham group, velocities did not change over time in any of the vessel categories.

\section{Leukocyte-vessel wall interactions}

In submucosal venules, leukocyte rolling and adhesion, as well as the total number of interacting leukocytes, increased significantly after ischemia compared with the sham group, whereas in muscle venules there were no differences between the two groups (Fig. 4). Sham values did not change over time except for a gradual decrease in leukocyte rolling in venules of the submucosa.

\section{Intestinal fatty acid binding protein}

At baseline, only low serum levels of I-FABP were found (Fig. 5). In the sham group, they remained within this range. However, ischemia and reperfusion $(/ / R)$ induced a significant increase in I-FABP release. 

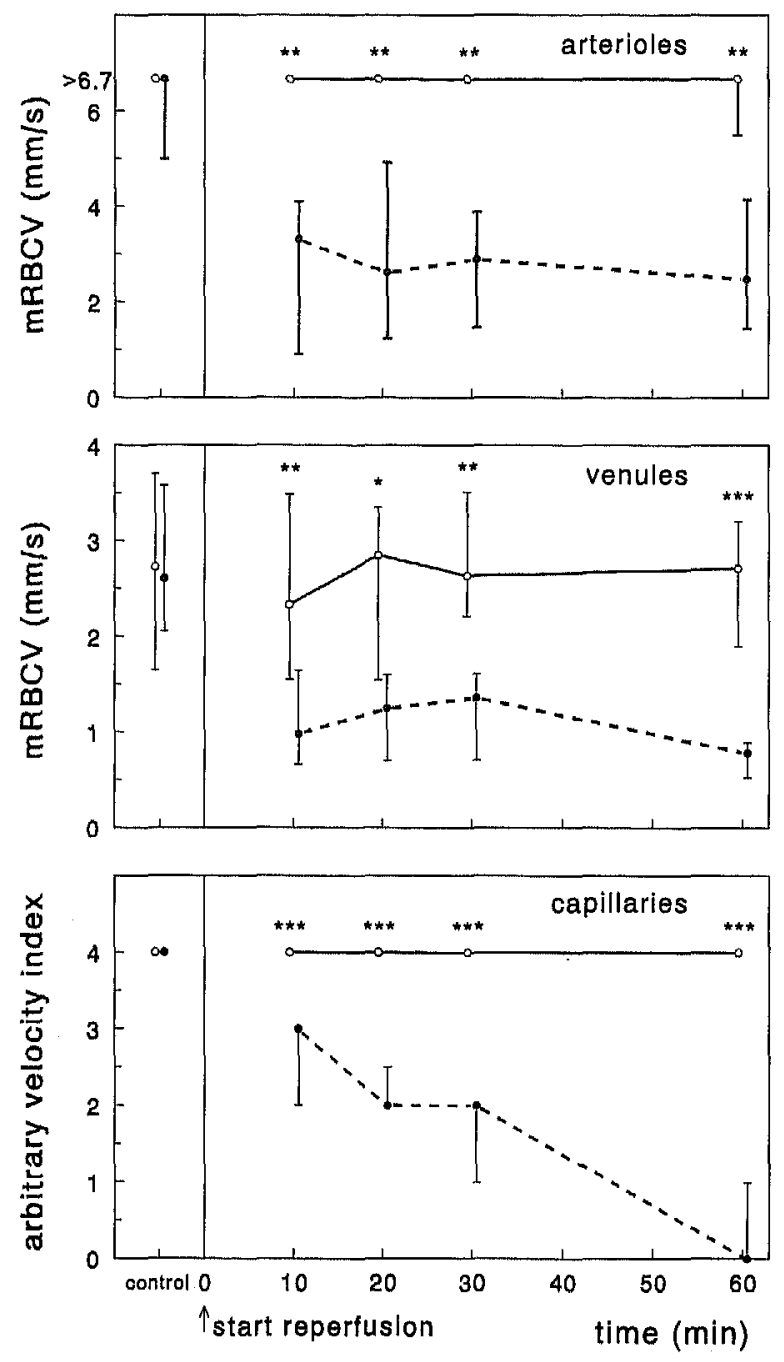

Figure 2: Mean red blood cell velocities (mRBCV) in arterioles (upper panel) and venules (middle panel) of the small bowel submucosa in the sham (solid line, o) and ischemia group (broken line, ${ }^{\bullet}$ ). In submucosal capillaries (lower panel), an arbitrary velocity index was determined. Medians with interquartile ranges (bars) are presented. The left side of the vertical line (start of reperfusion) represents the control period (baseline) before total warm ischemia (or sham). $* P<.05, * * P<.01$, $\star \star \star P<.001$ for ischemia vs. sham. 

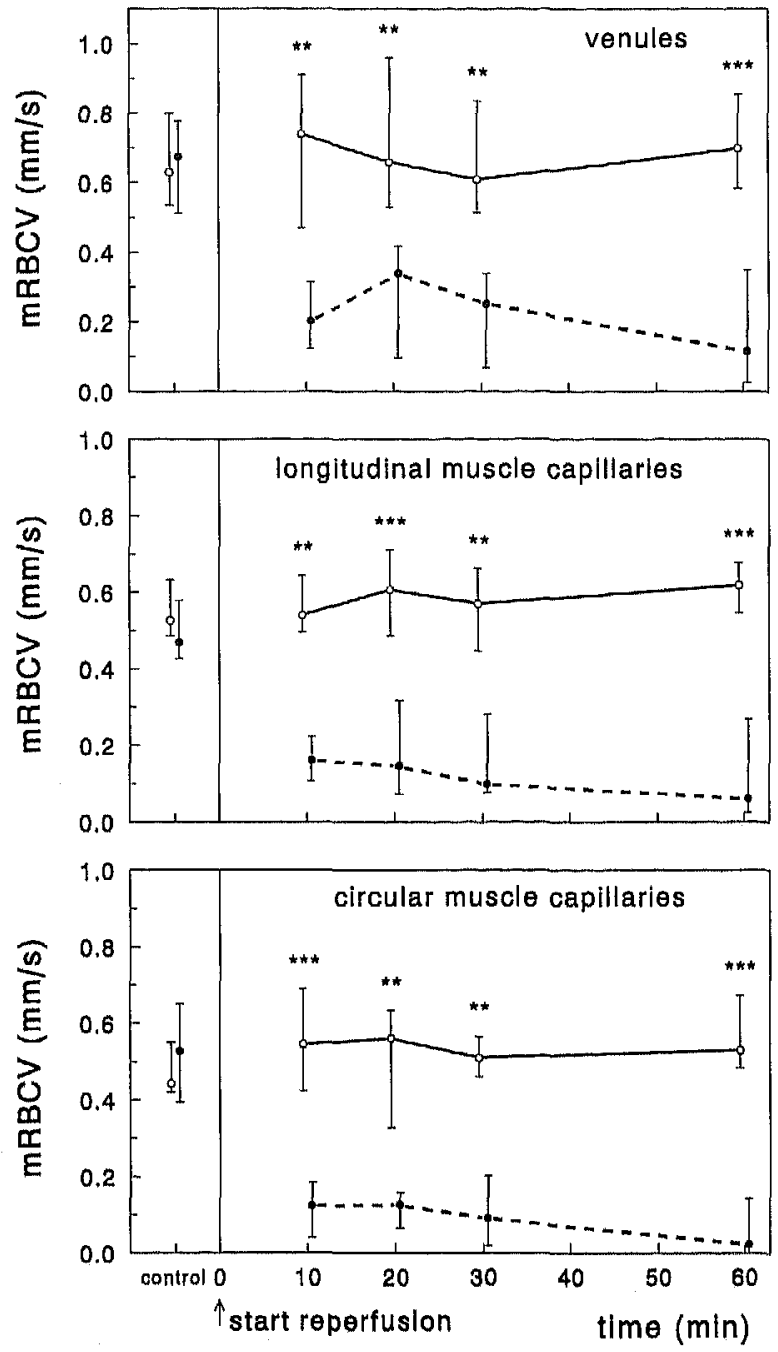

Figure 3: Mean red blood cell velocities (mRBCV) in venules between the muscle layers (upper panel), capillaries of the longitudinal muscle layer (middle panel), and capillaries of the circular muscle layer (lower panel) of the small bowel in the sham (solid line, 0 ) and ischemia group (broken line, $\bullet$ ). Medians with interquartile ranges (bars) are shown. The left side of the vertical line (start of reperfusion) represents the control period (baseline) before total warm ischemia (or sham), $* * P<.01, * * * P$ $<.001$ for ischemia vs. sham. 

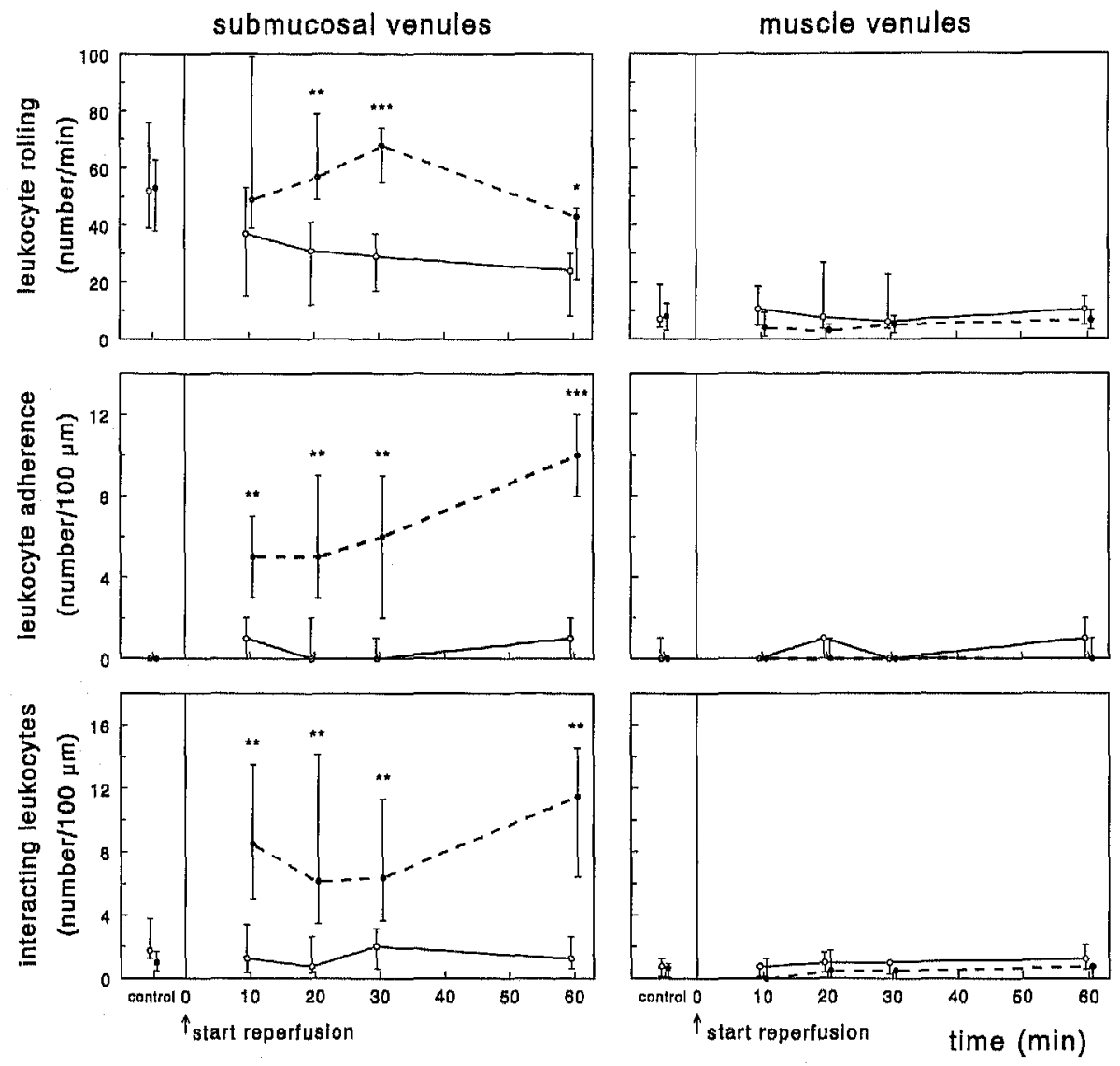

Figure 4: Effect of warm ischemia and subsequent reperfusion (broken line, $\bullet$ ) or sham (solid line, o) on leukocyte rolling (upper panels), leukocyte adherence (middle panels), and total number of leukocytes interacting with the vessel wall (lower panels) in venules of the small bowel submucosa (left column) and between the muscle layers (right column). Medians with interquartile ranges (bars) are presented. The left side of the vertical line (start of reperfusion) represents the control period (baseline) before total warm ischemia (or sham). $* P<.05, * * P<.01$, and $* * * P<.001$ for ischemia vs. sham. 
Histologic evaluation

I/R induced no histologic changes in liver, kidneys, lungs, heart, and gastrocnemius muscle. However, in the terminal ileum it clearly caused damage (Fig. 6); the median level of injury was 5.5 (range $4^{-6}$ ). This score indicates a total loss of villi, occasionally accompanied by crypt layer infarction. In the sham group, no changes were seen in any of the tissues investigated.

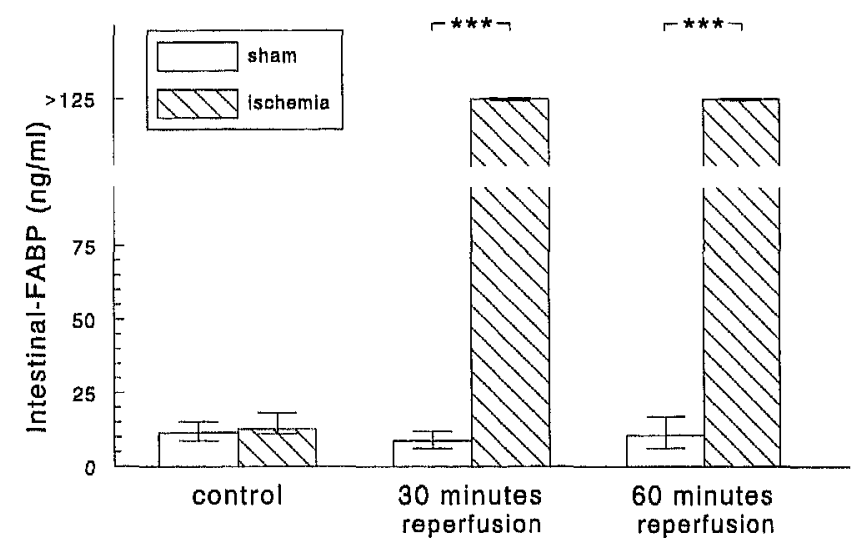

Figure 5: Median intestinal fatty acid binding protein (I-FABP) levels in serum at baseline (control) and at 30 and 60 minutes after the start of reperfusion in the ischemia and sham groups. Bars denote interquartile ranges. After ischemia, a large amount of I-FABP was released from the enterocytes, resulting in maximally detectable levels (i.e., $>125 \mathrm{ng} / \mathrm{mL}$ ). $* \star * P<.001$ for ischemia vs. sham.

\section{Discussion}

In this article, we present the first in vivo data with respect to the effects of total warm I/R of the gut on the microcirculation of different layers of the small bowel. Our findings in rats indicate that reperfusion after an ischemic period of 30 minutes produces significant microcirculatory impairment in all gut layers. Blood flow decreases significantly in both muscle layers and in the submucosa, whereas the level of leukocyte-vessel wail interactions increases in the submucosal venules but not in the venules between the muscle layers. At the same time, $I / R$ induces severe mucosal damage-a total loss of villi, occasionally accompanied by crypt layer infarction. The functional consequences are 
illustrated by the significant increase in I-FABP levels in the systemic circulation, indicating epithelial injury.

The most striking effect of $I / R$ is the reduction in red blood cell velocity both in the two muscle layers and in the submucosa, resulting in a greatly attenuated perfusion of the whole small bowel. This reduction was considerable early in the reperfusion period and became even more pronounced over time. One hour after the start of reperfusion, there was hardly any capillary flow left in both muscle layers and in the submucosa. At the same time, intestinal tissue was injured, but this injury was mostly restricted to the mucosa. One possible explanation for the fact that the mucosa was damaged, but no damage was found in the muscle layers, is that mucosal tissue is more vulnerable to flow attenuation than the gut muscle layers. A second possibility is that leukocyte-endothelial interactions also play a role, because these increased significantly in submucosal but not in muscle venules. The latter might seem to be inconsistent with the data of Kurtel et al,(22) who found higher myeloperoxidase levels in the muscle layers than in the mucosa or submucosa of the cat gut. However, this apparent inconsistency may be due to the differences in ischemia length (3 hours partial ischemia v5. 30 minutes total warm ischemia) and species in the studies. As discussed by Kurtel et al,(22) a preliminary study indicated that in hamsters, there is a different distribution in granulocytes adhering or extravasating after only 30 minutes of ischemia. In addition, muscle tissue is more resistant to ischemia than mucosa/submucosa.(23) Therefore, it is not surprising that a relatively short period ( 30 minutes) of ischemia did not induce an increase in leukocytevessel wall interactions in the muscle layers. It is possible that an ischemic period of 3 hours might do 50 .

The reason why total warm ischemia results in a permanent reduction of small bowel perfusion in all its layers is difficult to clarify. Microscopic examination of the SMA at the clamp site showed no irregularities that could have caused this. Further, there were no important differences in mean arterial pressure or heart rate between the two groups. Changes in microvascular diameters (i.e., arteriolar vasoconstriction) were not found either. Another mechanism that could have contributed to the decreased small bowel perfusion is an increase in flow resistance due to leukocyte-vessel wall interactions. However, although the total number of interacting leukocytes increased in the submucosal venules only, flow velocity decreased in the venules of all gut layers. Therefore, it seems unlikely that an increase in leukocyte-vessel wall interactions in venules played a decisive role in the reduction of small bowel perfusion. This still holds true despite the fact that the small muscle venules drain into the larger submucosal venules in which leukocyte-vessel wall interactions might be present as well, because at 
larger vessel diameters an influence of adhesive leukocytes on flow resistance becomes progressively smaller.(24)

Another explanation for the observed reduction of small bowel perfusion might be an I/R-induced activation of blood platelets. This notion is supported by a recent publication of Massberg et $a_{1}(25)$ who describe upregulation of platelet rolling in submucosal microvessels after an ischemic period. An increase in platelet-vessel wall interactions might be responsible for an increase in vascular resistance and, hence, might contribute to the reduction in small bowel perfusion. This possibility requires further investigation.
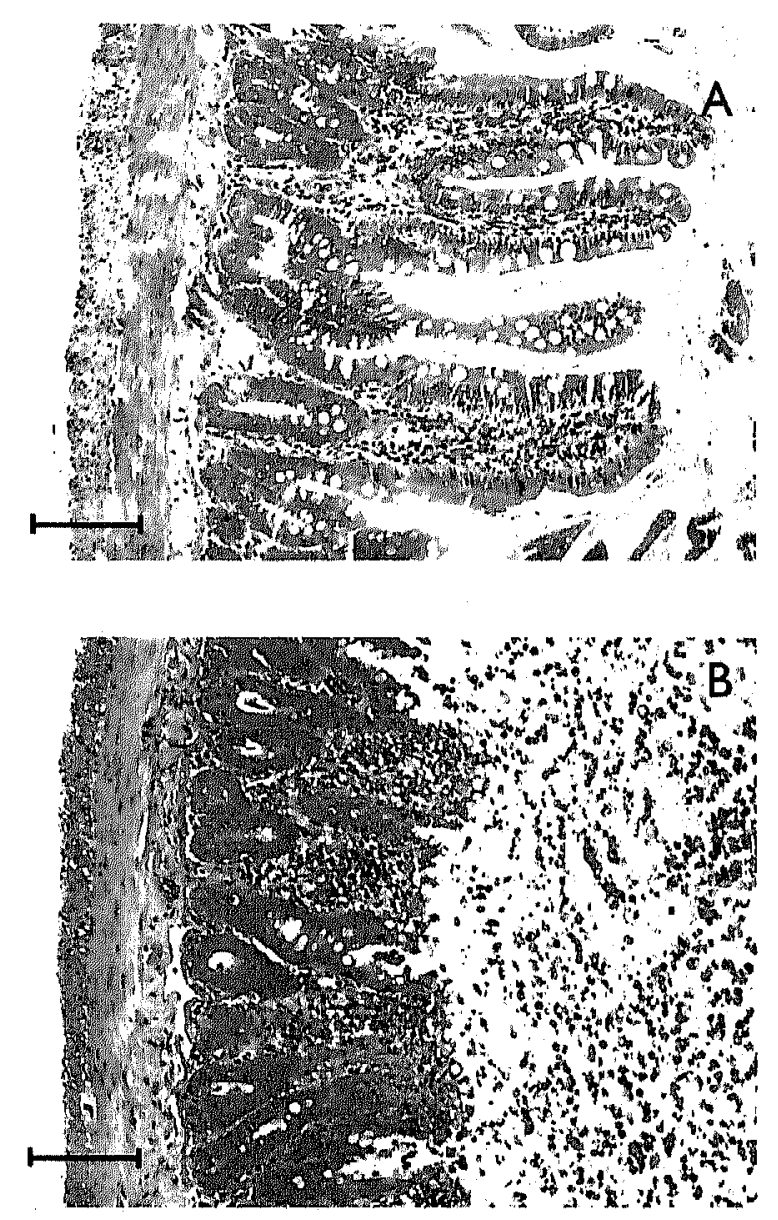

Figure 6: lleal histology after the sham procedure $(A)$ and 30 minutes of ischemia and 1 hour of reperfusion (B). In the sham group no injury was found, whereas in the ischemia group grade 5 injury was observed (complete loss of villi). Bars $=1.00 \mu \mathrm{m}$. 
Besides reduced perfusion, activated polymorphonuclear leukocytes may have contributed to $/ / R$-induced mucosal injury, among others, by the release of certain proteases and reactive oxygen metabolites that in turn may amplify the expression of adhesion molecules.(26) It has been shown that neutrophil depletion attenuates intestinal reperfusion injury in humans.(27) Before leukocytes can adhere to the venular wall and migrate into the postischemic tissue, they must marginate from the central bloodstream and roll along the vascular endothelium.(28) Therefore, leukocyte rolling along and adherence to the vascular wall are probably important steps in the development of leukocyte-mediated tissue injury. In the present study, both leukocyte rolling and adherence increased significantly after l/R. However, this phenomenon was restricted to the submucosal layer. The finding that the intestinal tissue damage was mainly restricted to the mucosa strongly suggests that leukocytes have contributed to the development of intestinal tissue injury.

Up to now, in vivo observation of microvessels in all layers of the small bowel has rarely been performed. This is the first study in which the effect of total warm I/R on small bowel microcirculation has been investigated so extensively. Two other intravital microscopic studies of the gut microcirculation concentrated on the effect of cold storage on microvascular reperfusion injury in transplanted small bowel isografts in rats. $(29 ; 30)$ Histologic evaluation in one of these studies was performed after different prolonged periods of cold storage and go minutes of reperfusion. After 6 hours of cold ischemia and reperfusion, only mild edema could be observed in the lamina propria. In fact, a 24 -hour period of cold preservation was needed to induce severe mucosal injury (i.e., completely denuded lamina propria).(30) In our model, the latter grade of tissue injury was achieved after only 30 minutes of total warm ischemia and 1 hour of reperfusion, indicating the relatively high level of destructiveness of total warm //R. The pathophysiologic mechanisms involved seem to be effectively inhibited by low temperatures.

In conclusion, a 30 -minute period of total warm ischemia of the rat intestine results in impaired perfusion of all small bowel layers. In contrast, leukocyte-vessel wall interactions increase only in the submucosal layer, not in the muscle layers, indicating that such interactions are not a decisive determinant of the impaired gut perfusion. In addition, it indicates that the early inflammatory response to $/ / R$ seems to be limited to the submucosa. The combination of microvascular effects due to $I / R$ in the submucosa may contribute to the severe mucosal tissue injury.

\section{Acknowledgements}

The authors thank Dick Slaaf for his advice and Sabrina van Velzen for her technical assistance.

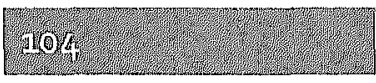




\section{References}

(1) Grant D, Wall W, Mimeault R, Zhong R, Ghent C, Garcia B, et al. Succesful smallbowel/liver transplantation. Lancet 1990;335:181-4.

(2) Grant D. Current results of intestinal transplantation. The International Intestinal Transplant Registry. Lancet 1996;347(9018):1801-3.

(3) Soong CV, Blair PH, Halliday MI, McCaigue MD, Hood JM, Rowlands BJ, et al. Bowel ischaemia and organ impairment in elective abdominal aortic aneurysm repair [see comments]. Br」 Surg 1994;81(7):965-8.

(4) Gennaro M, Ascer E, Matano R, Jacobowitz IJ, Cunningham JN, Jr., Uceda P. Acute mesenteric ischemia after cardiopulmonary bypass. Am J Surg 1993;166(2):231-6.

(5) Gutierrez G, Palizas F, Doglio G, Wainsztein N, Gallesio A, Pacin J, et al. Gastric intramucosal $\mathrm{pH}$ as a therapeutic index of tissue oxygenation in critically ill patients [see comments]. Lancet 1992 Jan 25;339(8787):195-9.

(6) Maynard N, Bihari D, Beale R, Smithies M, Baldock G, Mason R, et al. Assessment of splanchnic oxygenation by gastric tonometry in patients with acute circulatory failure [see comments]. JAMA 1993 Sep 8;270(10):1203-10.

(7) Klemm K, Moody FG. Regional intestinal blood flow and nitric oxide synthase inhibition during sepsis in the rat. Ann Surg $1998 \operatorname{Jan}_{i 2} 227(1): 126-33$.

(8) Nowicki PT, Nankervis CA. The role of the circulation in the pathogenesis of necrotizing enterocolitis. Clin Perinatol 1994;21(2):219-34.

(9) Hernandez LA, Grisham MB, Twohig B, Arfors KE, Harlan JM, Granger DN. Role of neutrophils in ischemia-reperfusion-induced microvascular injury. Am J Physiol 1987;253(3 Pt 2):H699-703.

(10) Fujimoto K, Price VH, Granger DN, Specian R, Bergstedt S, Tso P. Effect of ischemia-reperfusion on lipid digestion and absorption in rat intestine. Am J Physiol 1991;260:G595-602.

(11) Beuk RJ, Heineman E, Tangelder GJ, Kurvers HA, Bonke HJ, Oude Egbrink MG. Effects of different durations of total warm ischemia of the gut on rat mesenteric microcirculation. J Surg Res 1997 Novi73(1):14-23.

(12) Gollin G, Marks C, Marks WH. Intestinal fatty acid binding protein in serum and urine reflects early ischemic injury to the small bowel. Surgery 1993;113(5):545-51.

(13) Robinson JW, Mirkovitch $V$. The recovery of function and microcirculation in small intestinal loops following ischaemia. Gut 1972;13(10):784-9.

(14) Kanda T, Nakatomi $Y$, Ishikawa $H$, Hitomi M, Matsubara $Y$, Ono $T$, et al. Intestinal fatty acid-binding protein as a sensitive marker of intestinal ischemia. Dig Dis $\mathrm{Sci}$ 1992;37(9):1362-7. 
(15) Janssen GHGW Tangelder GJ, oude Egbrink MGA, Reneman RS. Different effects of anesthetics on spontaneous leukocyte rolling in rat skin. Int.J.Microcirc.Clin.Exp. 17, 305-313. 1997.

(16) Gore RW, Baldwin AL. Intestinal and mesenteric preparations for microvascular studies. In: Baker $\mathrm{CH}$, Nastuk WL, editors. Microcirculatory technology.Orlando: Academic Press, Inc.; 1986. p. 65-81.

(17) Bohlen HG, Gore RW. Preparation of rat intestinal muscle and mucosa for quantitative microcirculatory studies. Microvasc Res 1976 Jan;11(1):103-10.

(18) Intaglietta $M_{1}$ Tompkins WR. Microvascular measurements by video image shearing and splitting. Microvasc Res 1973;5(3):309-12.

(19) Tangelder GJ, Slaaf DW, Muijtjens AM, Arts T, oude Egbrink MGA, Reneman RS. Velocity profiles of blood platelets and red blood cells flowing in arterioles of the rabbit mesentery. Circ Res 1986 Nov;59(5):505-14.

(20) Gollin G, Marks WH. Elevation of circulating intestinal fatty acid binding protein in a luminal contents-initiated model of NEC. J Pediatr Surg 1993;28(3):367-70.

(21) Park PO, Haglund U, Bulkley GB, Falt K. The sequence of development of intestinal tissue injury after strangulation ischemia and reperfusion. Surgery 1990;107(5):574-80.

(22) Kurtel H, Tso P, Granger DN. Granulocyte accumulation in postischemic intestine: role of leukocyte adhesion glycoprotein $C_{11} / C_{18}$. Am J Physiol 1992;262:G87882.

(23) McCord JM. Oxygen-derived free radicals in postischemic tissue injury. $N$ Engl J Med $1985 ; 312(3): 159-63$.

(24) House SD, Lipowsky HH. In vivo determination of the force of leukocyteendothelium adhesion in the mesenteric microvasculature of the cat. Circ Res 1988;63:658-68.

(25) Massberg $S$, Enders $G$, Leiderer R, Eisenmenger $S$, Vestweber $D$, Krombach $F$, et al. Platelet-endothelial cell interactions during ischemia/reperfusion: the role of $\mathrm{P}$ selectin. Blood 1998 Jul 15;92(2):507-15.

(26) Inauen W, Suzuki M, Granger DN. Mechanisms of cellular injury: potential sources of oxygen free radicals in ischemia/reperfusion. Microcirc Endothelium Lymphatics 1989;5(3-5):143-55.

(27) Sisley AC, Desai T, Harig JM, Gewertz BL. Neutrophil depletion attenuates human intestinal reperfusion injury. J Surg Res 1994;57(1):192-6.

(28) Springer TA. Traffic signals for lymphocyte recirculation and leukocyte emigration: the multistep paradigm. Cell 1994;76(2):301-14. 


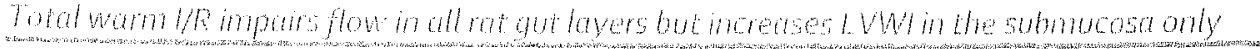

(29) Gonzalez AP, Sepulveda S, Massberg S, Baumeister R, Menger MD. In vivo fluorescence microscopy for the assessment of microvascular reperfusion injury in small bowel transplants in rats. Transplantation 1994;58:403-8.

(30) Massberg S, Gonzalez AP, Leiderer R, Menger MD, Messmer K. In vivo assessment of the influence of cold preservation time on microvascular reperfusion injury after experimental small bowel transplantation. Br.J.Surg. 85, 127-133. 1998. 


\section{Chapter 7}

Leukocyte and platelet adhesion in different layers of the small bowel during experimental total warm ischemia and reperfusion

Roland J. Beuk, Geert-Jan Tangelder, Ralph L.J.G. Maassen, Josine S.L.T. Quaedackers, Erik Heineman, and Mirjam G.A. oude Egbrink Based on: Britisch Journal of Surgery, 95, 2008: 1294-1304 


\section{Abstract}

Background: Ischemia and reperfusion (IR) of the small bowel is involved in many clinical conditions. A key component in IR-induced tissue damage is microvascular dysfunction. The aim was to investigate the role of leukocytes and platelets in capillary flow impediment and tissue damage.

Methods: Anaesthetized rats were subjected to $30 \mathrm{~min}$ warm ischemia of the small bowel, followed by $1 \mathrm{~h}$ reperfusion. To elucidate the influence of leukocytes on platelet adhesion, leukocyte-vessel wall interactions induced by IR were prevented by antiplatelet-activating factor (PAF) or anti-intercellular adhesion molecule (ICAM) 1. Intravital videomicroscopy was performed and tissue injury was evaluated histologically.

Results: In submucosal venules, $I R$ induced an increase in the median number of interacting leukocytes from 3 to 10 and 20 leukocytes per $100-\mu \mathrm{m}$ venule segment after 10 and $60 \mathrm{~min}$ reperfusion respectively. Anti-PAF or anti-ICAM-1 completely attenuated this increase, resulting in an eightfold improvement in submucosal capillary flow and reduced tissue injury. Shedding of villi no longer occurred. Platelet-vessel wall interactions occurred particularly in submucosal venules, but were not affected.

Conclusions: Small bowel IR initiated an inflammatory and thrombotic response in the submucosal layer only. Attenuation of leukocyte adhesion improved submucosal capillary perfusion, preventing shedding of mucosal villi. 


\section{Introduction}

Injury of the gut evoked by total warm ischemia and reperfusion (I/R) poses a problem in various clinical conditions, among others cardiac or aortic surgery(1-3) and small bowel transplantation(4-6). A key component in $\mathrm{l} / \mathrm{R}$ induced tissue damage is microvascular dysfunction(7), among others characterised by a decrease in capillary flow and an increase in leukocyte adhesion(8). In addition, increased platelet-vessel wall and plateletleukocyte interactions have been shown as well(9-11), which may also contribute to intestinal tissue damage.

Mutual interactions between the various microvascular impairments in the small bowel and their relative contribution to the decrease in capillary flow and the resulting reperfusion damage have not been elucidated so far. Activated and adhering leukocytes can directly impair capillary flow, which effect may be exaggerated by local platelet accumulation(11). in addition, activated leukocytes and platelets release oxygen radicals and certain proteases(12), which will influence tissue perfusion and integrity. Up to now, most studies performed on the (microvascular) consequences of intestinal I/R applied partial, and not total ischemia. Comparison indicates that the level of ischemia applied (partial or total ischemia) is an important, or maybe even the most important determinant of the outcome. In rats, a period of total warm ischemia of the small bowel of only $45-60$ min yields 90-100\% mortality $(13 ; 14)$, while similar periods of partial ischemia $(80 \%)$, as induced by occlusion of the superior mesenteric artery only, are tolerated significantly better(14). In addition, existing data suggest that total warm ischemia initiates different, more intense inflammatory and thrombotic reactions than partial ischemia $(9 ; 10)$. To which extent these more intense reactions contribute to the serious tissue damage after relatively short periods of total warm ischemia, i.e. the shedding of mucosal villi(8), is still largely unknown.

The aim of the present study was to investigate the role of leukocytes and platelets in the severe impairment of capillary flow throughout the small bowel wall and the serious tissue damage in case of total warm ischemia and reperfusion. To this purpose, we determined flow and behaviour of leukocytes and platelets in capillaries as well as arterioles and venules of the various bowel layers. To elucidate the relative contribution of leukocytes and their influence on platelet adhesion, two strategies were used to prevent the increase in leukocyte-vessel wall interactions as induced by $1 / R$. Firstly, a potent PAF (platelet activating factor) antagonist was applied and, secondly, a monoclonal antibody ( $\mathrm{MAb}$ ) against ICAM-1 was used. From earlier studies it is known that PAF is an important mediator activating leukocytes $(7 ; 15 ; 16)$, while ICAM-1 is involved in leukocyte adhesion. Moreover, the latter molecule has recently been implicated to play a role in leukocyte-dependent platelet adhesion(11). The study was 
performed using a well-established rat model of total warm intestinal $I / R$, which allows intravital microscopic observation of microvessels in all intestinal layers $\left(8_{i} 13\right)$.

\section{Methods}

\section{Animal preparation}

All procedures were reviewed and approved by the local ethical committee on the use of laboratory animals. Twenty-seven male Lewis rats with a mean weight of $270 \mathrm{~g}$ (range: 250-300 g) were used. Anaesthesia was achieved and maintained by inhalation of halothane in a mixture of $0.5 \mathrm{~L}$ air and $0.6 \mathrm{~L}$ oxygen per minute. Redundant and expirated halothane was removed by suction.

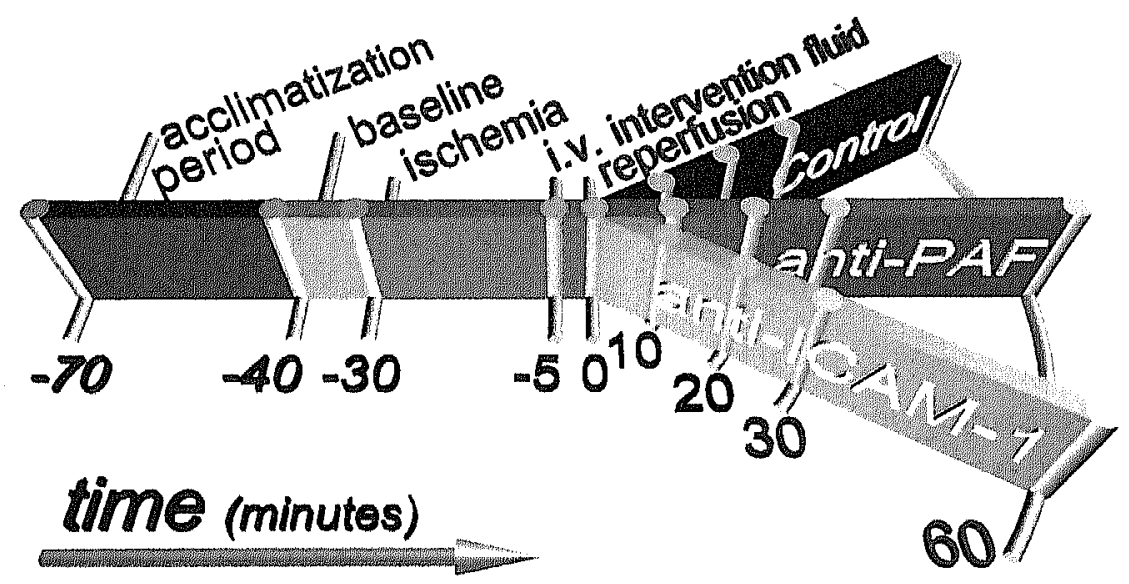

Figure 1: Experimental protocol. After preparation and positioning of the distal ileum segment under the microscope, the tissue was allowed to stabilise for 30 minutes (acclimatisation period) before baseline observations started. Clamping of the superior mesenteric artery evoked the ischemic period of 30 minutes. Five minutes before start of reperfusion the intervention fluid (vehicle, PAF- or ICAM-1antagonist) was administered intravenously. After start of reperfusion ( $t=0)$ images from all selected vessels were recorded in all three groups at 10, 20, 30 and 60 minutes. 
A catheter (PE 10) was placed in the right femoral artery to monitor arterial blood pressure and heart rate using a Uniflow external pressure transducer (Baxter, Santa Ana, (A, USA). This catheter was continuously perfused with physiological saline $(2 \mathrm{~m} / \mathrm{h})$ to prevent occlusion. The right femoral vein was cannulated $\left(\mathrm{PE}_{10}\right)$ for administration of a fluorescent dye (see below) to label leukocytes and platelets, and of experimentally used substances. Throughout the experiments the body temperature was kept at $37^{\circ} \mathrm{C}$, using an infrared heating lamp controlled by a thermoanalyser system connected to a rectal probe.

After a midline laparotomy, the superior mesenteric artery was identified, dissected, and marked by a vessel loop. The inferior mesenteric artery was ligated (Ethicon vicryl 3o). Subsequently, a longitudinal right flank incision was made to exteriorise a segment of the distal ileum. By locally injecting $0.5 \mathrm{ml}$ Imodium $(0.2 \mathrm{mg} / \mathrm{ml}$; Janssen Pharmaceutica B.V., Tilburg, the Netherlands) into the ileum peristalsis was suppressed. The ileum was then carefully positioned on an electrically heated plateau $\left(37^{\circ} \mathrm{C}\right)$ of an intravital microscope (see below) and continuously superfused with a buffered Tyrode's solution $\left(37^{\circ} \mathrm{C}, \mathrm{pH} 7.35\right.$ to 7.40$)$, that was bubbled with a mixture of $\mathrm{N}_{2}(95 \%)$ and $\mathrm{CO}_{2}(5 \%)$. The part of the ileum surrounding the observation area was kept moist with overlying wet gauses. Peristalsis was further decreased by positioning a multiple tip catheter (PE 10) parallel to the exteriorised ileum, that was continuously perfused with a solution containing Imodium (20\%) and isoproterenol hydrochloride ( $1 \mathrm{mg} / \mathrm{L}$ saline). This isoproterenol hydrochloride concentration was less than concentrations that result in vasoconstriction of gut microvessels (17). Finally, a thin cover glass was gently placed on top of the ileum to reduce microperistalsis. During the entire procedure, the utmost precaution was taken not to manipulate the abdominal contents any more than strictly necessary. Finally, the tissue was allowed to stabilise for 30 minutes before microscopic observations started. At the end of the last observation period, the animals were sacrificed. Subsequently, organs were harvested for histology (see below).

\section{Intravital (fluorescence) video microscopy}

Observations were performed under epi-illumination with a Leitz intravital microscope adapted to telescopic imaging and carrying a $1.25 \mathrm{x}$ Leitz Ploemopak 2.2 for interchangeable filter sets. A Leitz $\times 25$ salt-water immersion objective (numerical aperture 0.6 ) and a $100 \mathrm{~W}$ mercury lamp were used. Bright-field microscopy was performed with a Leitz Pol-cube, consisting of a $50 \%$ mirror in $45^{\circ}$ position with respect to the optical axis of the microscope, a polariser in the illumination pathway, and an analyser in the observation pathway. For fluorescence microscopy we used a Leitz N2.1 filter set (excitation filter BP 515-560, dichroic mirror RHP 580 and barrier filter LP 580 ). 
Images were projected on a charge-coupled device (CCD) camera (Hamamatsu Photonics, Hamamatsu-city, Japan), displayed on a monitor screen, and recorded for offline analysis on videotape (5-VHS NV-FS200 HQ, Panasonic, Osaka, Japan). The final optical magnification at the front plane of the camera was $\times 31.25$. In all experiments the midplane of a vessel was kept in focus.

In each experiment we observed 6 categories of vessels positioned in the different layers of the small bowel, as illustrated before( 8$)$. In short, we observed submucosal arterioles, capillaries and postcapillary venules, as well as capillaries in both the longitudinal and circular muscle layers and their collecting postcapillary venules. To visualise leukocytes and platelets, these cells were labelled in vivo with the fluorescent dye Rhodamin-6G (Mw 479, Sigma Chemical Co., St. Louis, U.S.A.). This dye (0.2 ml; I $\mathrm{mg} / \mathrm{ml}$ ) was administered intravenously before recordings started, at baseline (before the induction of ischemia) and at 10 and 60 minutes after start of reperfusion.

\section{Experimental protocol}

Rats were divided randomly in 3 groups (figure 1 ): an l/R control group (control; $n=7$ ), an I/R group treated with a PAF-antagonist (see below; anti-PAF; $n=8$ ), and an $1 / R$ group treated with a monoclonal antibody $(\mathrm{mAb}$ ) against ICAM-1 (see below; anti-ICAM-1; $n=9$ ).

As PAF-antagonist we used TCV-309 (3-bromo-5-[N-phenyl-N-[2-[2- (1,2,3,4tetrahydro-2-isoquinolycarbonyloxy)ethyl] carbamoyl]ethyl] carbamoyl]-1propylpyridinium nitrate]), which is a very potent chemically produced compound (Chemical Industries Ltd., Osaka, Japan; kindly provided by Prof. Dr. J.W. Greve, Department of Surgery, Maastricht University, the Netherlands).(18) As mAb against ICAM-1, we employed the mouse anti-rat ICAM-1 immunoglobulin $G_{1}{ }_{1} A 29$ (kindly provided by Prof. dr. D.N. Granger, Department of Molecular and Cellular Physiology, Louisiana State University Sciences Center, Shreveport, LA, USA). To control for non* specific effects of this antibody, 3 additional rats were treated with a mouse anti-human immunoglobulin $G_{1}$ ENA-1 (kindly provided by Prof. dr. W.A. Buurman, Department of Surgery, Maastricht University, the Netherlands); data obtained from these rats were similar to those obtained in the control group.

In all experiments total warm ischemia was induced by clamping the superior mesenteric artery. The clamp was released after 30 minutes, initiating the reperfusion phase. Just before start of reperfusion, the vehicle (saline), TVC 309 (1 mg/kg), 1 A29 (2 $\mathrm{mg} / \mathrm{kg}$ ) or ENA-1 (2 mg/ $\mathrm{kg}$ ) was administered intravenously in a volume of $1.35 \mathrm{ml} / \mathrm{kg}$. Before each experiment we randomised the order of microscopical observation of the different vessel categories. Images from all selected vessels were recorded on videotape 
before the induction of ischemia (baseline), as well as around 10, 20,30, and 60 minutes after start of reperfusion. Each recording lasted at least 1 minute.

Both at baseline and 60 minutes after start of reperfusion arterial blood samples were taken to determine the systemic leukocyte count in a Bürker chamber $(20 \mu \mathrm{L}$ blood collected in $20 \mu \mathrm{L}$ Türk's solution), and hematocrit ( $20 \mu \mathrm{L}$ blood) by centrifugation.

\section{Off-line analysis of microvascular parameters}

Local fluid dynamic conditions as well as leukocyte-vessel wall interactions were analysed off-line as described before(8). In short, mean red blood cell velocities (mRBCV) in the vessels of the muscle layers were measured with a flying spot device. In submucosal venules and arterioles the centreline velocity was determined by frame-to-frame analysis using the fastest passing fluorescent leukocytes as markers. This centreline velocity was divided by 1.5 to calculate mRBCV.(19) In submucosal capillaries RBCV could not be measured on an ordinal scale, but was scored using an arbitrary velocity index, where 0 ) designated a complete flow stop, 1) individual cells visible but slow flowing, 2) individual cells visible but fast flowing, 3) cell images appearing as interrupted streaks, and 4) cell images seen as solid streaks.

Leukocyte-vessel wall interactions were observed in muscular and submucosal venules. Quantification of leukocyte rolling was performed by counting the number of rolling leukocytes per minute that pass an imaginary line perpendicular to the venular axis. The number of adherent leukocytes was determined in a $100 \mu \mathrm{m}$ segment of the venule. Leukocytes were considered to be firmly adherent (sticking) when they remained stationary for $\geq 30 \mathrm{~s}$. The total number of leukocytes interacting with the vessel wall, which is an important parameter to assess possible leukocyte mediated changes in vascular resistance, was determined by counting, in a frozen video frame, the total number of rolling and adhering leukocytes present within a $100 \mu \mathrm{m}$ vessel segment. At each time point this count was performed in 4 randomly chosen video frames, after which data were averaged.

Platelet-vessel wall interactions were quantified for 1 minute in a $100 \mu \mathrm{m}$ segment of all microvessels, using an arbitrary scale (o: no platelet-vessel wall interactions, 1: $\leq 5$ individual platelets interacting with the wall, $2:>5$ individual platelets interacting with the wall, 3: one platelet aggregate attaching to the wall, 4: several aggregates attaching to the wall, and 5 : embolising aggregates). Platelets were considered to 'interact' with the vessel wall from the moment their velocity decreased at least an order of magnitude as compared to that of the free flowing blood cells, or when their velocity decreased to zero. Interacting leukocytes and platelets could be discriminated because of their difference in size. 

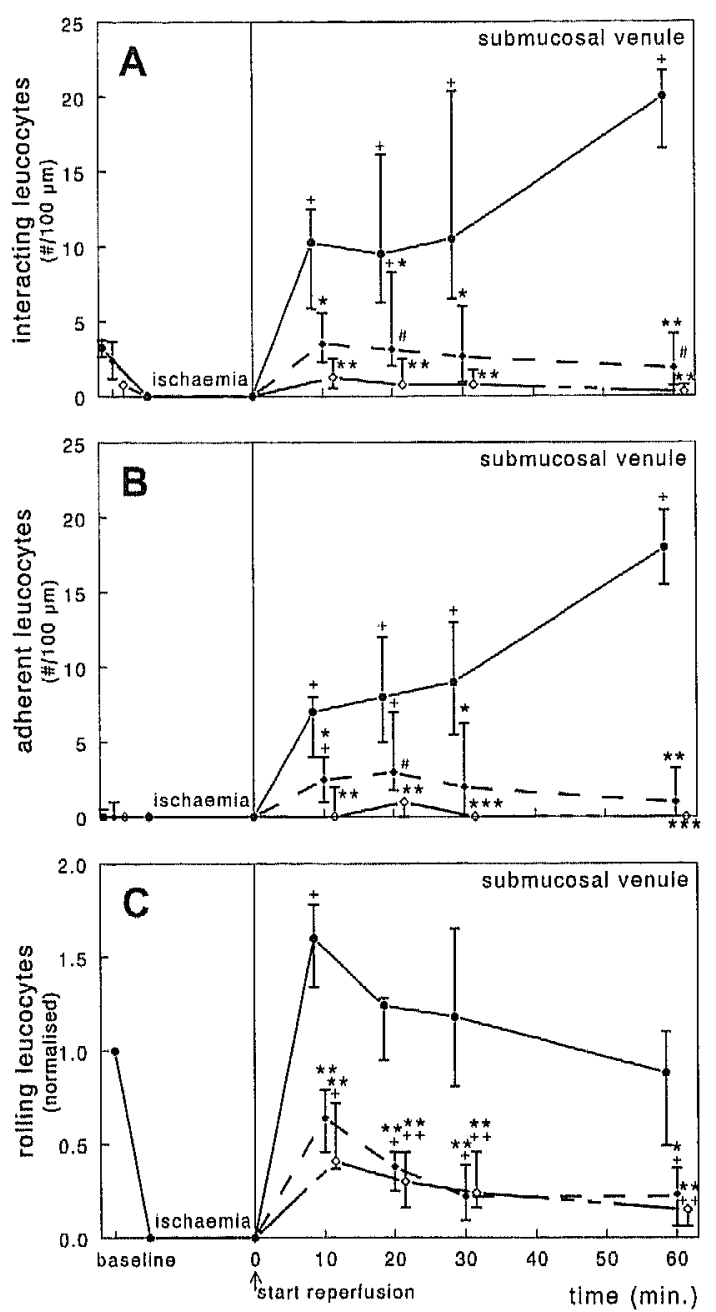

Figure 2: Leukocyte-vessel wall interactions in submucosal venules in the control $(-, \bullet)$, anti-PAF $(-\cdots$,$) and anti-ICAM-1 (-\cdots, 0)$ group, before (baseline) and after 30 minutes of total, warm ischemia of the small bowel. (A) Total number of leukocytes interacting with the vessel wall, (B) level of leukocyte adherence, and (C) level of leukocyte rolling normalised to baseline values (medians per minute: control: 27, anti-PAF: 39, anti-ICAM-1: 46). Medians and interquartile ranges are presented. ${ }^{*} p<0.05,{ }^{++} p<0.01$ as compared to baseline ${ }_{i}{ }^{*} p<0.05, * * p<0.01, * * *$ $p<0.001$ as compared to control; ${ }^{*} p<0.05$ anti-PAF versus anti-ICAM-1. 


\section{Histology}

At the end of the experiments the rats were sacrificed after which the clamp site of the superior mesenteric artery, the terminal ileum, liver, lungs, heart, and left gastrocnemius muscle were taken out and immediately fixed in 1.0\% formaldehyde-saline solution. The fixed tissue was embedded in paraffin, sectioned in $4 \mu \mathrm{m}$ slides, and stained with haematoxylin and eosin (HE). The degree of intestinal injury was evaluated according to the combined grading system of Chiu and Park (as described in (20)). Grade 0 is defined as normal mucosa. Grades 1 to 5 indicate increasing degrees of villous damage: grade 1) subepithelial space at the tips of the villi, grade 2) more extended subepithelial space, grade 3) massive epithelial lifting down the sides of the villi, grade 4) villi denuded of epithelium, and grade 5) loss of villi themselves. In grade 6) the intestinal crypt layer is also affected and in grade 7) transmucosal infarction is present. Finally, grade 8) represents transmural infarction.

\section{Statistics}

The number of animals needed per experimental group was determined with the use of the 'Power and Sample Size Program' by Dupont and Plummer (http://biostat.mc.vanderbilt.edu/twiki/bin/view/Main/PowerSampleSize). All data were independently quantified by two investigators and the average was taken. Because of their asymmetrical distribution, most data are presented as medians with interquartile ranges. To enable comparison between groups, some data were normalised to their preischemic baseline values. The Friedman Two-Way Anova and the Wilcoxon signed ranks test were used to test changes within one group for their statistical significance. The Mann-Whitney $U$ test was used to compare data between groups at each time point. Finally, the Spearman rank correlation test $\left(r_{s}\right)$ was used to test the significance of correlations between histological injury and in vivo parameters. These nonparametric tests also allow handling of categorical data and of values that exceed a measuring limit. $P<0.05$ was considered to be statistically significant.

\section{Results}

Because the inferior mesenteric artery was ligated, occlusion of the superior mesenteric artery immediately resulted in a complete flow stop within the various layers of the small bowel, as verified through the microscope. All rats survived throughout the observation period and were sacrificed after $1 \mathrm{~h}$ of reperfusion. Histological examination of the superior mesenteric artery at the clamp site did not show any sign of obstruction (i.e., thrombus formation) that could have reduced blood flow to the small bowel during the reperfusion phase. 
Table 1: Baseline mean red blood cell velocities ( $m R B C V$ ) in the six vessel categories

\begin{tabular}{|c|c|c|c|}
\hline \multirow[b]{2}{*}{ Vessel type } & \multirow[b]{2}{*}{ Group } & \multicolumn{2}{|c|}{ Mean red blood cel velocity } \\
\hline & & Group median & Interquartiles \\
\hline Submucosal arteriole & Control & $>6.7$ & $>6.7->6.7$ \\
\hline \multirow[t]{2}{*}{$(\mathrm{mm} / \mathrm{s})$} & Anti-PAF & $5 \cdot 7$ & $2.6->6.7$ \\
\hline & Anti-ICAM-1 & $>6.7$ & $4.6->6.7$ \\
\hline Submucosal venule & Control & 3.4 & $3.2-4.0$ \\
\hline \multirow[t]{2}{*}{$(\mathrm{mm} / \mathrm{s})$} & Anti-PAF & 3.0 & $2.8-3 \cdot 3$ \\
\hline & Anti-ICAM-1 & 2.8 & $2.5-3.2$ \\
\hline Submucosal capillaries & Control & 4 & $4-4$ \\
\hline \multirow[t]{2}{*}{ (arbitrary velocity index; scale 0-4) } & Anti-PAF & 4 & $3-4$ \\
\hline & Anti-ICAM-1 & 4 & $4-4$ \\
\hline Muscle venule & Control & 1.7 & $1.3-1.9$ \\
\hline \multirow[t]{2}{*}{$(\mathrm{mm} / \mathrm{s})$} & Anti-PAF & 0.9 & $0.8-1.6$ \\
\hline & Anti-ICAM-1 & 1.8 & $1.2-1.9$ \\
\hline Longitudinal muscle layer capillaries & Control & 1.5 & $0.9-1.8$ \\
\hline \multirow[t]{2}{*}{$(\mathrm{mm} / \mathrm{s})$} & Anti-PAF & 0.7 & $0.6-1.0$ \\
\hline & Anti-ICAM-1 & 0.9 & $0.6-1.1$ \\
\hline \multirow{3}{*}{$\begin{array}{l}\text { Circular muscle layer capillaries } \\
(\mathrm{mm} / \mathrm{s})\end{array}$} & Control & 1.2 & $1.0-1.3$ \\
\hline & Anti-PAF & 0.5 & $0.4-0.7$ \\
\hline & Anti-ICAM-1 & 0.8 & $0.5-1.0$ \\
\hline
\end{tabular}

\section{Leukocyte-vessel wall interactions}

Intervention with both anti-PAF and anti-ICAM-1 were successful in attenuating the increase in leukocyte-vessel wall interactions in the submucosal venules during reperfusion after 30 minutes of total, warm ischemia of the small bowel (Figure 2). The significant rise in total level of interacting leukocytes observed in the control group (Figure $2 \mathrm{~A}$ ) predominantly reflected an increase in leukocyte adhesion (Figure 2B), while the number of rolling leukocytes was increased during the first 10 minutes of reperfusion only (Figure $2 \mathrm{C}$ ). Both anti-PAF and anti-ICAM-1 intervention almost completely attenuated the increase in leukocyte adhesion during the entire reperfusion phase as well as the early increase in rolling; thereafter, rolling even remained below baseline level.

In venules between the muscle layers, the level of leukocyte-vessel wall interactions was relatively low at baseline and not influenced by reperfusion after 30 minutes of total, 
warm ischemia (baseline values: 1 interacting and o adhering cells/100 $\mu \mathrm{m}$ vessel length, and 7 rolling cells/min). Neither anti-PAF nor anti-ICAM-1 intervention had any effect on these low values. No leukocyte-vessel wall interactions were observed in small bowel capillaries or arterioles in any of the experimental groups.

\section{Local fluid dynamic parameters}

Figure 3 presents the changes in mean red blood cell velocities (RBCV) during reperfusion and the effects of anti-PAF and anti-ICAM-1 intervention; all RBCVs were normalised to baseline (see Table 1 for baseline values). During the first 20 minutes of reperfusion, flow velocities recovered only partly in all investigated vessels of the control rats. No further recovery was observed during the remaining reperfusion period: RBCV stayed at the same level in most vessels, but decreased clearly in the submucosal capillaries. Intervention with both anti-PAF and anti-ICAM-1 prevented this further decline in submucosal capillary reperfusion (Figure ${ }_{3}$ lower panel left column). However, both interventions did not clearly improve reperfusion in the submucosal arterioles and venules. RBCV in the submucosal capillaries correlated negatively with the number of adherent leukocytes $\left(r_{5}=-0.283, p<0.01\right)$ and the total number of interacting leukocytes in the submucosal venules $\left(r_{s}=-0.22, p<0.05\right)$, but not with the number of rolling leukocytes.

In the muscle layers (Figure 3, right column), recovery of capillary perfusion was increased by anti-PAF intervention, albeit mostly at start of reperfusion. A similar effect was apparent in the venules between the muscle layers. Intervention with anti-ICAM-1 was less effective.

Vascular diameters were not influenced by ischemia and reperfusion in any of the experimental groups (baseline medians: submucosal arterioles $28-42 \mu \mathrm{m}$ and venules 36 $41 \mu \mathrm{m}$; muscle venules $14-18 \mu \mathrm{m}$; capillaries 3-5 $\mu \mathrm{m}$ ).

\section{Platelet-vessel wall interactions}

Neither anti-PAF nor anti-ICAM- 1 had any effect on levels of platelet-vessel wall interactions (Figure 4 ). Following release of the vessel clamp, these interactions increased especially in the submucosal venules of all groups (Figure $4 A$ ), and to a lesser extent in the submucosal arterioles (Figure $4 \mathrm{~B}$ ), but not in the venules between the muscle layers (Figure $4 \mathrm{C}$ ). Embolising platelet aggregates during reperfusion were only occasionally observed in the submucosal venules (Figure $4 \mathrm{D}$ ). 

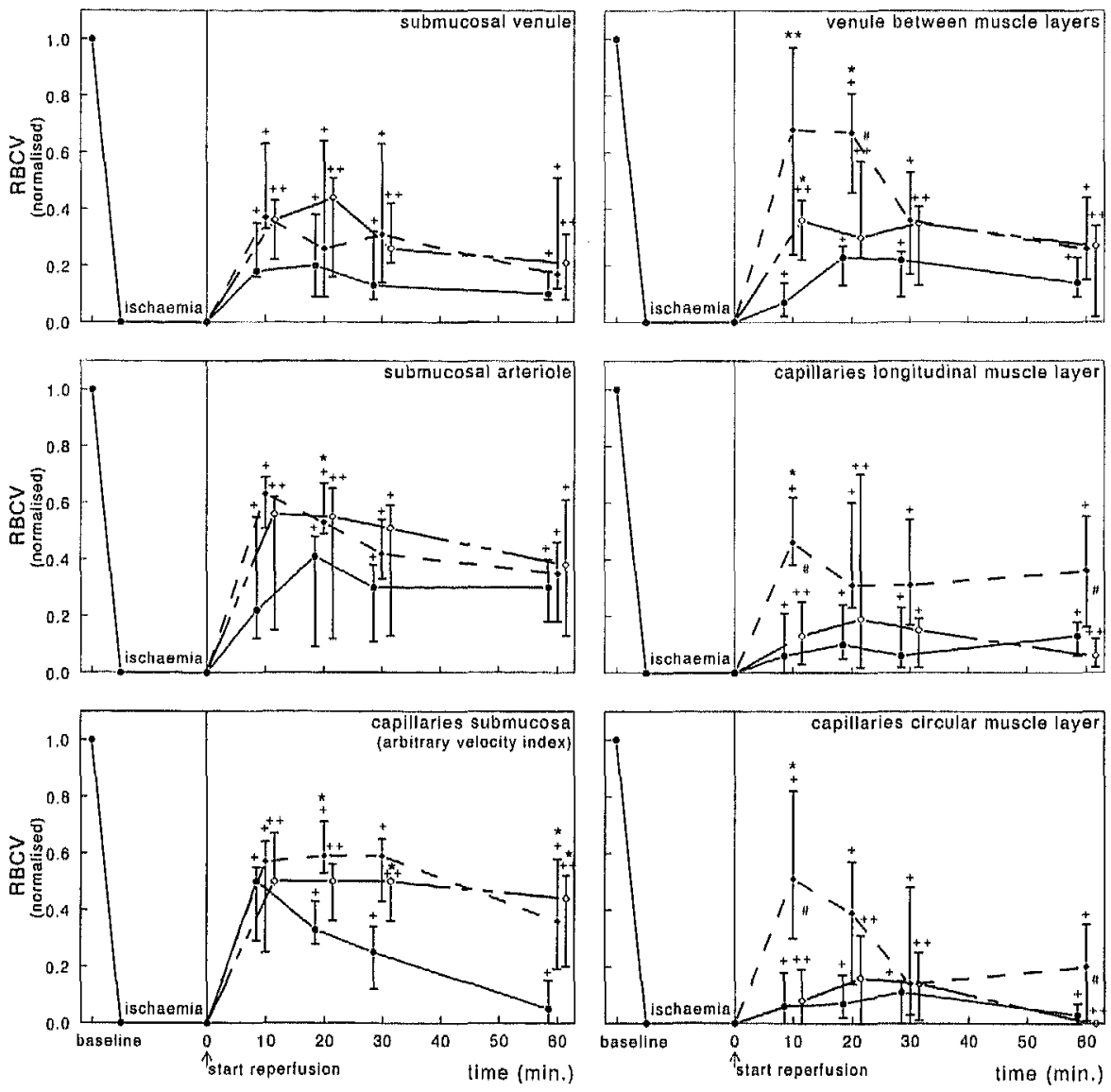

Figure 3: Changes in mean red blood cell velocity (RBCV) after 30 minutes of total, warm ischemia of the small bowel in vessels of the submucosa (left column) and muscle layers (right column) in the control $(-, \bullet)$, anti-PAF $(-,-\bullet)$ and antiICAM-1 group (- - , 0). All data are normalised to baseline values (see Table 1 ), the latter being 1.0 in this figure. Medians and interquartile ranges are presented.

${ }^{+} p<0.05{ }_{1}{ }^{++} p<0.01$ as compared to baseline; ${ }^{*} p<0.05, * * p<0.01$ as compared to controli $_{i}^{\#} p<0.05$ anti-PAF versus anti-ICAM-1. 

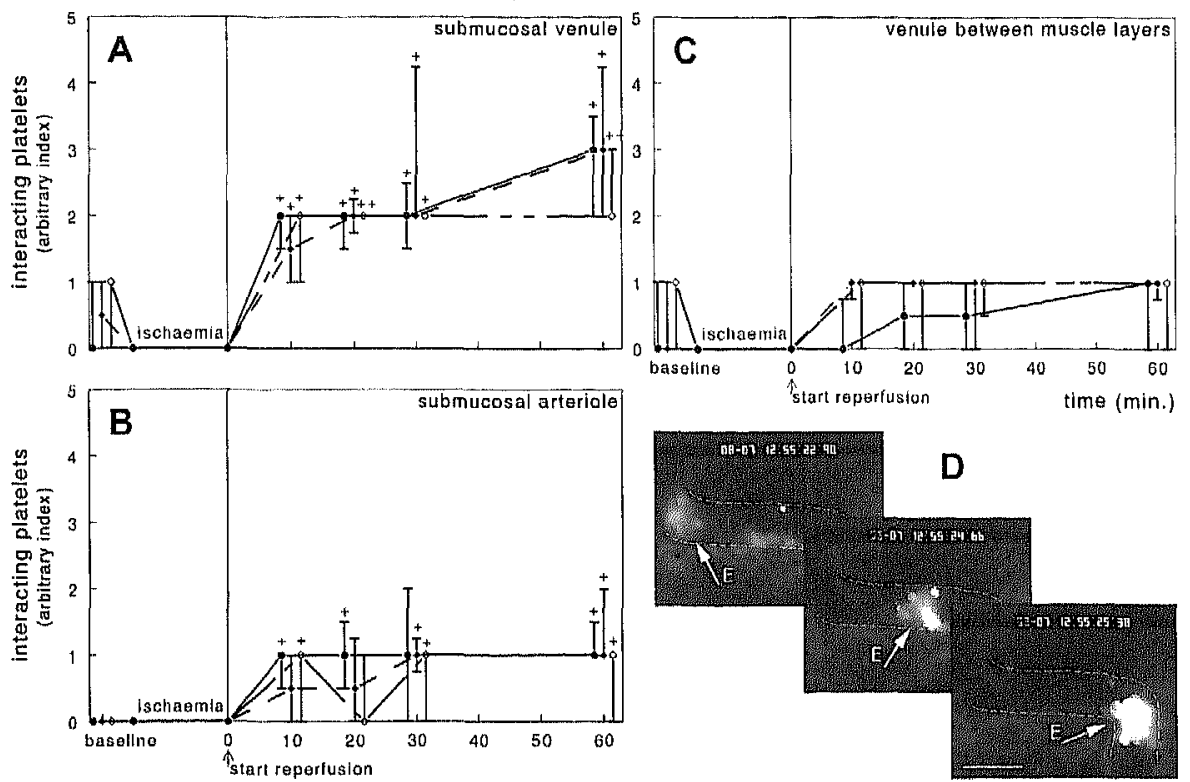

Figure $k_{p}$ "Platelet-vessel wall interactions in submucosal venules (A), submucosal arterioles $(B)$ and venules between muscle layers $(C)$ in the control $(-, \bullet)$, anti-PAF $(-\cdots$,$) and anti-ICAM-1 (-\cdots, 0)$ group, before (baseline) and after 30 minutes of total, warm ischemia of the small bowel. The level of platelet-vessel wall interactions was determined using an arbitrary scale (see text). Medians and interquartile ranges are presented. ${ }^{+} p<0.05,{ }^{++} p<0.01$ as compared to baseline.

$D$ : Series of three subsequent intravital microscopic images, showing a large, embolising platelet aggregate $(E)$ passing within about $2.5 \mathrm{~s}$ through a submucosal venule during reperfusion. Bar indicates $50 \mu \mathrm{m}$.

\section{Histology}

Both anti-PAF and anti-ICAM-1 intervention resulted in significant reduction of the tissue injury that was seen in the control group. Whereas ischemia and reperfusion resulted in loss of villi in the terminal ileum (injury grade 5 ; Figure 5), both interventions limited the intestinal villous damage to subepithelial space enlargement only (injury grade 2). In none of the groups histological changes in liver, kidneys, lungs, heart, and gastrocnemius muscle were observed. The degree of intestinal injury correlated positively with submucosal leukocyte-vessel wall interactions (rolling: $r_{5}=0.475, p<0.001$; adhesion: $r_{5}=$ 
$0.401, p<0.001$; total level of interaction: $r_{5}=0.438, p<0.001$ ), whereas it correlated inversely with submucosal capillary flow $\left(r_{s}=-0.450, p<0.001\right)$.

\section{Systemic parameters}

Neither systemic leukocyte count nor hematocrit was significantly affected during any of the experimental protocols and remained on average between $3 \cdot 6 \cdot 10^{6}$ leukocytes $/ \mathrm{ml}$ and $44-47 \%$, respectively.

At baseline, mean arterial pressure (MAP) and heart rate (HR) were similar in all groups, with median values around $85 \mathrm{mmHg}$ and $287 \mathrm{bpm}$, respectively. Immediately after induction of ischemia, MAP increased significantly to about $95 \mathrm{mmHg}$, while it dropped to its baseline value towards the end of the ischemic period. HR was not affected during ischemia.

One minute after start of reperfusion, MAP dropped to about $50 \mathrm{mmHg}$ and after 10 minutes increased to about $60 \mathrm{mmHg}$, staying at this level, with no differences between groups. At the same time, HR increased gradually and significantly to 317 and $350 \mathrm{bpm}$ at 60 minutes of reperfusion in the control and anti-ICAM-1 groups, respectively; no significant changes in heart rate occurred in the anti-PAF group.

\section{Discussion}

The present study shows that attenuation of the significant increase in leukocyte-vessel wall interactions occurring in submucosal venules during reperfusion after total, warm ischemia of the small bowel is accompanied by a clearly improved submucosal capillary flow throughout reperfusion. The increase in platelet-vessel wall interactions in submucosal venules and arterioles during reperfusion following ischemia was not influenced. The improvement in submucosal capillary flow was accompanied by a considerable limitation of mucosal tissue damage: no shedding of villi was observed.

It should be possible to prevent the increase in leukocyte-vessel wall interactions during reperfusion of the small bowel in controlled clinical situations, such as small bowel transplantation or aortic surgery with supracoeliac clamping. In conditions where the IR is not controlled, such as mesenteric ischemia or necrotizing enterocolitis in neonates, prompt intervention as soon as bowel ischemia and/or reperfusion is diagnosed might avoid further damage. However, a quick diagnosis in these uncontrolled situations appears hard to achieve in clinical practice. $(21 ; 22)$

In this rat model, thirty minutes of total warm ischemia and 1 hour reperfusion of the small bowel resulted in an inflammatory response characterised among others by a significant increase in the number of leukocyte-vessel wall interactions in submucosal venules. Both anti-PAF and anti-ICAM- 1 intervention proved to be effective in preventing 
this increase in leukocyte-vessel wall interactions. This was due to an effect of both interventions on leukocyte adhesion and also on leukocyte rolling, resulting in levels of leukocyte-vessel wall interactions after one hour of reperfusion which were rather close to or even less than baseline values. By contrast, only a limited inflammatory response -as judged by leukocyte behaviour- was observed in the muscle layers of the bowel, strengthening the notion that submucosal tissue is more vulnerable to I/R than muscle tissue. $(8 ; 23)$ In rat striated muscles, periods of at least 4 hours of total, warm ischemia are necessary to induce an increase in venular leukocyte-vessel wall interactions during reperfusion (24;25). However, intervention with anti-PAF did have some attenuating effect on the decrease in perfusion of capillaries within the muscle layers, in contrast to anti-ICAM-1, indicating the release of PAF in response to $1 / R$, and possibly other inflammatory mediators, also in the muscle layers of the bowel.

The increase in submucosal leukocyte-vessel wall interactions during reperfusion was prevented by both by anti-PAF or anti-ICAM-1; importantly, with both interventions it was accompanied by a clear improvement of submucosal capillary perfusion, from almost zero to about $50 \%$ of baseline values. With anti-ICAM-1 no such effect was observed in the capillaries of the muscle layers, and with anti-PAF only in the longitudinal, but not or hardly in the circular muscle layer. In addition, we found a negative correlation between submucosal capillary perfusion and leukocyte adherence or total number of interacting leukocytes in submucosal venules. This relationship and the above mentioned difference between the two layers suggests that the improvement in flow through the submucosal capillaries resulted at least in part from a reduction in local vascular resistance to flow due to the decrease in leukocyte-vessel wall interactions.

In contrast to leukocyte-vessel wall interactions, both anti-PAF and anti-ICAM-1 intervention did not influence the increase in platelet-vessel wall interactions. Firstly, this indicates that these interactions were not leukocyte-dependent. Secondly, this suggests that the contribution of adhering platelets and platelet aggregates to the decrease in submucosal capilary perfusion is less than that of the adhering leukocytes. The fact that the improvement in capillary flow by anti-PAF and anti-ICAM-1 intervention was only half indicates that other factors than leukocytes affect submucosal capillary perfusion during I/R as well. Although platelets may be involved in the remaining decrease, it is likely that also other factors are important, such as the decrease in systemic arterial blood pressure. Constriction of microvessels was not observed, and it seems unlikely that vasospasm of the superior mesenteric artery, if any, contributed substantially to the decrease in submucosal capillary flow, because in that case submucosal arteriolar flow would have diminished as well, which did not occur. Moreover, endothelial cell activation and/or damage is indicated by the increased platelet-vessel wall interactions that were still 
observed in submucosal venules and arterioles after anti-PAF and anti-ICAM- 1 intervention. Hence, it is likely that endothelial cells were also activated and/or damaged in submucosal capillaries, which may have contributed to capillary flow decrease.
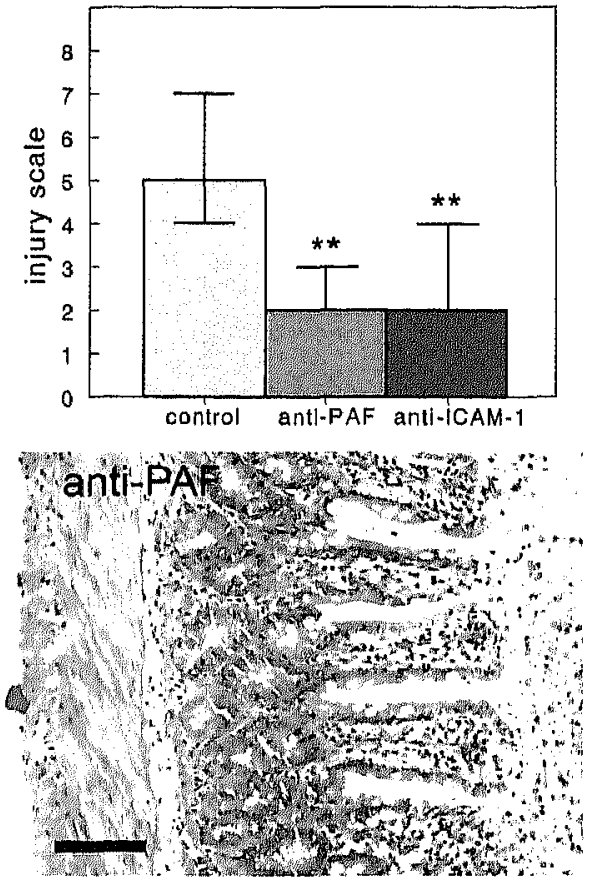
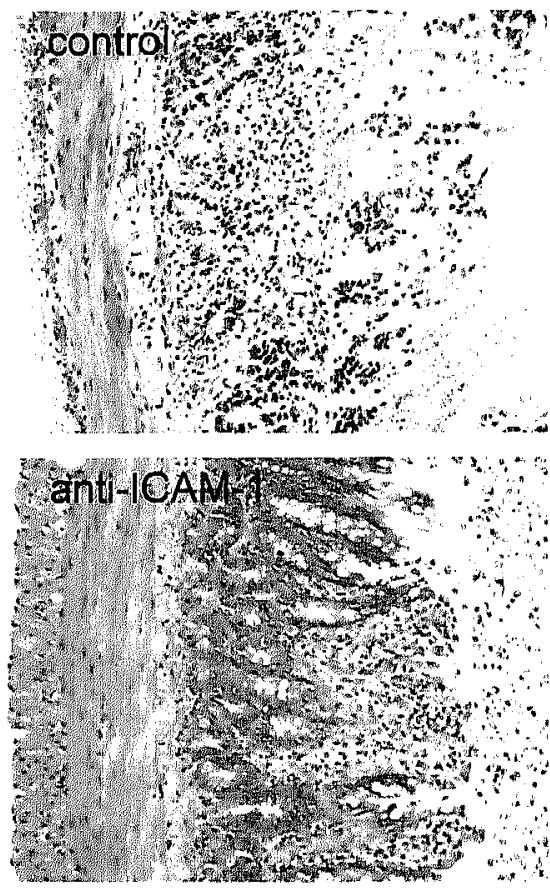

Figure 5: Level of histological injury in the terminal ileum caused by 30 minutes of total, warm ischemia of the small bowel followed by 60 minutes of reperfusion in the control, anti-PAF, and anti-ICAM-1 group. Tissue sections were stained with haematoxylin and eosin (HE). The degree of injury was quantified using the combined grading system of Chiu and Park (see text). Medians and interquartile ranges are presented. $* * p<0.01$ as compared to control. There was complete loss of villi in the control group, whereas in the anti-PAF and anti-ICAM-1 group intestinal injury was limited to more extended subepithelial space. Bar indicates $100 \mu \mathrm{m}$.

Small bowel tissue injury as induced by I/R decreased from loss of villi (injury grade 5) in the untreated group to an extended subepithelial space only (injury grade 2) in both intervention groups. The histological scores correlated positively with submucosal leukocyte-vessel wall interactions and negatively with submucosal capillary flow. This 
$s$ that the reduced tissue damage is related to the improvement of submucosal , perfusion. In addition, the reduction in tissue injury may to a certain extent be related to a decrease in leukocyte infiltration into the tissue, where leukocytes zrt damaging effects through free oxygen radical production and proteolytic release $(12 ; 26 ; 27)$. To which extent I/R induced mucosal apoptosis was involved is ly unknown(28;29). Platelet-vessel wall interactions, as well as systemic leukocyte and systemic haemodynamic parameters, like mean arterial pressure and heart are not influenced by anti-PAF or anti-ICAM-1 intervention, indicating that these ters are likely not involved in the reduction in mucosal tissue damage.

finding that after total, warm ischemia of the small bowel platelet adhesion is not te-dependent is in contrast to findings after partial ischemia of the same 1). In our study we observed an increase in platelet-vessel wall interactions in both :osal venules and arterioles. The same was observed by Massberg and ses $(9 ; 30)$ who applied total warm ischemia as well, In contrast, in case of partial a platelet-vessel wall interactions were observed in venules but not in arterioles, ly after a clearly longer reperfusion period(10;11). Our study also shows a ice in platelet adhesion and aggregation between submucosal vessels and venules $n$ the muscle layers, again suggesting a higher level of endothelial cell activation in imucosa as compared to the muscle layer of the small bowel. These findings : that total warm ischemia initiates a different, more intense thrombotic reaction rtial warm ischemia.

onclusion, 30 minutes of total, warm ischemia of the small bowel initiates an natory and thrombotic response in the submucosal layer, but not in the muscle with decreased bowel perfusion and histological loss of villi. Attenuation of te adhesion as hallmark of the inflammatory response clearly improves zosal capillary flow, preventing shedding of the mucosal villi. Hence, partial tion of submucosal capillary perfusion by attenuation of the increase in leukocytevall interactions may be sufficient to prevent the detrimental shedding of mucosal sed by total, warm ischemia of the small bowel.

\section{whedgement}

ank Prof. Dr. J.W. Greve, Department of Surgery, Maastricht University, the lands, for his contributions. 


\section{References}

(1) Soong CV, Blair PH, Halliday MI, MCCaigue MD, Hood JM, Rowlands BJ, et al. Bowel ischaemia and organ impairment in elective abdominal aortic aneurysm repair [see comments]. Br J Surg 1994;81(7):965-8.

(2) Gennaro M, Ascer E, Matano R, Jacobowitz IJ, Cunningham JN, Jr., Uceda P. Acute mesenteric ischemia after cardiopulmonary bypass. Am J Surg 1993;166(2):231-6.

(3) Kurt M, Litmathe J, Roehrborn A, Feindt P, Boeken U, Gams E. Abdominal complications following open-heart surgery: a report of 12 cases and review of the literature. Acta Cardiol 2006 Jun;61(3):301-6.

(4) Grant D, bu-Elmagd K, Reyes J, Tzakis A, Langnas A, Fishbein T, et al. 2003 report of the intestine transplant registry: a new era has dawned. Ann Surg 2005 Apr;241(4):607-13.

(5) Goulet $O$, Lacaille $F_{1}$ Jan $D_{1}$ Ricour $C$. Intestinal transplantation: indications, results and strategy. Curr Opin Clin Nutr Metab Care 2000 Sep;3(5):329-38.

(6) Goulet $O$, Auber F, Fourcade L, Sarnacki S, Jan D, Colomb V, et al. Intestinal transplantation including the colon in children. Transplant Proc 2002 Aug;34(5):1885-6.

(7) Granger DN. Ischemia-reperfusion: mechanisms of microvascular dysfunction and the influence of risk factors for cardiovascular disease. Microcirculation 1999 Sep; 6(3):167-78

(8) Beuk RJ, Heineman E, Tangelder GJ, Quaedackers JS, Marks WH, Lieberman JM, et al. Total warm ischemia and reperfusion impairs flow in all rat gut layers but increases leukocyte-vessel wall interactions in the submucosa only. Ann Surg 2000 Jan;231(1):96-104.

(9) Massberg $S$, Enders $G$, Leiderer $R$, Eisenmenger $S$, Vestweber D, Krombach $F$, et al. Platelet-endothelial cell interactions during ischemia/reperfusion: the role of $P$ selectin. Blood $1998 \mathrm{Jul}$ 15;92(2):507-15.

(10) Cooper D, Chitman KD, Williams MC, Granger DN. Time-dependent platelet-vessel wall interactions induced by intestinal ischemia-reperfusion. Am J Physiol Gastrointest Liver Physiol 2003 Jun;284(6):G1027-G1033.

(11) Cooper D, Russell J, Chitman KD, Williams MC, Wolf RE, Granger DN. Leukocyte dependence of platelet adhesion in postcapillary venules. Am J Physiol Heart Circ Physiol 2004 May; 286(5):H1895-H1900.

(12) Inauen W, Suzuki M, Granger DN. Mechanisms of cellular injury: potential sources of oxygen free radicals in ischemia/reperfusion. Microcirc Endothelium Lymphatics $1989 ; 5(3-5): 143-55$. 
(13) Beuk RJ, Heineman E, Tangelder GJ, Kurvers HA, Bonke HJ, Oude Egbrink MG. Effects of different durations of total warm ischemia of the gut on rat mesenteric microcirculation. J Surg Res 1997 Novi73(1):14-23.

(14) Megison SM, Horton JW, Chao $\mathrm{H}$, Walker PB. A new model for intestinal ischemia in the rat. J Surg Res 1990;49(2):168-73.

(15) Zimmerman BJ, Granger DN. Reperfusion injury. Surg Clin North Am 1992;72:65* 83 .

(16) Ishii S, Shimizu T. Platelet-activating factor (PAF) receptor and genetically engineered PAF receptor mutant mice. Prog Lipid Res 2000 Jan;39(1):41-82.

(17) Bohlen HG, Gore RW. Preparation of rat intestinal muscle and mucosa for quantitative microcirculatory studies. Microvasc Res 1976 Jan;11(1):103-10.

(18) Terashita $Z$, Kawamura $M$, Takatani $M$, Tsushima $S_{1}$ Imura $Y$, Nishikawa K. Beneficial effects of TCV-309, a novel potent and selective platelet activating factor antagonist in endotoxin and anaphylactic shock in rodents. J Pharmacol Exp Ther 1992 Feb; $260(2): 748-55$.

(19) Tangelder GJ, Slaaf DW, Muijtjens AM, Arts T, oude Egbrink MGA, Reneman RS. Velocity profiles of blood platelets and red blood cells flowing in arterioles of the rabbit mesentery. Circ Res I986 Novi59(5):505-14.

(20) Quaedackers JS, Beuk RJ, Bennet L, Charlton A, Oude Egbrink MG, Gunn AJ, et al. An evaluation of methods for grading histologic injury following ischemia/reperfusion of the small bowel. Transplant Proc 2000 Sep;32(6):1307-10.

(21) Freeman AJ, Graham JC. Damage control surgery and angiography in cases of acute mesenteric ischaemia. ANZJ Surg 2005 May;75(5):308-14.

(22) Oldenburg WA, Lau LL, Rodenberg TJ, Edmonds HJ, Burger CD. Acute mesenteric ischemia: a clinical review. Arch Intern Med 2004 May 24;164(10):1054-62.

(23) McCord JM. Oxygen-derived free radicals in postischemic tissue injury. N Engl J Med $1985 ; 312(3): 159-63$.

(24) Ferrante RJ, Hobson RW, Miyasaka M, Granger DN, Duran WN. Inhibition of white blood cell adhesion at reperfusion decreases tissue damage in postischemic striated muscle. J Vasc Surg 1996 Aug;24(2):187-93.

(25) Bastiaanse J, Anderson GL, Franken RJ, van der Heijden BE, Oude Egbrink MG, Slaaf DW, et al. Effect of HTK on the microcirculation in the rat cremaster muscle during warm ischemia and reperfusion. Microsurgery 2005;25(2):174-80.

(26) Gaboury J, Woodman RC, Granger DN, Reinhardt P, Kubes P. Nitric oxide prevents leukocyte adherence: role of superoxide. Am J Physiol 1993;265:H862-7.

(27) Grisham MB, Granger DN. Neutrophil-mediated mucosal injury. Role of reactive oxygen metabolites. Dig Dis Sci 1988;33(3 Suppl):65-15S. 
(28) Wu B, Iwakiri R, Ootani A, Fujise T, Tsunada S, Fujimoto K. Platelet-activating factor promotes mucosal apoptosis via FasL-mediating caspase-9 active pathway in rat small intestine after ischemia-reperfusion. FASEB J 2003 Jun; $17(9): 1156-8$.

(29) Navarro-Zorraquino M, Guemes A, Pastor C, Soria J, Sousa R, Salinas JC, et al. Apoptosis and $C D 8$ and $C D 54$ cell expression in rat small bowel transplantation. J Surg Res 2002 Mar;103(1):37-40.

(30) Massberg S, Enders G, Matos FC, Tomic LI, Leiderer R, Eisenmenger S, et al. Fibrinogen deposition at the postischemic vessel wall promotes platelet adhesion during ischemia-reperfusion in vivo. Blood 1999 Dec 1;94(11):3829-38. 
Chapter 8

\section{General discussion}




\section{General discussion}

Ischemia and subsequent reperfusion can initiate a devastating inflammatory response leading to local tissue injury, but also distant organs may become involved. Especially, complete (total) warm ischemia with an acute onset results in a severe reaction. The bowel is known to be exceptionally vulnerable to ischemia and reperfusion (l/R) injury(1), and is often described as the motor of a systemic response leading to Multiple Organ Failure (MOF).(2) Bowel ischemia plays an important role in many clinical conditions where it may contribute to the relatively high mortality rates (table 1 ). Therefore, it is important to gain more knowledge about the pathophysiological mechanisms of bowel ischemia and reperfusion. More knowledge will help to develop new tools to decrease injury as a result of ischemia and reperfusion.

Table 1: Clinical conditions in which bowel ischemia plays an important role regarding the occurrence of complications

\begin{tabular}{|c|c|c|c|c|}
\hline $\begin{array}{l}\text { Clinical conditions } \\
\text { involving bowel } \\
\text { ischemia }\end{array}$ & $\begin{array}{l}\text { Seriousness of } \\
\text { ischemia }\end{array}$ & $\begin{array}{l}\text { Moment of } \\
\text { appearance of } \\
\text { ischemia }\end{array}$ & $\begin{array}{l}\text { Warm ischemia } \\
\text { or } \\
\text { cold ischemia }\end{array}$ & $\begin{array}{l}\text { Mortality rate, period } \\
\text { (in centers of excellence) }\end{array}$ \\
\hline $\begin{array}{l}\text { Small bowel } \\
\text { transplantation }\end{array}$ & total & acute & cold & $\begin{array}{l}30 \%, 1 \text { year } \\
40-50 \%, 5 \text { year }^{2}\end{array}$ \\
\hline $\begin{array}{l}\text { Bowel artery } \\
\text { surgery }\end{array}$ & total & acute & warm & $6 \%$, perioperative(3) \\
\hline $\begin{array}{l}\text { Mesenteric } \\
\text { embolus }\end{array}$ & total & acute & warm & $\begin{array}{l}41 \%, 90 \text { days } \\
57 \%, 1 \text { year } \\
68 \%, 3 \text { year }(4)\end{array}$ \\
\hline Volvulus & total & acute & warm & $9 \%$, perioperative $(5)$ \\
\hline NEC & $\begin{array}{l}\text { total and/or } \\
\text { partial }\end{array}$ & $\begin{array}{l}\text { acute and/or } \\
\text { chronic }\end{array}$ & warm & $49 \%$, perioperative(6) \\
\hline Aortic surgery & partial & acute & warm & not applicable \\
\hline Cardiac surgery & partial & acute & warm & not applicable \\
\hline Atherosclerosis & partial & chronic & warm & not applicable \\
\hline
\end{tabular}

In the studies described in this thesis, we used intravital videomicroscopy to observe, in vivo, the early inflammatory reaction that is induced by acute total warm ischemia of the bowel, followed by reperfusion (first described in chapter 3 ). This technique enabled observation of the intestinal microcirculation and quantifications of local red blood cell velocity, vessel diameter, leukocyte-vessel wall interactions, and in a later stage plateletvessel wall interactions. In addition, the degree of tissue injury was determined

${ }^{1}$ WwW.intestinaltransplant.org 
histologically. Furthermore, systemic hemodynamic changes were monitored, i.e. blood pressure and heart rate. To gain more knowledge of the pathophysiological reaction in the bowel as a result of ischemia and reperfusion, we first developed a rat model in which we induced total warm ischemia and reperfusion in the bowel. It is already known from studies in several organs that warm ischemia initiates a more intense reaction than cold ischemia.(7)

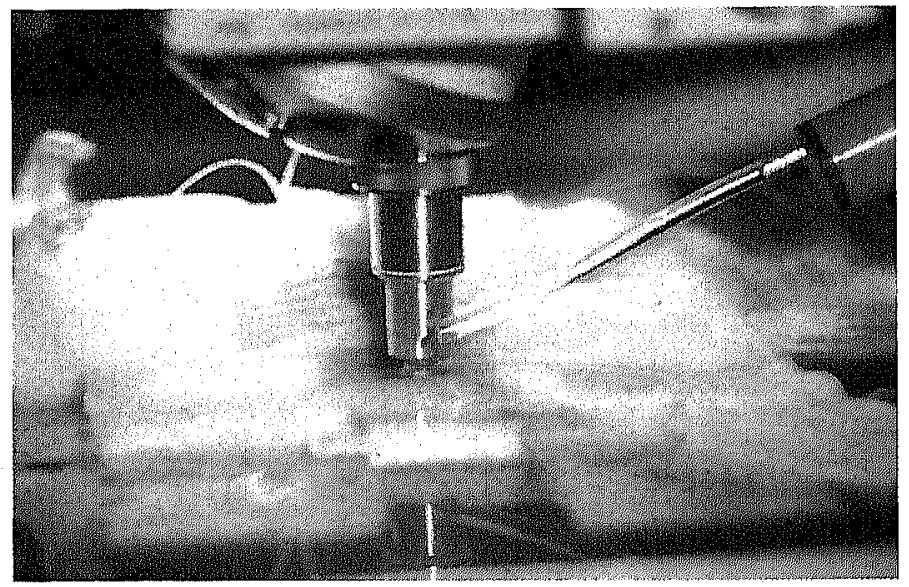

Figure $x$ shows an experimental setup, with the objective of the microscope focused on the intestine. The rat lies in supine position, with its terminal ileum exteriorized through a right flank incision. The table is heated $\left(37^{\circ} \mathrm{C}\right)$, the bowel is covered with wet gauze and a cover glass superfused with a buffered Tyrode's solution $\left(37^{\circ} \mathrm{C}\right)$.

Our main reason to use a model of total bowel ischaemia and reperfusion is the relevance of this model for a number of clinical conditions, such as small bowel transplantation, aortic surgery with supracoeliac clamping, splanchnic artery surgery, (acute) thrombosis of pre-existent atherosclerotic disease in the mesenteric arterial circulation, sudden embolic mesenteric artery occlusion and volvulus. In addition, from clinical and experimental data, we know that total ischemia is much more devastating than partial ischemia.(8-12) Up to know, most studies performed on the (microvascular) consequences of bowel ischemia and reperfusion applied partial ischemia.(10;13) Megison et. al.(14) investigated the reproducibility of the effects of partial ischemia in the rat bowel after they had had difficulties in their lab. Using quantitative measurements of blood flow with radiolabeled microspheres as well as mortality rates after partial and total 
warm ischemia, they concluded that partial ischemia resulted in inconsistent and not reproducible intestinal flow patterns and mortality rates. By contrast, the reproducibility of the consequences of total intestinal ischemia was much better.(14) Furthermore, the more intense reaction as a result of total warm ischemia results in larger effects, that start earlier. In our rat model, we achieved total ischemia of the whole bowel, via a median laparotomy, by ligating the inferior mesenteric artery and temporarily clamping the superior mesenteric artery; this resulted in total stop of flow throughout the bowel, as verified through the microscope. An additional right flank incision was made through which the terminal ileum was exteriorized, after which it was continuously superfused with a buffered Tyrode's solution at $37^{\circ} \mathrm{C}$ (figure 1 ).

The development of the gut model continued by determining the effect of the length of the ischemic period (chapter 4 ). We investigated periods of $0,15,30$, and 60 minutes of total warm ischemia followed by 2 hours reperfusion. As the length of the ischemic period became greater, intestinal blood flow was more severely impaired and local leukocytevessel wall interactions increased during reperfusion. Following 60 minutes of total warm ischemia all rats died between 30 and 90 minutes after start of reperfusion. From these results we concluded it was best to apply 30 minutes ischemia in our further studies. Other groups investigating the microcirculation following bowel ischemia and reperfusion applied either 90 minutes total warm ischemia of a segment of the bowel(12), or 1 hour of partial warm ischemia of the whole bowel $(9 ; 11)$. The possibility to induce longer ischemic periods in these studies, suggests that segmental ischemia does not result in a systemic response leading to early death, and that partial ischemia is significantly less devastating than total ischemia.

To determine microcirculatory changes as a result of ischemia and reperfusion we initially focused on the microvessels in the rat mesentery, a thin, transparent tissue that can be observed through the microscope using transillumination (chapter 3 and 4 ). However, these mesenteric microvessels are anatomically not connected to the bowel itself; blood enters the mesenteric microvessels via the larger arcade vessels and is transported via collecting veins into the portal circulation without perfusing the bowel. Therefore, we extended our rat model in such a way that we were able to investigate microcirculatory changes in the small bowel itself (chapter 6 ). We used rats instead of mice, because rats, as opposed to mice(15), show a vascular anatomy in their bowel that is most similar to the human situation, where the longitudinal and circular muscle layers have separate capillary beds. The animal preparation procedure was only partly adjusted. To investigate small bowel microvessels we had to use epiillumination, and visualization of leukocytes and platelets was only possible by fluorescence microscopy after labeling these cells with the fluorescent dye Rhodamine-6G. With the microscopic setup used, 
with high optical resolution, distinction between Rhodamine-6G stained leukocytes and platelets was possible because of their clear difference in size. Leukocytes and platelets were considered to 'interact' with the wall from the moment their velocity decreased at least an order of magnitude as compared to that of the free flowing blood cells, or when their velocity decreased to zero. Six categories of microvessels in the different layers of the small bowel could be observed by moving the microscope objective up and down, see figures 2 and 3 . The deepest tissue layer that could be visualized in this way was the submucosa. Observation of the mucosal (villus) capillaries was not possible, because light penetration and reflexion through all bowel layers resulted in inferior image quality. In one study(16), a longitudinal incision was made at the anti-mesenteric side of the small bowel to study, by means of intravital microscopy, the villus capillary perfusion from the lumen. We did not apply this surgical technique, because it may influence results by initiating an inflammatory response itself, and the microcirculatory flow pattern might change. In addition, by cutting the bowel the lumen will be flushed, whereby fecal material might inflame the surrounding tissue and the intraluminal molecular compound, i.e. electrolytes, can be disturbed. To determine mucosal injury, we measured the release of intestinal fatty acid binding protein (I-FABP) into the blood and investigated the bowel tissue histologically.

The method we used to score the degree of tissue injury was not chosen randomly. We compared several grading systems to score intestinal tissue damage (chapter 5)(17). To this purpose, we examined the validity, reliability, and ease of use of these systems. From the literature we selected 3 different scoring systems: the ones described by Parks et al(18), Sonnino et al(19), and Park et al(20) (which authors extended the scoring system of Chiv et al(21); further named Park/Chiu system) and used these systems to quantify the degree of injury in histological tissue samples from our rat model. The Parks scoring system, as well as the Park/Chiu scoring system showed to be very reliable. However, the Parks system does not include injury beyond the mucosa. Sonnino and colleagues developed a very detailed scoring system, but criteria were not always explained properly, which resulted in difficult interpretation and a higher inter-observer variability. Furthermore, severely injured small bowel samples only scored half of the maximum using the Sonnino system. The Park/Chiu system scores parallel to the morphologic appearance of intestinal injury; where low scores mean injury limited to the mucosa, and high scores mean extensive injury from the lumen untill the muscle layer. We concluded that the combined grading system of Park and Chiu is the most suitable one for histological evaluation of intestinal I/R damage. In the current thesis this evaluation was performed by two independent, experienced observers, blinded to the treatment groups. The data obtained by these two observers appeared to be highly correlated.

\section{6}


Thirty minutes of total warm ischemia resulted in reduced perfusion in all layers of the bowel during the complete reperfusion phase. As compared to the situation before ischemia as well as compared to a sham operated group (which showed no differences over time), microvascular red blood cell velocity in most layers returned to a value of only 10 to $40 \%$ during reperfusion. In the submucosa, capillary perfusion (measured on an ordinary scale, using an arbitrary velocity index) was about $50 \%$ of baseline at 10 minutes of reperfusion, but decreased progressively to less than $10 \%$ after 60 minutes reperfusion (chapter 6 and 7). Such a compromised perfusion will finally lead to serious tissue injury and probably death. The reason for this significant decline in blood flow is hard to clarify. Compared to baseline, mean arterial pressure dropped significantly during reperfusion, from around 80 to $60 \mathrm{mmHg}$ respectively (chapter 7). However, as compared to a sham operated group there was only a significant reduced mean arterial pressure at 1 minute reperfusion $(57 \mathrm{mmHg}$ ), which from here on improved to around $80 \mathrm{mmHg}$ (chapter 6). Although the perfusion of the different bowel layers decreased significantly following ischemia in both studies (chapter 6 and 7), mean arterial pressure decreased compared to baseline, but not compared to a sham operated group. In addition, in our study described in chapter 4, mean arterial pressure dropped significantly during reperfusion following 30 minutes ischemia, but not after a 15-minute ischemic period; at the same time mesenteric flow decreased during reperfusion in both the 15- and 30-minute ischemia group. Therefore, mean arterial pressure can, at the most, only partly be held responsible for the dropped bowel perfusion during reperfusion. Thrombotic obstruction at the clamping site at the basis of the superior mesenteric artery was excluded by histological evaluation. Besides the occurrence of vasomotion (rhythmic changes in diameter) in 2 of 4 arterioles observed in the mesentery following 30 minutes ischemia (chapter 4), vasoreactivity (vasospasms) as a result of clamping and releasing the superior mesenteric artery was not observed. In all layers of the small bowel itself we registered microvascular diameters throughout the experimental protocol, and no changes were observed at all (chapter 6 and 7). We have not studied diameter changes in larger arteries like the superior mesenteric artery. However, it seems unlikely that vasospasms of the superior mesenteric artery, if any, contributed substantially to the decrease in submucosal capillary flow, because in that case submucosal arteriolar flow would have diminished as well, which did not occur. Another possible explanation for the compromised perfusion of all small intestinal layers could be an increased resistance to flow as a result of leukocyte- and/or platelet-vessel wall interactions. However, leukocyte- and platelet-vessel wall interactions were increased in the submucosal layer only, whereas, flow decreased in the muscle layers as well. In our study described in chapter 7, rats were treated with either a Platelet Activating Factor (PAF) antagonist or a monoclonal antibody against Intercellular 


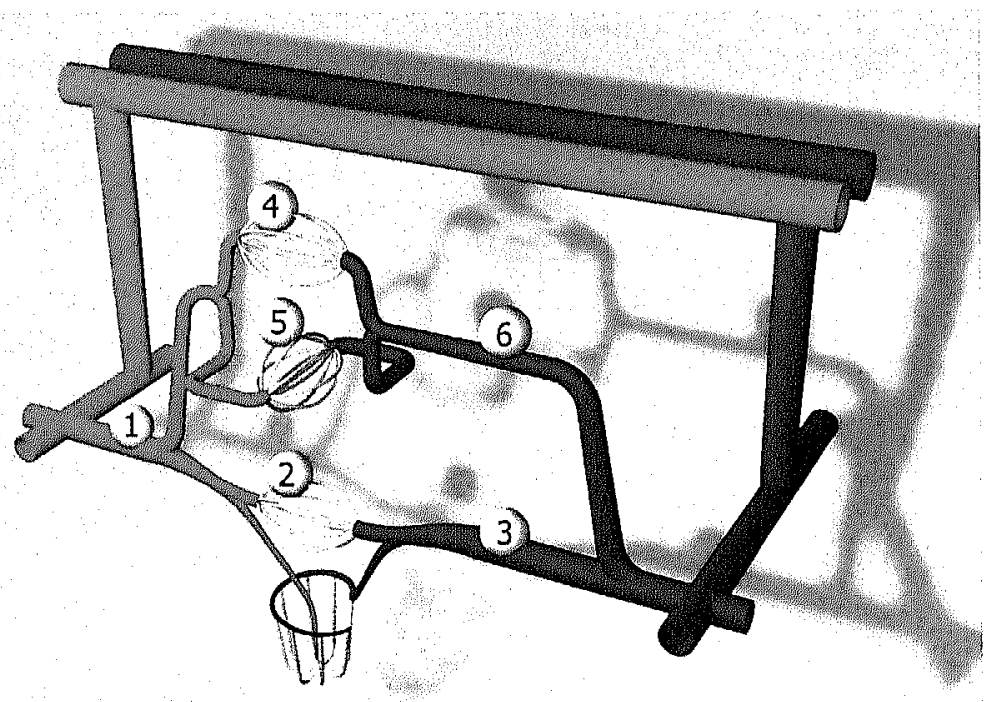

Figure 2 (top): Schematic of the small bowel microcirculation, illustrating the six sites of intravital microscopic observation. From the arterial arcade in the mesentery (upper vessels) blood flows to the submucosal arterioles (1) and, subsequently, perfuses the different capillary beds. These include capillaries in the submucosa (2) as well as in the longitudinal (outer; 4) and circular (inner; 5) muscle layers. From these capillaries, blood is drained into venules of the submucosa (3) or located between the two muscle layers (6), after which it returns to the mesentery. Figure 3 (bottom): Microscopic images during reperfusion of a submucosal venule ( $A$; location 3 in figure 2 ) and a venule between the two muscle layers ( $B$; location 6 in figure 2). By using a filter, fluorescently labeled leukocytes (white dots) can be identified.
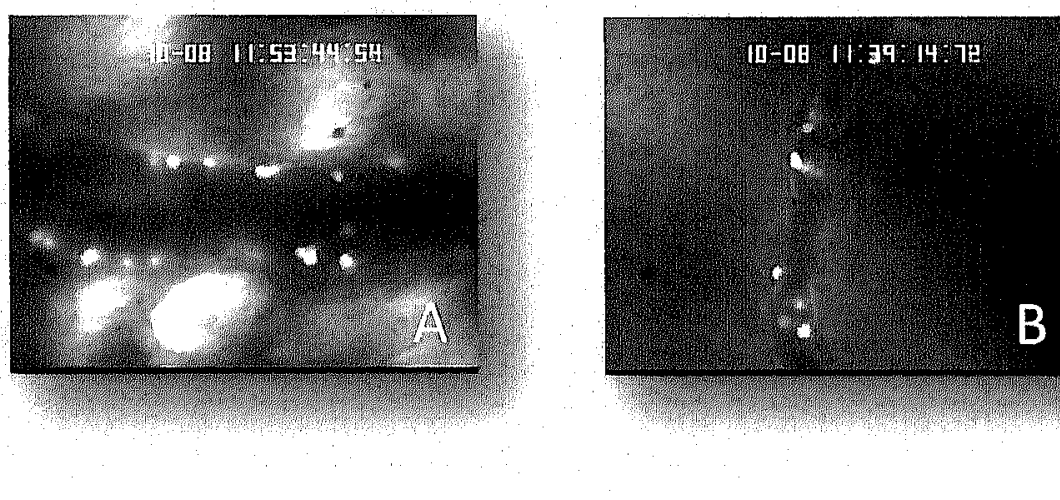
Adhesion Molecule-1 (ICAM-1) to prevent the increase in leukocyte-vessel wall interactions after $/ / R$. As a result, submucosal perfusion was significantly improved after $I / R$ as compared to the rats that were treated with vehicle. In addition, submucosal perfusion was found to be correlated negatively with the number of adherent leukocytes and the total number of interacting leukocytes, but not with the number of rolling leukocytes (chapter 7). This suggests a possible role for adherent leukocytes to influence blood flow. The fact that rolling leukocytes did not correlate may be explained by the behaviour of leukocytes when not activated. Following activation integrins are added to the surface of the leukocytes, strengthening its interaction with the vessel wall. In addition, as a result of leukocyte activation secondary leukocyte recruitment is initiated as well. The redistribution of P-selectin glycoprotein ligand-1 (PSGL-1) and L-selectin to high-density areas on the leukocyte membrane presumably allows leukocyte-leukocyte interactions through secondary tethers (22). By contrast, the intervention with anti-PAF or anti-ICAM-1 did not affect platelet-vessel wall interactions, which therefore seem not responsible influencing submucosal capillary flow. However, activated platelets bind avidly to leukocytes, forming platelet-leukocyte complexes; this is mediated by platelet P-selectin (from alpha-granules) and by PSGL-1 on the leukocyte(23;24). The formation of these complexes interacting with the vessel wall, may be involved in reducing blood flow by increasing venular resistance. In addition, shedding of glycosaminoglycan chains from the endothelial glycocalyx following intestinal ischemia and reperfusion may offer leukocytes and platelets greater access to endothelial receptors $(25 ; 26)$. Other factors contributing to capillary flow reduction following ischemia and reperfusion can be endothelial swelling and plugging of capillaries by leukocytes and/or red blood cells.

During reperfusion after total, warm ischemia of the small bowel large numbers of leukocytes and platelets interacting with the wall could be observed in submucosal venules, thereby showing an early inflammatory response. The amount of interacting leukocytes with the endothelium became greater with increasing duration of the ischemic period. However, as indicated before, there was a maximum ischemic length that could be tolerated. Sixty minutes of total warm intestinal ischemia resulted in death of all rats within go minutes of reperfusion, whereas all rats subjected to 30 minutes of total, warm intestinal ischemia survived at least 2 hours of reperfusion (chapter 4). During reperfusion, the number of venular leukocyte-vessel wall interactions increased progressively in the mesentery (chapter 4), and the intestinal submucosa (chapter 6 and 7), but not in the muscle layers of the small bowel (chapter 6 and 7). The different responses at these different locations can be explained by the fact that submucosal tissue is much more vulnerable to ischemia and reperfusion than muscle tissue(1). In rat striated muscles, periods of at least 4 hours of total, warm ischemia are necessary to induce an 
increase in venular leukocyte-vessel wall interactions during reperfusion( $27 ; 28)$. Similar to leukocytes, the number of platelets interacting with the vessel wall following ischemia and reperfusion increased in the submucosal layer only. However, unlike leukocytes, platelets interacted with the arteriolar wall as well. This phenomenon has been described before following total warm ischemia but not following partial ischemia of the bowel(1012;29). Administration of a PAF or ICAM-1 antagonist just before start of reperfusion did not influence these platelet-vessel wall interactions, while the increase in leukocytevessel wall interactions was almost completely prevented. PAF is not an adhesion molecule, but acts as a pro-inflammatory mediator. From our data (chapter 7) we can conclude that PAF plays a significant role in regulating leukocyte-vessel wall interactions, but surprisingly has no effect on platelet-vessel wall interactions following intestinal ischemia and reperfusion. Probably there are other substances initiating the thrombotic response, like von Willebrand factor (especially in low shear conditions)(30), P-selectin, and the major platelet integrin $\alpha \|_{3}$, which binds to fibrin/fibrinogen anchoring to endothelial $\alpha V \beta_{3}$ or ICAM-1(29;31). The differential effect of ICAM-1 blockade on leukocyte- and platelet-vessel wall interactions may be explained by the fact that we injected the monoclonal antibody against ICAM-1 just before start of reperfusion. By that time, fibrin/fibrinogen may already be anchored to ICAM-1, and hence, be available for passing platelets to bind to. By contrast, the interaction of ICAM-1 with integrins on passing leukocytes, which is responsible for leukocyte adhesion and transmigration, can only take place during reperfusion when leukocytes are mobilized to the tissue involved and is prevented by the antibody.

Thirty minutes of total warm ischemia and 1 hour reperfusion resulted in severe mucosal injury (grade 5: complete loss of villi, with the outer muscular layer still intact), whereas in sham operated (control) rats no injury was found (chapter 6 and 7). This mucosal injury could be significantly reduced to subepithelial space enlargement (grade 2) by treatment of the rats with either a PAF antagonist or monoclonal antibody against ICAM-1 (chapter 7). The degree of intestinal injury correlated positively with submucosal leukocyte-vessel wall interactions and negatively with submucosal perfusion. This strongly suggests that both submucosal leukocytes and submucosal capillary flow play a pivotal role in the formation of intestinal tissue injury following ischemia and reperfusion. Furthermore, the plasma concentration of intestinal-fatty acid binding protein (I-FABP), which is released from the cytosol of injured enterocytes, increased significantly during reperfusion (chapter 6). Together, these results strongly suggest that the (inner) (sub)mucosal layer is the most affected by intestinal $U / R$, and not the (outer) muscle layers. Probably, most of the (sub)mucosal damage originates during reperfusion. Preliminary experiments suggest that circulating factors from ischemic bowel tissue and 
captured stationary blood do not play an important role. In these experiments, we flushed the bowel circulation at the end of a 1 hour-period of total warm ischemia and collected $1.5 \mathrm{ml}$ of blood from the portal vein (by injecting $2 \mathrm{ml}$ of saline in the superior mesenteric artery, which diluted the collected blood at the end of the injection). Subsequently, this blood sample was injected into the circulation of healthy rats $(n=5)$. After 1 hour these rats were sacrificed and their organs were studied histologically. No tissue injury was observed (unpublished data, 1999).

\section{Conclusion}

Total warm ischemia and reperfusion of the small bowel increases the level of leukocytevessel wall interactions and induces platelet-vessel wall interactions, especially in the submucosal layer, which is accompanied by a clear decrease in submucosal capillary perfusion. Altogether, this results in significant tissue injury, especially in the intestinal mucosa. This thesis shows that an early intervention (just before start of reperfusion) to prevent the increase in leukocyte-vessel wall interactions, with no effect on plateletvessel wall interactions, can improve submucosal capillary perfusion in such way that tissue injury is reduced significantly. From a clinical point of view this might mean that it is important to intervene in an early stage, to prevent the increase in leukocyte-vessel wall interactions during reperfusion; this is feasible in clinical situations in which the moment of start of bowel reperfusion is controlled, such as small bowel transplant procedures, aortic surgery with supra coeliac clamping, and splanchnic artery surgery. In many other conditions where the l/R protocol is not controlled, e.g. (acute) thrombosis of pre-existent atherosclerotic disease in the mesenteric arterial circulation, sudden embolic mesenteric artery occlusion, volvulus, and Necrotising Enterocolitis (NEC) in neonates, it is tempting to suggest to intervene as soon as bowel ischemia and/or reperfusion is diagnosed to avoid further damage. However, a quick diagnosis in these uncontrolled situations appears hard to achieve in the present clinical practice; intestinal $1 / R$ typically presents late and has very high mortality rates.(32;33)

\section{Future directions}

Above all, we need to develop tools to diagnose bowel ischemia before irreversible injury has occurred. The development of rapid kits to measure fatty acid binding protein subtypes, which leak from specifically defined areas of injured tissue into the circulation and urine, seems very promising. The subtype intestinal fatty acid binding protein (IFABP) was shown to be a sensitive marker for bowel ischemia in strangulated mechanical small bowel obstruction(34) and mesenteric infarction(35). Measurement of I-FABP in rat serum can detect small bowel allograft rejection in such an early stage, that treatment 
with cyclosporine immunotherapy consistently reversed rejection.(36) Moreover, I-FABP appears to be a specific parameter for early detection of intestinal injury leading to severe necrotizing enterocolitis (NEC), although for this disease also liver fatty acid binding protein seems a promising sensitive marker.(37) Other possible diagnostic, and prognostic, tools may be the detection of circulating endothelial progenitor cells(38;39), endothelial microparticles (small vesicles released from disturbed endothelial cells)(40), and circulating endothelial cells(41;42). However, these cells/particles are not specifically related to the bowel and should therefore be followed by imaging (CT-scan or angiography) when elevated levels are found. It is important to further unravel the usefulness of fatty acid binding proteins and circulating endothelial (progenitor) cells/particles to diagnose bowel ischemia.

To gain more knowledge of the pathophysiological mechanism of bowel ischemia and reperfusion more intervention studies should be performed. These studies should aim at improving bowel perfusion, and control of the interaction between leukocytes, platelets, and the vessel wall, leading to the development of drugs to support treatment of bowel ischemia and reperfusion injury. Treatments should be initiated before, during ischemia, and during reperfusion, depending on the different clinical situations.

In this thesis, we used a rat model, because rats have separate capillary beds for the longitudinal and circular muscle layer, which is comparable to the human situation. Opposite to rats, mice have a very thin muscle layer with only one layer of capillaries, anatomically situated in random directions. Because our rat studies (chapter 6 and 7) showed that the inflammatory reaction takes place in de (sub)mucosa only, future studies can be performed studying the (sub)mucosa of mice. The use of mice provides the advantage of larger numbers of antibodies that can be used, as well as the availability of manipulated (knockout) mice. Furthermore, even better (fluorescent) microscopic images are expected as a result of a thinner (mouse) bowel wall.

Hopefully, we will soon be able to diagnose intestinal ischemia quickly, and from there on support the patient with protective drugs. At the same time a surgical and/or endovascular intervention may be performed to induce reperfusion if needed, thereby reversing intestinal injury and improving patient survival.

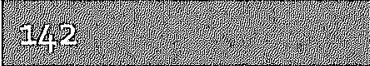




\section{References}

(1) McCord JM. Oxygen-derived free radicals in postischemic tissue injury. N Engl J Med 1985;312(3):159-63.

(2) Ciesielski L, Modzelewski B. Pathogenesis and treatment of multiorgan failure dysfunction syndrome in shock. Rocz Akad Med Bialymst 1995;40(1):13-24.

(3) Giswold ME, Landry GJ, Taylor LM, Jr., Moneta GL. Outcomes after redo procedures for failed mesenteric revascularization. Vasc Endovascular Surg 2004 Juli38(4):315-9.

(4) Park WM, Gloviczki P, Cherry KJ, Jr., Hallett JW, Jr., Bower TC, Panneton JM, et al. Contemporary management of acute mesenteric ischemia: Factors associated with survival. J Vasc Surg 2002 Mar;35(3):445־52.

(5) Roggo A, Ottinger LW. Acute small bowel volvulus in adults. A sporadic form of strangulating intestinal obstruction. Ann Surg 1992;216(2):135-41.

(6) Blakely ML, Lally KP, McDonald S, Brown RL, Barnhart DC, Ricketts RR, et al. Postoperative outcomes of extremely low birth-weight infants with necrotizing enterocolitis or isolated intestinal perforation: a prospective cohort study by the NICHD Neonatal Research Network. Ann Surg 2005 Jun;241(6):984-9.

(7) Ikeda T, Yanaga K, Kishikawa K, Kakizoe S, Shimada M, Sugimachi K. Ischemic injury in liver transplantation: difference in injury sites between warm and cold ischemia in rats. Hepatology 1992 Aug; 16(2):454-61.

(8) Sternbach $Y$, Perler BA. Acute mesenteric ischemia. In: $Y e o \mathrm{CJ}_{\text {, editor. }}$ Shackleford's surgery of the alimentary tract. 5 ed. WB Saunders; 2001. p. 17-31.

(9) Kubes P, Ibbotson G, Russell J, Wallace JL, Granger DN. Role of platelet-activating factor in ischemia/reperfusion- induced leukocyte adherence. Am J Physiol 1990;259:G300-5.

(10) Cooper D, Russell J, Chitman KD, Williams MC, Wolf RE, Granger DN. Leukocyte dependence of platelet adhesion in postcapillary venules. Am J Physiol Heart Circ Physiol 2004 May;286(5):H1895-H1900.

(11) Cooper D, Chitman KD, Williams MC, Granger DN. Time-dependent platelet-vessel wall interactions induced by intestinal ischemia-reperfusion. Am J Physiol Gastrointest Liver Physiol 2003 Jun;284(6):G1027-G1033.

(12) Massberg $S$, Enders $G$, Leiderer R, Eisenmenger $S$, Vestweber $D$, Krombach $F$, et al. Platelet-endothelial cell interactions during ischemia/reperfusion: the role of $\mathrm{P}$. selectin. Blood $1998 \mathrm{Jul}$ 15;92(2):507-15.

(13) Kubes P, Suzuki M, Granger DN. Platelet-activating factor-induced microvascular dysfunction: role of adherent leukocytes. Am J Physiol 1990;258:G158-63. 
(14) Megison SM, Horton JW, Chao H, Walker PB. A new model for intestinal ischemia in the rat. J Surg Res 1990;49(2):168-73.

(15) Massberg S, Eisenmenger S, Enders G, Krombach F, Messmer K. Quantitative analysis of small intestinal microcirculation in the mouse. Res Exp Med Berl 1998 Jul;198(1):23-35.

(16) Gonzalez AP, Sepulveda S, Massberg S, Baumeister R, Menger MD. In vivo fluorescence microscopy for the assessment of microvascular reperfusion injury in small bowel transplants in rats. Transplantation 1994;58:403-8.

(17) Quaedackers JS, Beuk RJ, Bennet L, Charlton A, Oude Egbrink MG, Gunn AJ, et al. An evaluation of methods for grading histologic injury following ischemia/reperfusion of the small bowel. Transplant Proc 2000 Sep;32(6):1307-10.

(18) Parks DA, Bulkley GB, Granger DN, Hamilton SR, McCord JM. Ischemic injury in the cat small intestine: role of superoxide radicals. Gastroenterology $1982 ; 82(1): 9-$ 15.

(19) Sonnino RE, Riddle JM, Pritchard TJ. Grading system for histologic changes in rat small bowel transplants. Transplant Proc 1992;24(3):1201-2.

(20) Park PO, Haglund U, Bulkley GB, Falt K. The sequence of development of intestinal tissue injury after strangulation ischemia and reperfusion. Surgery 1990;107(5):574-80.

(21) Chiu CJ, McArdle AH, Brown R, Scott HJ, Gurd FN. Intestinal mucosal lesion in lowflow states. I. A morphological, hemodynamic, and metabolic reappraisal. Arch Surg 1970;101(4):478-83.

(22) Sperandio $M$, Smith ML, Forlow SB, Olson TS, Xia $L, M c E v e r ~ R P$, et al. P-selectin glycoprotein ligand-1 mediates L-selectin-dependent leukocyte rolling in venules. J Exp Med 2003 May 19;197(10):1355-63.

(23) Larsen E, Celi A, Gilbert GE, Furie BC, Erban JK, Bonfanti R, et al. PADGEM protein: a receptor that mediates the interaction of activated platelets with neutrophils and monocytes. Cell 1989 Oct 20;59(2):305-12.

(24) Moore KL, Stults NL, Diaz S, Smith DF, Cummings RD, Varki A, et al. Identification of a specific glycoprotein ligand for P-selectin (CD62) on myeloid cells. J Cell Biol $1992 \mathrm{Jul} ; 118(2): 445^{-56}$.

(25) Mulivor AW, Lipowsky HH. Inflammation- and ischemia-induced shedding of venular glycocalyx. Am J Physiol Heart Circ Physiol 2004 May;286(5):H1672$\mathrm{H}_{1} 680$.

(26) Reitsma S, Slaaf DW, Vink $H$, van Zandvoort MA, Oude Egbrink MG. The endothelial glycocalyx: composition, functions, and visualization. Pflugers Arch 2007 Jun; $454(3): 345-59$. 
(27) Ferrante RJ, Hobson RW, Miyasaka M, Granger DN, Duran WN. Inhibition of white blood cell adhesion at reperfusion decreases tissue damage in postischemic striated muscle. J Vasc Surg 1996 Aug;24(2):187-93.

(28) Bastiaanse J, Anderson GL, Franken RJ, van der Heijden BE, Oude Egbrink MG, Slaaf DW, et al. Effect of HTK on the microcirculation in the rat cremaster muscle during warm ischemia and reperfusion. Microsurgery 2005;25(2):174-80.

(29) Massberg S, Enders G, Matos FC, Tomic LI, Leiderer R, Eisenmenger S, et al. Fibrinogen deposition at the postischemic vessel wall promotes platelet adhesion during ischemia-reperfusion in vivo. Blood 1999 Dec 1;94(11):3829-38.

(30) Andre P, Denis CV, Ware J, Saffaripour S, Hynes RO, Ruggeri ZM, et al. Platelets adhere to and translocate on von Willebrand factor presented by endothelium in stimulated veins. Blood 2000 Nov 15;96(10):3322-8.

(31) Wagner DD, Frenette PS. The vessel wall and its interactions. Blood 2008 Jun 1;111(11):5271-81.

(32) Freeman AJ, Graham JC. Damage control surgery and angiography in cases of acute mesenteric ischaemia. ANZ J Surg 2005 May;75(5):308-14.

(33) Oldenburg WA, Lau LL, Rodenberg TJ, Edmonds HJ, Burger CD. Acute mesenteric ischemia: a clinical review. Arch Intern Med 2004 May 24;164(10):1054-62.

(34) Cronk DR, Houseworth TP, Cuadrado DG, Herbert GS, MCNutt PM, Azarow KS. Intestinal fatty acid binding protein (I-FABP) for the detection of strangulated mechanical small bowel obstruction. Curr Surg 2006 Sep;63(5):322-5.

(35) Kanda T, Fujii H, Tani T, Murakami H, Suda T, Sakai $Y$, et al. Intestinal fatty acidbinding protein is a useful diagnostic marker for mesenteric infarction in humans. Gastroenterology 1996;110(2):339-43.

(36) Morrissey PE, Gollin G, Marks WH. Small bowel allograft rejection detected by serum intestinal fatty acid-binding protein is reversible. Transplantation 1996 May 27;61(10):1451-5.

(37) Guthmann F, Borchers T, Wolfrum C, Wustrack T, Bartholomaus S, Spener F. Plasma concentration of intestinal- and liver-FABP in neonates suffering from necrotizing enterocolitis and in healthy preterm neonates. Mol Cell Biochem 2002 Oct;239(1-2):227-34.

(38) Barber $C L$, Iruela-Arispe ML. The ever-elusive endothelial progenitor cell: identities, functions and clinical implications. Pediatr Res 2006 Apr;59(4 Pt 2):26R$32 \mathrm{R}$.

(39) Thum T, Baversachs J. Spotlight on endothelial progenitor cell inhibitors: short review. Vasc Med 2005 jul;10 Suppl 1:559-564. 
Chapter 3

(40) Horstman LL, Jy W, Jimenez JJ, Ahn YS. Endothelial microparticles as markers of endothelial dysfunction. Front Biosci 2004 May 1;9:11:18-35.

(41) Gupta M. Circulating endothelial cells and circulating endothelial cell progenitors as surrogate markers for determining response to antiangiogenic agents. Clin Colorectal Cancer 2007 Jan;6(5):337-8.

(42) Bertolini F, Shaked $Y$, Mancuso P, Kerbel RS. The multifaceted circulating endothelial cell in cancer: towards marker and target identification. Nat Rev Cancer 2006 Nov;6(11):835-45. 
Chapter 9

Summary

Samenvatting

Curriculum Vitae

Dankwoord 


\section{Summary}

Ischemia (inadequate blood supply) of the small bowel can lead to accumulation of (potentially) toxic agents and as the ischemic period lasts longer manifestation of tissue injury is likely to occur. If blood supply is not restored this harmful reaction will aggravate and may lead to death. Consequently, it is important to counteract ischemia and initiate reperfusion of the tissue. However, beside oxygenation, reperfusion of the bowel can also cause a response which is harmful, among others by the formation of oxygen radicals and by activation and/or attraction of leukocytes and platelets. This causes strong chemoattractant gradients and amplifies the inflammatory response, contributing to further endothelial and parenchymal cell death. Especially the bowel is known to be vulnerable to ischemia and reperfusion. Reperfusion is inevitable for the small bowel to survive. This thesis provides an overview of animal studies we performed to gain more knowledge about the pathophysiological mechanisms underlying the damaging consequences of ischemia and reperfusion of the small bowel. In clinical practice, doctors find it difficult to diagnose bowel ischemia before irreversible damage to the bowel has occurred. They need more tools, like diagnostic markers, to be able to respond early enough. In addition, therapeutic means to reduce bowel injury need to be developed.

In chapter 2 a brief overview of literature on ischemia and reperfusion of the bowel is presented. Clinical conditions in which ischemia and reperfusion of the bowel occur include small bowel transplantation, shock situations, necrotizing enterocolitis (NEC), and as a result of cardiac surgery or during clamping of the aorta (supracoeliacal, but also infrarenal). Furthermore, patients are known to develop bowel ischemia as a result of an embolus or thrombus formation in one or more of the bowel arteries. Other patients arrive with a volvulus, malrotation or strangulated ileus.

To study the pathophysiological mechanisms of bowel ischemia and reperfusion a rat model was developed. As described in chapter 3 , mesenteric venules and arterioles could be visualized in vivo using intravital videomicroscopy and transillumination. A midline laparotomy was performed, the inferior mesenteric artery was ligated and the superior mesenteric artery was marked by a vessel loop. By placing a vessel clamp on the superior mesenteric artery total warm ischemia of the bowel was achieved, as verified through the microscope. Using this model we were able to quantify diameter changes, red blood cell velocities and leukocyte-vessel wall interactions in the mesenteric microcirculation. These measurements were performed before ischemia and during the first 2 hours of reperfusion. In chapters 3 and 4 , microvascular consequences of different durations of the ischemic period were studied in the mesentery. It was shown that even short periods of total warm ischemia of the bowel resulted in severe microvascular changes and that 
these effects increased with prolongation of the ischemic period. Mesenteric venular blood flow was already severely compromised during reperfusion after 15 and 30 minutes of total warm ischemia, dropping to 40 and $25 \%$ of control, respectively. Following 60 minutes ischemia blood flow did not exceed $10 \%$ of control. Leukocyte-vessel wall interactions increased up to 5 or 10 times the control value following 15 or 30 minutes ischemia. Following 60 minutes ischemia leukocyte-vessel wall interactions could not be studied due to the low blood flow. In the latter group, all rats died between 30 and go minutes reperfusion.

In studies on the effect of ischemia and reperfusion on the bowel, it is important to quantify the level of tissue injury induced. In most studies, bowel tissue injury is assessed by histologic evaluation of standard hematoxylin and eosin (H\&E) stained tissue sections. However, comparing the degree of bowel tissue injury between studies is difficult, because different scoring systems are used. Therefore, we considered it important to determine a recommendation for a standard histologic grading system, which would be broadly suitable for use in typical experimental studies of ischemia and reperfusion of the bowel. From a literature search the 3 most popular grading systems were selected: the combined grading system developed by Park and Chiu, and the grading systems developed by Parks and Sonnino (chapter 5 ). Using bowel tissue sections from rats subjected to 30 minutes ischemia and 1 hour reperfusion and sham operated controls, two independent observers demonstrated that the Park/Chiu system showed the best correlation between the two observers. Although the Parks system was also reliable it did not include injury beyond the mucosa. Sonnino's grading system showed the least correlation. We therefore proposed that the combined grading system by Park and Chiu is the most suitable to be recommended as a standard scoring scale for histological evaluation of intestinal ischemia and reperfusion injury.

Although our mesenteric model was suitable to determine the duration of total warm bowel ischemia needed to induce attenuation of blood flow and increased leukocytevessel wall interactions, it was still unknown whether ischemia and reperfusion had similar detrimental microvascular consequences in the bowel wall itself. For this purpose, we developed a new rat model in which we were able to visualize, in vivo, the different layers of the small bowel. As described in chapters 6 and 7, both bright-field and fluorescence intravital microscopic observations were performed under epi-illumination. With this method, we were able to quantify red blood cell velocity, diameter changes, leukocyte and platelet-vessel wall interactions in the submucosal microcirculation, and also in the longitudinal and circular muscle layers of the bowel. In chapter 6, we investigated the effect of ischemia and reperfusion on tissue perfusion, leukocyte-vessel wall interactions and tissue integrity. To determine enterocyte damage at different time

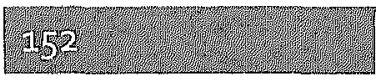


points, serum levels of intestinal fatty acid binding protein (1-FABP) were measured. In addition, intestinal histologic changes were examined. During the first hour following 30 minutes of total warm bowel ischemia, mean red blood cell velocity attenuated significantly in all layers of the small bowel, without significant diameter changes. Leukocyte-vessel wall interactions increased in the submucosa but not in the muscle layer. In addition, plasma levels of I-FABP increased significantly from 30 minutes reperfusion onward, indicating severe epithelial injury. Tissue damage at the luminal side of the bowel was also observed in histologic images, which showed severe mucosal injury. Distant organs did not show damage on H\&E sections. Both the impaired perfusion in the whole small bowel and the early submucosal inflammatory response may have contributed to the severe mucosal injury observed after ischemia and reperfusion.

In the subsequent study (chapter 7), we investigated the role of leukocytes and platelets in intestinal capillary flow impediment and tissue damage as caused by ischemia and reperfusion. Interventions with a platelet activating factor (PAF) antagonist or a monoclonal antibody against intercellular adhesion molecule-1 (ICAM-1), added intravenously just before start of reperfusion, completely prevented the increase in leukocyte-vessel wall interactions during reperfusion following 30 minutes of total warm ischemia of the bowel. This resulted in an 8-fold improvement in submucosal capillary flow as compared to vehicle-treated controls. At the same time, bowel tissue injury was significantly reduced; shedding of mucosal villi no longer occurred. The thrombotic response was not affected; platelet-vessel wall interactions, which particularly occurred in submucosal venules, were not influenced by the interventions. Therefore, partial restoration of submucosal perfusion by attenuation of the increase in leukocyte-vessel wall interactions may be sufficient to prevent the detrimental shedding of mucosal villi by total, warm ischemia of the small bowel.

In conclusion, total warm ischemia and reperfusion of the small bowel initiates an inflammatory and thrombotic response, especially in the submucosal microcirculation, accompanied by a clear decrease in bowel perfusion. Altogether, this results in severe bowel tissue injury, especially in the mucosa. Early interventions (just before start of reperfusion) to prevent the increase in leukocyte-vessel wall interactions can improve submucosal capillary perfusion in such a way that tissue injury is reduced significantly. Such interventions may be feasible in clinical situations in which the moment of start of bowel reperfusion can be controlled. To intervene in such an early stage, clinical diagnostic tools are needed to determine bowel ischemia before irreversible injury has occurred. 


\section{Samenvatting}

Ischemie (onvoldoende doorbloeding) van de dunne darm kan tot plaatselijke stapeling van toxische stoffen leiden. Hoe langer de ischemische periode aanhoudt, hoe meer weefselschade kan ontstaan. Zonder herstel van de doorbloeding zal deze schadelijke reactie continueren en kan deze zelfs tot de dood leiden. Daarom is het noodzakelijk de ischemie op te heffen en daarmee reperfusie (herstel doorbloeding) van het darmweefsel te bewerkstelligen. Echter, naast reoxygenatie, leidt herstel van de darmdoorbloeding eveneens tot een mogelijke schadelijke respons, o.a. ten gevolge van het ontstaan van zuurstof radicalen en activatie en/of aantrekken van leukocyten en bloedplaatjes. Hierdoor wordt een grote chemoattractieve gradiënt tot stand gebracht en versterkt de inflammatoire respons, wat juist tot toename van weefselschade en celdood leidt. Maar zonder reperfusie zal herstel van het weefsel niet mogelijk zijn. Bovendien blijkt vooral de darm erg gevoelig voor ischemie en reperfusie. Dit proefschrift geeft een overzicht van dierexperimenten, die we hebben vitgevoerd om meer inzicht te krijgen in het pathofysiologische mechanisme achter de schadelijke gevolgen van ischemie en reperfusie van de dunne darm. In de praktijk blijken artsen het erg lastig te vinden de diagnose darm ischemie tijdig te stellen, voordat irreversibele darmschade optreedt. Daarom hebben artsen meer hulpmiddelen nodig, zoals diagnostische markers, om op tijd te kunnen ingrijpen. Bovendien moeten therapeutische mogelijkheden om schade ten gevolge van darm ischemie tegen te gaan ontwikkeld worden.

In hoofdstuk 2 wordt een kort overzicht van de literatuur met betrekking tot ischemie en reperfusie van de darm gegeven. Klinische situaties waarin darm ischemie optreedt zijn: dunne darm transplantatie, shock, necrotiserende enterocolitis (NEC) en ten gevolge van hartchirurgie of tijdens afklemmen van de aorta (boven, maar ook onder de splanchnische vaten). Patiënten kunnen ook darm ischemie ontwikkelen ten gevolge van een embolus of thrombus vorming in een of meer van de darmslagaders. Andere patiënten melden zich met een volvulus, malrotatie of strangulatie ileus.

Om de pathofysiologische mechanismen van darm ischemie en reperfusie te bestuderen hebben we een ratten model ontwikkeld. Zoals beschreven in hoofdstuk 3 , was het mogelijk mesenteriale venules en arteriolen in vivo te visualiseren met behulp van een intravitaal microscoop en transilluminatie. Middels een mediane laparotomie werd de arterie mesenterica inferior geligeerd en de arterie mesenterica superior geteugeld. Door een vaat buldog klemmetje op de arterie mesenterica superior te plaatsen werd totale warme ischemie van de darm geïnduceerd, wat op beelden door de microscoop bevestigd werd. Met behulp van dit model was het voor ons mogelijk om diameter veranderingen, rode bloedcel snelheden en leukocyt-vaatwand interacties van 
de mesenteriale microcirculatie te kwantificeren. Deze metingen werden voorafgaand aan de ischemie en gedurende de eerste 2 uren reperfusie verricht. In hoofdstuk 3 en 4 werden de microvasculaire veranderingen na verschillende periodes van darm ischemie bestudeerd in het mesenterium. Hierbij bleek, dat zelfs korte periodes van totale warme darm ischemie resulteerden in forse microvasculaire veranderingen. Deze veranderingen werden duidelijker, naarmate de ischemie duur toenam. De reperfusie van venules in het mesenterium was al ernstig gecompromitteerd na 15 en 30 minuten totale warme darm ischemie, waarbij de doorbloeding, respectievelijk, daalde naar 40 en $25 \%$ van de controle situatie voor aanvang van ischemie. $\mathrm{Na} 60$ minuten ischemie kwam de doorbloedings snelheid tijdens reperfusie niet hoger dan $10 \%$ van de controlesituatie. Na 15 of 30 minuten ischemie steeg het aantal leukocyt-vaatwand interacties, respectievelijk, met factor 5 of 10 keer ten opzichte van de controlesituatie. $\mathrm{Na} 60$ minuten ischemie konden leukocyt-vaatwand interacties niet meer bestudeerd worden door de zeer lage doorbloedingsnelheid. In deze laatste groep overleden alle ratten tussen 30 en go minuten reperfusie.

Als men de effecten van ischemie en reperfusie op de darm bestudeert is het belangrijk om ook histologische schade te kwantificeren. In de meeste onderzoeken werd darmweefsel schade histologisch vastgelegd vanaf standaard hematoxyline en eosine $(\mathrm{H}$ \& E) gekleurde weefsel coupes. Het vergelijken van de mate van weefselschade bleek echter nauwelijks mogelijk, omdat verschillende scoringssystemen gehanteerd werden. Derhalve vonden we het belangrijk één standaard histologisch scoringssysteem aan te bevelen, dat toepasbaar is in ischemie en reperfusie onderzoek van de darm. Na een uitgebreid literatuur onderzoek hebben we de 3 meest populaire graderingssystemen geselecteerd: het gecombineerde scoringssysteem van Park en Chiu en de scoringssystemen van respectievelijk Parks en Sonnino (hoofdstuk 5). Gebruik makende van coupes van de rattendarm na zo minuten ischemie en 1 uur reperfusie en "sham" geopereerde controle ratten, bleek dat 2 onafhankelijke observeerders het beste correleerden met het gecombineerde Park en Chiu scoringssysteem. Alhoewel het systeem van Parks ook betrouwbare resultaten opleverde, werd met behulp van dit systeem de schade die zich niet beperkte tot de mucosalaag, maar bijvoorbeeld in de spierlaag er buiten, niet vastgelegd. Sonnino's scoringssysteem correleerde het minst. We stelden dan ook voor, dat het gecombineerde scoringssysteem van Park en Chiu de best bruikbare is als standaard scoringssysteem voor histologische evaluatie van darm ischemie en reperfusie schade.

Alhoewel ons mesenterium model goed bruikbaar was om de duur van de totale warme darm ischemie te bepalen die nodig was om afname van doorbloeding en toename van leukocyt-vaatwand interacties te induceren, was nog steeds onbekend of

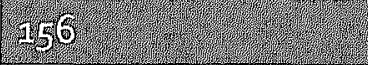


ischemie en reperfusie dezelfde microvasculaire effecten in de darmwandlagen zelf had. Om dit te bestuderen ontwikkelden we een nieuw ratten model, waarin het mogelijk was, de microcirculatoire veranderingen in de verschillende darmlagen te visualiseren. Zoals beschreven in hoofdstuk 6 en 7 , werden zowel lichtveld, als fluorescentie intravitaal microscopie toegepast met behulp van epi-illuminatie. Met deze methode, waren we in staat de rode bloedcel snelheid, diameter veranderingen, leukocyt- en plaatjes-vaatwand interacties te kwantificeren in de submucosale microcirculatie, alsook in de longitudinale en circulaire spierlagen van de dunne darm. In hoofdstuk 6 hebben we het effect van intestinale ischemie en reperfusie onderzocht op de weefsel perfusie, leukocyt-vaatwand interacties en weefsel integriteit. Om enterocyt schade vast te leggen werd op verschillende momenten de hoeveelheid in serum aanwezige "intestinal fatty acid binding protein" (I-FABP) gemeten. Bovendien werden histologische veranderingen van het darmweefsel onderzocht. Gedurende het eerst uur van de reperfusie, volgende op 30 minuten totale warme darm ischemie, daalde de rode bloedcel snelheid significant in alle lagen van de dunne darm, zonder dat de diameters veranderden. Het aantal leukocytvaatwand interacties nam in de submucosa toe, maar niet in de spierlaag. Tevens was vanaf 30 minuten reperfusie de hoeveelheid I-FABP in plasma significant verhoogd, hetgeen ernstige epitheliale schade aantoonde. Weefselschade aan de lumen zijde van de darm werd ook op de histologische coupes waargenomen en toonde ernstige mucosale schade. Op H \& E coupes werd geen schade van organen op afstand geobserveerd. Zowel de afname van de perfusie van de hele dunne darm, alsmede de vroege submucosale inflammatoire respons zouden hebben bijgedragen aan de ernstige geobserveerde mucosale schade na ischemie en reperfusie.

In de daaropvolgende studie (hoofdstuk 7), hebben we de rol van leukocyten en bloedplaatjes met betrekking tot de vermindering van intestinale capillaire doorbloeding en ontstane weefsel schade ten gevolge van ischemie en reperfusie onderzocht. Interventie met een "platelet activating factor" (PAF) antagonist of een monoklonaal antilichaam tegen "intercellular adhesion molecule-1" (ICAM-1), intra veneus toegediend vlak voor aanvang van de reperfusie, leidde tot een volledige verdwijning van de toegenomen leukocyt-vaatwand interacties gedurende reperfusie na 30 minuten totale warme darm ischemie. Dit resulteerde in een 8-voudige verbetering van de submucosale capillaire doorbloeding vergeleken met vehikel behandelde controle ratten. Tegelijkertijd was darm weefselschade significant verminderd; afstoting van mucosale villi kwam niet meer voor. De thrombotische respons was niet aangedaan; plaatjes-vaatwand interacties, welke voornamelijk voorkwamen in mucosale venules, werden niet beïnvloed door de interventies. Het gedeeltelijke herstel van de submucosale perfusie door verminderde stijging van leukocyt-vaatwand interacties was mogelijk in staat om de 
afstoting van mucosale villi ten gevolge van totale warme ischemie van de dunne darm te voorkomen.

Concluderend veroorzaakt totale warme ischemie en reperfusie van de dunne darm een inflammatoire en thrombotische respons, met name in de submucosale microcirculatie, vergezeld door een duidelijke daling van darm perfusie. Dit alles resulteert in ernstige schade van darmweefsel, en dan met name de submucosa. Vroege interventies (vlak voordat reperfusie aanvangt) om toename van leukocyt-vaatwand interacties te voorkomen kunnen de submucosale capillaire perfusie zodanig verbeteren, dat darm weefsel schade significant minder optreedt. Dergelijke interventies zijn toepasbaar in praktijk situaties, waarbij het initiëren van de reperfusie bepaald kan worden. Om in een dergelijke vroege fase te kunnen interveniëren, zijn diagnostische hulpmiddelen nodig om darm ischemie vast te stellen voordat irreversibele darmschade is opgetreden. 


\section{Curriculum Vitiae}

Roland Johannes Beuk werd op 12 oktober 1966 te Wassenaar geboren. Na het behalen van het HAVO en daarop volgende VWO diploma aan respectievelijk het St. Adelbert College en het Rijnlands Lyceum te Wassenaar, begon hij in 1987 met de studie Geneeskunde aan de Universiteit Maastricht. Tijdens de doctoraalfase was hij werkzaam als uithulp ambulance verpleegkundige, bij de DGD Heerlen en werkte tevens als studentassistent aan de afdeling Algemene Chirurgie van het Academisch Ziekenhuis Maastricht (tegenwoordig: Maastrichts Universitair Medisch Centrum). In deze periode vervulde Roland verschillende bestuurlijke functies in het dispuutsleven en organiseerde als landelijke voorzitter het Medisch Interfacultair Congres over transplantatie geneeskunde. Het laatste jaar van de $2^{e}$ fase van de studie geneeskunde (co-schappen) combineerde hij part-time met zijn aanstelling als AlO bij het Cardiovascular Research Institute Maastricht (CARIM), afdelingen Fysiologie en Algemene Chirurgie (1994-1999). In deze periode won Roland 4 prijzen: Peter Paul Rickham prize, XLII ${ }^{\text {nd }}$ Annual International Congress of the British Association of Pediatric Surgeons, Sheffield, Engeland, 28 juli 1995; Klopperprijs 1995, Rotterdam, 9 november 1995i Collegium Chirurgicum Neerlandicum-prijs, $8^{\mathrm{e}}$ Symposium Experimenteel Onderzoek Heelkundige Specialismen (SEOHS), Rotterdam, 9 november 1995; Studentenprijs Nederlandse Vereniging voor Gastro-Enterologie, voorjaarsvergadering Nederlandse Vereniging voor Gastro-Enterologie, Veldhoven, 20 maart 1998. Daarnaast was Roland 2 maal genomineerd voor een prijs. Op 31 juli 1998 behaalde Roland het arts-examen. Gedurende de laatste 2 jaren van zijn AIO aanstelling was hij tevens actief als voorzitter van de AlO Vereniging Universiteit Maastricht. Op 1 januari 2000 start Roland met de opleiding tot Algemeen Chirurg in het Atrium Medisch Centrum Heerlen (opleider: dr. P.R.G. Brink), waarna hij de opleiding vanaf a januari 2003 vervolgde in het Academisch Ziekenhuis Maastricht (opleiders: Prof. dr. M.J.H.M. Jacobs en later Prof. dr. J.W. Greve). Alhier was hij penningmeester van de assistenten algemene chirurgie, alsmede penningmeester van de Stichting Wetenschappelijk Onderzoek Heelkundige Specialismen (SWOAHS). Daarnaast was Roland coördinator van het grondgebonden mobiel medisch team van het Traumacentrum Limburg. Op 30 juni 2005 rond hij de opleiding tot algemeen chirurg af. Direct daaropvolgend is Roland aangesteld als chirurg in vervolgopleiding (CHIVO) tot vaatchirurg in het Medisch Spectrum Twente te Enschede (opleider: dr. R.H. Geelkerken). In deze periode was hij ook lid van de Commissie Opleiding Vaatchirurgie (COV). Op 20 september 2007 behaalde Roland zijn European Board of Vascular Surgery (EBVS) certificaat te Madrid en vervolgens op 31 december 2007 zijn certificaat vaatchirurgie. Vanaf 1 januari 2008 is Roland als vaatchirurg lid van de Maatschap Heelkunde van het Medisch Spectrum Twente. 


\section{Dankwoord}

Het is zover, het boekje is af! De totstandkoming van dit proefschrift was nooit gelukt zonder de inhoudelijke en mentale steun van vele anderen, die ik graag wil bedanken.

Het inhoudelijke werk was een hele klus die is geklaard met mijn promotores, Prof. dr. E. Heineman en Prof. dr. G.J. Tangelder, en co-promotor Dr. M.G.A. oude Egbrink.

Erik, ondanks je tussentijdse vertrek naar Nieuw-Zeeland, heb je contact gehouden en er voor gezorgd dat dit proefschrift tot stand is gekomen. Als jij (of $i k$ ) in de buurt was nam je altijd ruim de tijd voor me, wat tot goede ideeën heeft geleid. De gastvrijheid bij je thuis heb ik altijd bijzonder gevonden; Simone, bedankt! Naast het samenstellen van dit proefschrift, heb ik ook van je bijzondere opleidingskwaliteiten als (kinder)chirurg mogen profiteren.

Geert Jan, ook jij vertrok, al was het maar naar het westen van het land. Dat kwam vooral goed uit als ik mijn ouderlijk huis bezocht. Je bent een druk bezet persoon, maar weet toch altijd snel te reageren op stukken. Ook hebben we vele dagen, samen met de rest van het promotieteam, uitgebreid aan het proefschrift gewerkt. Dit deden we dan op de kamer van Mirjam. Ik kijk met veel genoegen terug naar deze zeer nuttige "sessies", waarbij we van je onuitputtelijke bron van kennis gebruik konden maken. Hopelijk gaan we hier gewoon mee door om nieuwe ideeën te blijven genereren voor verder onderzoek in de toekomst.

Mirjam, je bent niet voor niets $c_{e} 0$-promoter van dit proefschrift. Als een waardig "chief (executive) officer"-promotor heb je me door dit boek heen gesleurd! Je bent zeer gemakkelijk benaderbaar en retourneerde in record tijd stukken van dit proefschrift, die daarmee een briljante verandering doormaakten. Het was een voorrecht en zeer plezierig om met je samen te werken en ik hoop dit dan ook te kunnen blijven doen.

Prof, dr. P.J.E.H.M. Kitslaar, beste Peter, ik dank jou speciaal voor je hulp op de momenten dat de anderen er, begrijpelijk, even niet konden zijn.

De ondersteuning op het lab microcirculatie vergeet ik niet. Sabrina, je bent de eerste geweest die me de operatie technieken heeft bijgebracht $t_{i}$ en wel onder de microscoop! Je bent zeer prettig in de omgang en het is daarom niet onlogisch dat je later het lab hebt verruild met een baan waarin juist deze kwaliteit een belangrijke rol speelt. Verder wil ik graag Rinus, Huub en Viviane bedanken voor hun (technische) hulp op de meestal onverwachte momenten. Prof. dr. D. Slaaf, beste Dick, zonder jou was dit lab microcirculatie er niet geweest; dank voor je veelal technische en methodische inzichten en het benadrukken van het belang hiervan (wat ook tijdens het golfspel een belangrijke rol schijnt te spelen). 
Graag wil ik mijn bijzondere student-assistenten, Josine en Ralph, bedanken. Vele uren hebben we samen op het lab doorgebracht. Wat hebben we een plezier gehad! Ik zou niet weten hoe ik zonder jullie deze klus had moeten klaren.

En dan nu mijn oude lab maatjes, Martijn, Marc, Ellen en Selma. Het waren goede oude tijden, met elk jaar als hoogtepunt de cursus in Houthalen. Selma, zoals beloofd, we houden de trompocyten en beukocyten erin!

Hierbij bedank ik ook, officieel, mijn paranimfen Paddy en Ellen. Deze kei goeie kerel en het sjiek pittige dametje regelen zo'n beetje alles buiten het boekje om (letterlijk en figuurlijk). Door hun kundigheid, inzet en vooral medeleven ben ik ervan overtuigd dat de promotie op 12 juni een groot feest wordt!

Niet iedereen komt in aanmerking om een traject in te gaan wat viteindelijk tot promotie, en ook de opleiding tot chirurg leidt. Om dergelijke dromen waar te maken moet hard gewerkt worden, maar heb je ook hulp nodig. Die hulp kreeg ik van Harrie, onvoorwaardelijk! Harrie, door jou ben ik dit traject in gerold, wat ik nooit zal vergeten. Ik waardeer bovenal je loyaliteit en goede vriendschap. De samenwerking dateert al uit de tijd dat je nog Citroën DS "reed". Vele congressen zijn we samen opgetrokken en in New York was het geen probleem om bij je te komen logeren. Het was een prachtige tijd.

De laatste periode is de totstandkoming van dit boekje in een stroomversnelling terecht gekomen. Hiervoor hebben mijn collega chirurgen in de maatschap me wat extra vrijheid gegeven, wat ik waardeer. Bob wil ik speciaal bedanken voor het overbrengen van zijn (praktische) inzichten in de darm ischemie problematiek. Ik sta telkens weer versteld van de inventiviteit, gedrevenheid en energie die je gebruikt om darm ischemie patiënten te helpen. Het samenwerken met jou als maat en als vriend heeft zeker aan de kwaliteit van dit boekje bijgedragen.

Ik dank mijn ouders en mijn broer voor hun onvoorwaardelijke steun om dit proefschrift af te ronden. Helaas heeft het niet zo mogen zijn dat mijn vader de promotie zelf kan meemaken, al ben je er in onze gedachten wel bij. Mijn schoonfamilie en vrienden dank ik voor de blijvende interesse en steun gedurende alle jaren in de aanloop naar het boekje.

Lieve Helena, Ewout, Marike en Florian. Met de afronding van dit proefschrift komt er veel tijd vrij, waarin we vele leuke dingen zullen gaan doen. Lieve Helena, al die tijd heb je me volledig gesteund, waardoor ik de energie had het proefschrift te schrijven. Ik ben je hiervoor eeuwig dankbaar. Lieve Ewout, het is zover, het boekje is af! 
Financial support for the publication of this thesis was kindly provided by: Vascutek

Medtronic 